\title{
AVALIAÇÃO DOS SISTEMAS DE INFORMAÇÃO DE NASCIDOS VIVOS E DE MORTALIDADE PARA A OBTENÇÃO DA MORTALIDADE NEONATAL EM ILHÉUS, BAHIA
}

\section{ADÉLIA MARIA CARVALHO DE MELO PINHEIRO}

Tese de Doutorado apresentada ao Departamento de Epidemiologia da Faculdade de Saúde Pública da Universidade de São Paulo para obtenção do Grau de Doutor.

Área de Concentração:

Epidemiologia

ORIENTADORA: Profa. Dra. MÁRCIA FURQUIM DE ALMEIDA

São Paulo - SP 2003

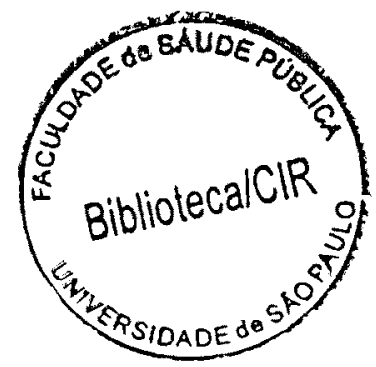


Autorizo, exclusivamente para fins acadêmicos e científicos, a reprodução total ou parcial desta tese, por processos fotocopiadores.

Assinatura:

Data: Sdélip Ma M. Melo tinherro

$$
44939 / 2004 \text { doc }
$$




\section{AGRADECIMENTOS}

A elaboração de trabalho desta natureza exige momentos solitários, de recolhimento do autor e outros de troca que acontecem na relação entre pessoas.

Colegas, amigos, alunos, parceiros, autoridades, instituições, mães e crianças, muitos contribuíram neste processo. De forma geral agradeço a todos que direta ou indiretamente contribuíram para a efetivação do estudo. Mesmo correndo o risco de, por esquecimento, deixar de citar alguém, devo particularizar o agradecimento a algumas pessoas e instituições.

À Profa. Dra. Márcia Furquim de Almeida, orientadora desta tese, que alternando papéis de amiga e técnica, esteve disponível em todos os momentos;

À Universidade Estadual de Santa Cruz, na pessoa da Reitora Profa. Renée Albagli Nogueira, que investindo na qualificação do corpo docente e desenvolvimento da pesquisa, possibilitou a realização do curso e deste trabalho;

Aos bolsistas de iniciação científica, Valmor e Tiago, que com interesse e sempre disposição pelo aprender acompanharam e colaboraram na pesquisa;

À Marciene, amiga e colaboradora dos diversos momentos do trabalho, atuando como digitadora e coordenadora de campo;

À toda a equipe da PROGRAD e GERAC, Profas. Rosana Lopes e Ana Maria Moreau, Andréa Sauer, Senize, Patrícia e Alex que de diversas formas contribuíram para a concretização deste trabalho;

À Dra. Irene Cazorla pela colaboração na análise estatística;

À Lindolfo pelas "lições" sobre elaboração de bancos de dados e compromisso institucional;

À Profa. Mércia Margotto, colega, companheira de jornadas e de desafios; 
À Secretaria de Saúde de llhéus, que através do Sr. Secretário Dr. Paulo Medauar Reis, permitiu o uso de dados do SIM e SINASC, mostrando sempre compromisso com as informações de saúde;

Aos técnicos e digitadores do Setor de Vigilância Epidemiológica da Secretaria de Saúde de Ilhéus, Regina, Julio e Almir, sempre disponiveis a auxiliar;

Ao Juiz de Direito da Vara de Registros Públicos da Comarca de llhéus, Dr. Helvécio Giudice de Argôllo que permitiu o acesso aos arquivos de registros civis;

Aos diretores médicos dos hospitais de llhéus, que permitiram o acesso aos arquivos hospitalares;

Aos funcionários de cartórios do município, Emília, IIma, Eliete e Darci, que facilitaram a tarefa de busca de dados em arquivos;

Às enfermeiras e funcionários dos hospitais pesquisados, Inaja, Eliana, Ana Marta, Estela, que comprometidos com a assistência à saúde, facilitaram a consulta e busca de dados em arquivos;

À minha família ampliada, pais, sogros, irmãs, em especial meus filhos e companheiro, que partilhando de opções pessoais minhas, abdicaram de momentos de convivência;

Às crianças e mães de llhéus, na esperança de melhor condição de vida. 


\section{RESUMO}

Pinheiro AMCM. Avaliação dos sistemas de informação de nascidos vivos e de mortalidade para a obtenção da mortalidade neonatal em Ilhéus, Bahia. São Paulo; 2003. [Tese de Doutorado - Faculdade de Saúde Pública - Universidade de São Paulo].

Informações sobre nascimentos vivos e óbitos, com boa cobertura e qualidade, asseguram indicadores de saúde capazes de atender às demandas de gestores do Sistema de Saúde e população. A descentralização dos sistemas de informação impõe a realização de estudos de avaliação no nivel local. O objetivo deste trabalho é avaliar o SINASC e o SIM como fontes de dados para obtenção da probabilidade de morte neonatal em Ilhéus, Bahia. Utilizou-se como população de referência os nascidos vivos hospitalares com ocorrência e residência em llhéus, em 2001. Os instrumentos de coleta de dados foram elaborados à semelhança da DN e DO. Os dados foram coletados em hospitais e cartórios do município e dos bancos de dados do SIM e SINASC cedidos pela Secretaria de Saúde de llhéus. Foram compostos seis bancos de dados, utilizando-se a técnica de linkage para identificar os mesmos indivíduos nos diferentes bancos de dados. A coorte é formada por 3426 nascidos vivos, dos quais 3308 foram captados pelo SINASC, representando cobertura de $96,6 \%$. O subregistro civil na coorte foi de $14,4 \%$. Observou-se diferenças estatisticamente significante entre os nascidos vivos captados e não captados pelo SINASC e mês de nascimento, hospital de nascimento, peso ao nascer e registro civil. Dos 68 óbitos neonatais da coorte, 34 foram captados pelo SIM como óbito neonatal, 29 captados como óbitos fetais e 5 não captados. Constatou-se diferenças estatisticamente significantes entre os óbitos neonatais captados e não captados pelo SIM e hospital de ocorrência do óbito, idade ao morrer e registro civil do óbito. A probabilidade de morte neonatal na coorte foi de $19,84 \%$ nascidos vivos e no SIM/SINASC de $9,97 \%$ nascidos vivos, indicando que os dados oficiais subestimam em cerca $100 \%$ a probabilidade de morte neste grupo. Conclui-se pela 
necessidade de implementar estratégias para melhoria da cobertura e qualidade dos sistemas de informação em llhéus.

Descritores: Sistemas de Informação; Mortalidade Neonatal; Estatísticas Vitais; Registros de Mortalidade. 


\section{SUMMARY}

Pinheiro AMCM. Information Systems Evaluation of alive births and deaths in order to obtain the probability of newborn death in Ilhéus, Bahia. São Paulo (BR); 2003. [Tese de Doutorado - Faculdade de Saúde Pública - Universidade de São Paulo].

Information about alive births and deaths with good covering and quality assure health indicators capable to attend the demands of managers of the Health and Population System. The decentralization of the information systems imposes the accomplishment of studies of evaluation in the local level. The aim of this work is to evaluate the SINASC and SIM as sources of data for obtaining the probability of newborn death in Ilhéus, Bahia. It was used as reference population the alive born hospital with occurrence and residence in llhéus, 2001. The instruments of collection of data had been elaborated to the resemblance from DN and DO. The data had been collected in hospitals and notary's offices of the city and the data bases of SIM and SINASC, given by the llhéus Secretary of Health. It was composed six data bases, using the technique of linkage to identify the same individuals in the different data bases. The cohort is formed by 3426 alive births, which 3308 had been picked-up by the SINASC, representing $96,6 \%$ covering. The civil sub-register in cohort was $14,4 \%$. From 68 newborn deaths of cohort, 34 had been picked-up by SIM as newborn deaths, 29 had been picked-up as fetus deaths, and 5 had not been picked-up. The probability of newborn death in cohort was $19,84 \%$ alive births, and in the SIM/SINASC 9,97\% alive births, indicating that the official data underestimate it around $100 \%$ the probability of death in this group. In conclusion, there is the necessity to implement strategies for improvement of the covering and quality of the information systems in llhéus.

Descriptors: Information Systems; Neonatal Mortality; Vital Statistics; Mortality Registries. 


\section{ÍNDICE}

\section{RESUMO}

SUMMARY

LISTA DE TABELAS

LISTA DE FIGURAS

LISTA DE GRÁFICOS

\section{LISTA DE QUADROS}

\section{SIGLAS UTILIZADAS}

1.1 Importância da mortalidade infantil e seus componentes .

1.2 Histórico e importância dos Sistemas de Informação de Nascido Vivo e de Mortalidade

1.3 Avaliação dos Sistemas de Informação de Nascido Vivo e de Mortalidade

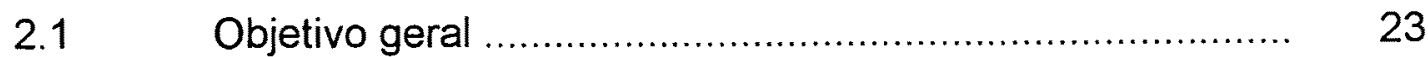

2.2 Objetivos específicos .......................................... 23

3 MATERIAL E MÉTODO ..................................... 24

3.1 Área de estudo .................................................. 24

$3.2 \quad$ População de estudo ........................................... 26

3.3 Periodo de referência ............................................. 26

3.4 Delineamento do estudo ..................................... 26

3.4.1 Nascidos vivos .............................................. 28

3.4.1.1 Nascidos vivos hospitalares .................................... 28

3.4.12 Nascidos vivos registrados em cartório ....................... 30

3.4.13 Nascidos vivos captados pelo SINASC ....................... 31

3.4.2 Óbitos neonatais ............................................... 32

3.4.2.1 Óbitos neonatais hospitalares ................................. 32

3.4.2.2 Óbitos neonatais registrados em cartório ....................... 33

3.4.2.3 Óbitos Neonatais Captados pelo SIM ......................... 33

$3.5 \quad$ Variáveis ....................................................... 33

Coleta de dados ............................................. 38 
3.7 Instrumentos de coleta de dados .................................. 40

3.8 Consolidação dos dados .............................................. 40

Análise dos dados .................................................. 40

3.10 Aspectos éticos ...................................................... 42

$4 \quad$ RESULTADOS E DISCUSSÃO …............................... 43

$4.1 \quad$ Os Dados do SINASC e SIM em Ilhéus ........................... 43

4.2 Os Sistemas de Informação em Saúde em Ilhéus ............ 58

4.3 Os nascidos vivos em llhéus, segundo fonte de dados ..... 60

4.4 Avaliação da captação pelo SINASC dos nascidos vivos hospitalares com ocorrência e residência em llhéus ......... 62

4.5 Avaliação do registro em cartório dos nascidos vivos hospitalares com ocorrência e residência em llhéus ......... 63

4.6 Avaliação da captação pelo SINASC dos nascidos vivos hospitalares originados na coorte e dos nascidos vivos registrados em cartórios

4.7 Perfil dos nascidos vivos hospitalares segundo captação ou não pelo SINASC ................................................... 67

4.8 Óbitos neonatais segundo fonte de obtenção dos dados ..

4.9 Avaliação da captação pelo SIM de óbitos neonatais originados na coorte de nascidos vivos hospitalares

4.10 Perfil dos óbitos neonatais originados na coorte de nascidos vivos hospitalares com ocorrência e residência em llhéus, segundo captação pelo SIM ............................ 80

4.11 Probabilidade de morte neonatal .................................. 85

$5 \quad$ CONSIDERAÇÕES FINAIS E CONCLUSÕES ................ 88

$6 \quad$ RECOMENDAÇÕES .............................................. 95

REFERÊNCIAS BIBLIOGRÁFICAS ........................... 96 ANEXOS

Anexo 1 - Declaração de Nascido Vivo - DN

Anexo 2 - Declaração de Óbito - DO

Anexo 3 - Termo de Consentimento Consulta a Arquivos Hospitalares 
Anexo 4 - Autorização Judicial para Pesquisa em Arquivos de Cartórios de Registro Civil

Anexo 5 - Termo de Consentimento do gestor municipal Anexo 6 - Declaração de Nascido Vivo Hospitalar - DNh Anexo 7 - Declaração de Nascido Vivo Cartório - DNc Anexo 8 - Declaração de Óbito Hospitalar - DOh Anexo 9 - Declaração de Óbito Cartório - Doc 


\section{LISTA DE TABELAS}

1 Número de nascidos vivos captados pelo SINASC e percentual de variação anual, llhéus, 1994 a 2000

2 Número de nascidos vivos captados pelo SINASC, população residente menor de um ano e proporção de captação de nascidos vivos pelo SINASC, Ilhéus, 1994 a 2000

3 Número de nascidos vivos captados pelo SINASC e Taxa de Natalidade (\%o habitantes), Ilhéus, 1994 a 2000

4 Número de óbitos infantis segundo idade ao morrer, llhéus, 1986 a 2000

5 Variação anual (\%) do número de óbitos infantis segundo idade ao morrer, llhéus, 1986 a 2000

6 Variação por período(\%) do número de óbitos infantis segundo idade ao morrer, Ilhéus, 1980-89 e 1990-99

7 Taxa de Mortalidade Infantil segundo idade ao morrer calculada por diferentes métodos, llhéus, 1989 a 2000

8 Variação anual (\%) da Taxa de Mortalidade Infantil -TMI, Neonatal -TMN e Pós-Neonatal - TMP (por 1000 menores de um ano), llhéus, 1993 a 2000

9 Variação por período(\%) da Taxa de Mortalidade Infantil (TMI), Neonatal (TMN) e Pós-Neonatal (TMP), llhéus, 1991-99

10 Número de nascidos vivos segundo captação pelo SINASC e mês de nascimento, llhéus, 2001

11 Número de nascidos vivos segundo captação pelo SINASC e área de residência, llhéus, 2001

12 Número de nascidos vivos segundo captação pelo SINASC e hospital de ocorrência, llhéus, 2001

13 Número de nascidos vivos segundo captação pelo SINASC e idade da mãe, llhéus, 2001

14 Número de nascidos vivos segundo captação pelo SINASC e estado civil da mãe, llhéus, 2001

15 Número de nascidos vivos segundo captação pelo SINASC e duração da gestação, llhéus, 2001 
16 Número de nascidos vivos segundo captação pelo SINASC e peso ao nascer, llhéus, 2001.

17 Número de nascidos vivos segundo captação pelo SINASC e registro civil, llhéus, 2001

18 Número de óbitos neonatais segundo captação pelo SIM e área de residência, llhéus, 2001

19 Número de óbitos neonatais segundo captação pelo SIM e hospital de ocorrência do nascimento, llhéus, 2001

20 Número de óbitos neonatais segundo captação pelo SIM e idade da mãe, llhéus, 2001

21 Número de óbitos neonatais segundo captação pelo SIM e duração da gestação, llhéus, 2001

22 Número de óbitos neonatais segundo captação pelo SIM e peso ao nascer, llhéus, 2001

23 Número de óbitos neonatais segundo captação pelo SIM e idade ao morrer, llhéus, 2001

24 Número de óbitos neonatais segundo captação pelo SIM e registro civil, llhéus, 2001 


\section{LISTA DE FIGURAS}

1 Representação esquemática do desenho do estudo, fontes de dados, procedimentos de coleta e tratamento de dados

2 Representação dos dados do SINASC, llhéus, 2001

3 Representação esquemática do procedimento de linkage entre os bancos de dados de nascidos vivos da coorte $\left(\mathrm{NV}_{\text {coorte }}\right) \mathrm{e}$ nascidos vivos captados pelo SINASC (NV sinasc), Ilhéus, 2001....

4 Representação esquemática dos procedimentos de linkage entre os bancos de dados de nascidos vivos registrados em cartório ( $\left(\mathrm{DN}_{\text {cartório }}\right)$ e nascidos vivos da coorte $\left(\mathrm{DN}_{\text {coorte }}\right)$, llhéus, 2001

$5 \quad$ Síntese da linkage entre os bancos de dados de nascidos vivos da coorte ( $D N_{\text {coorte }}$ ), nascidos vivos registrados em cartório (DN $N_{\text {cartório }}$ ) e nascidos vivos captados pelo SINASC (DN $N_{\text {sinasc }}$ ), Ilhéus, 2001

6 Representação esquemática do procedimento de linkage entre os bancos de dados de nascidos vivos da coorte $\left(N_{\text {coorte }}\right)$ e óbitos neonatais captados pelo SIM (SIM neonatal $_{\text {) }}$, llhéus, 2001

7 Representação esquemática do procedimento de linkage entre os bancos de dados de nascidos vivos da coorte ( $\left.N V_{\text {coorte }}\right)$ e óbitos fetais captados pelo SIM (SIM fetal ), Ilhéus, 2001

8 Representação dos procedimentos de linkage entre os bancos de dados de óbitos neonatais registrados em cartório ( $\mathrm{DO}_{\text {cartorio}}$ ) e nascidos vivos da coorte ( $\left.\mathrm{DN}_{\text {coorte }}\right)$, llhéus, 2001

9 Representação do procedimento de linkage entre os bancos de dados de nascidos vivos da coorte $\left(\mathrm{NV}_{\text {coorte }}\right)$ e óbitos neonatais captados em registros hospitalares (DO hospital), llhéus, 2001

10 Representação esquemática do procedimento de linkage entre os bancos de dados de nascidos vivos da coorte $\left(N_{\text {coorte }}\right)$ e óbitos neonatais identificados por diversas fontes e captados pelo SIM (SIM), Ihéus, 2001

11 Síntese dos óbitos neonatais pertencentes à coorte de nascidos vivos hospitalares com residência e ocorrência em llhéus, segundo fonte de captação, 2001 


\section{LISTA DE GRÁFICOS}

1 Desvios da Taxa de Natalidade em relação a média, llhéus, 1994 a 2000

2 Desvios da Taxa de Mortalidade Infantil (por 1000 menores de um ano) em relação a média, Ilhéus, 1993 a 2000

3 Desvios da Taxa de Mortalidade Neonatal (por 1000 menores de um ano) em relação a média, llhéus, 1993 a 2000

4 Desvios da Taxa de Mortalidade Pós-Neonatal (por 1000

menores de um ano) em relação a média, llhéus, 1993 a 2000 


\section{LISTA DE QUADROS}

1 Fontes de coleta utilizadas para obtenção de dados de nascidos vivos e óbitos neonatais, segundo unidade hospitalar

2 Variáveis estudadas relativas aos nascidos vivos, segundo relação com o evento, categorização e origem dos dados

3 Variáveis estudadas relativas aos óbitos neonatais, segundo relação com o evento, categorização e origem dos dados

4 Cartórios de Registro Civil da comarca de llhéus, maio de 2002 ...... 


\section{SIGLAS UTILIZADAS}

BPN

CGM

CGMp

$\mathrm{CMI}$

DMCGM

$D M_{T N}$

DN

DNc

DNh

DO

DOc

DOh

FUNASA

GEVIMS

IBGE

IML

MS

OMS

OPAS

PAISM

PIG

RIPSA

SCB

SES

SIM

SINASC

SIS

SMS

SUS

TMI
Baixo Peso ao Nascer

Coeficiente Geral de Mortalidade

Coeficiente Geral de Mortalidade Padronizado

Coeficiente de Mortalidade Infantil

Desvio Médio do Coeficiente Geral de Mortalidade

Desvio Médio da Taxa de Natalidade

Declaração de Nascido Vivo

Declaração de Nascido Vivo Cartório

Declaração de Nascido Vivo Hospitalar

Declaração de óbito

Declaração de Óbito Cartório

Declaração de Óbito hospitalar

Fundação Nacional de Saúde

Grupo de Estatísticas Vitais

Instituto Brasileiro de Geografia e Estatística

Instituto Médico Legal

Ministério da Saúde

Organização Mundial de Saúde

Organização Panamericana de Saúde

Programa de Atenção Integral à Saúde da Mulher

Pequeno para Idade Gestacional

Rede Integrada de Informações para a Saúde

Seletor de Causa Básica

Secretaria Estadual de Saúde

Sistema de Informação de Mortalidade

Sistema de Informação de Nascidos Vivos

Sistema de Informação em Saúde

Secretaria Municipal de Saúde

Sistema Único de Saúde

Taxa de Mortalidade Infantil 
TMlx

TMN

$\mathrm{TMN}_{\mathrm{X}}$

TMP

TMPX

$\mathrm{TN}_{\mathrm{X}}$
Taxa de Mortalidade Infantil Média

Taxa de Mortalidade Neonatal

Taxa de Mortalidade Neonatal Média

Taxa de Mortalidade Pós-Neonatal

Taxa de Mortalidade Pós-Neonatal Média

Taxa de Natalidade 


\section{INTRODUÇÃO}

\subsection{Importância da mortalidade infantil e seus componentes}

A mortalidade de crianças antes de completar um ano de vida é sempre um tema revestido de importância, seja pelo seu valor social, cultural ou econômico. Resultado da interrupção do ciclo vital logo ao iniciarse, a morte infantil muitas vezes está relacionada às desigualdades definidas pela estrutura social. De acordo com Victora e col (1989), o estado de saúde de crianças é afetado por fatores imediatos, porém estes não estão distribuídos ao acaso, sendo influenciados pela formação sócio-econômica, a qual determina o perfil de classes sociais. É oportuno, no entanto, citar Monteiro e cols.(1996) ao considerarem que é errôneo pressupor-se uma relação direta entre variáveis econômicas e sobrevivência infantil.

De acordo com Simões e Monteiro (1995), citado por Monteiro e col (1996, p.7), no Brasil, há uma evolução das taxas de mortalidade infantil ao longo dos anos, que, embora ainda elevadas quando considerada a riqueza nacional, apresentam tendência de redução, com marcadas diferenças regionais. Szwarcwald e col (1997), ao estudarem a evolução da mortalidade infantil no Brasil, na década de 80 , concluem que a parte mais pobre do território nacional persiste com o padrão similar ao da Índia e, mesmo em estados mais desenvolvidos, a redução dos coeficientes de mortalidade neonatal precoce é pouco expressiva e, por fim, que o declínio observado na década foi pobre quando comparado com a experiência internacional. Os autores frisam que é evidente a necessidade de intervenções específicas sobre os componentes neonatal e pós-neonatal.

Segundo Simões (2002), a mortalidade infantil no Brasil, obtida a partir de estimativas por técnicas demográficas aplicadas aos dados dos censos demográficos e pesquisa por amostras de domicílios, no período de 1990 a 2000 , passa de 48,4 óbitos de menores de um ano de idade por mil nascidos vivos para $33,6 \%$, registrando um decréscimo de $30,6 \%$. Para o 
mesmo período, a Bahia apresentou comportamento semelhante, com taxas de mortalidade infantil de 65,2 por mil nascidos vivos em 1990 e 44,7\%o em 2000 , correspondendo a um decréscimo de $31,5 \%$.

Carvalho e Costa (1998) estudaram a mortalidade infantil e seus comportamentos em Salvador, de 1980 a 1991, mostrando que houve um decréscimo do Coeficiente de Mortalidade Infantil - CMI - de 79,2/1000 menores de um ano em 1980 para 28,8/1000 menores de um ano em 1991, eqüivalendo a uma queda de $63,6 \%$ no período.

A análise da tendência da mortalidade neonatal em São Luiz do Maranhão, no periodo de 1979 a 1996 (RIBEIRO e SILVA, 2000) possibilitou a afirmação pelos autores de que, no Maranhão, de forma semelhante a outras regiōes brasileiras, a mortalidade infantil vem diminuindo, entretanto, o decréscimo ai observado tem sido mais lento que em outros estados.

Ainda sobre a evolução da mortalidade infantil, Barros e col (1996) ao compararem os coeficientes encontrados para mortes infantis em duas coortes - 1982 e 1993, referem queda de 36,4/1000 nascidos vivos para $21,1 / 1000$ nascidos vivos, o que corresponde a um decréscimo de $42 \%$. Observaram também que, ainda que tenha havido queda do coeficiente na camada mais carente da população, não houve redução nas diferenças existentes entre os grupos sociais. Os autores ressaltam que a redução encontrada foi superior para óbitos pós-neonatais do que para os neonatais.

Menezes e col (1996), ao analisarem a queda da mortalidade infantil em Pelotas na década de 80 e a permanência das diferenças sociais no mesmo período, concluem ser ainda possivel a redução da mortalidade infantil através da diminuição das desigualdades sociais e de cuidados médicos adequados para todas as crianças de risco.

Szwarcwald, Bastos e Andrade (2002), ao discutirem aspectos teóricos/metodológicos sobre as desigualdades em saúde, utilizando como exemplo a mortalidade neonatal na cidade do Rio de Janeiro, encontraram disparidades importantes no indicador segundo o grau de escolaridade da mãe, principalmente no grupo de mães analfabetas em relação aos demais grupos. Os autores referem a necessidade de aperfeiçoamento dos 
Sistemas de Informação em Saúde - SIS - permitindo o seu uso em investigações voltadas para as desigualdades, considerando o princípio da equidade no Sistema Único de Saúde - SUS - e a possibilidade de desenvolvimento de ações efetivas que reduzam as desigualdades em saúde.

Além da análise de tendência de decréscimo da taxa de mortalidade infantil e seus componentes ao longo do tempo pode-se observar modificações da participação dos subgrupos etários dentre os menores de um ano. Diversos autores discutem o aumento proporcional dos óbitos neonatais precoces na composição da mortalidade infantil e neonatal na década de 90 (BARROS e COLS, 1996; LEAL e SZWARCWALD, 1996; MENEZES e col, 1996). De acordo com Leal e Szwarcwald (1997), com a nova composição etária das mortes de menores de um ano, deslocam-se para a esfera dos serviços de saúde as possibilidades de intervenção sobre a realidade e, não mais como na década anterior, através de ações intersetoriais voltadas para o coletivo. As autoras reafirmam, no trabalho citado, que a situação atual indica uma necessária imbricação da atenção coletiva e individual, para alcançar melhores resultados na qualidade de saúde das populações, aliada à necessidade de estudos para conhecer o complexo mortalidade infantil no nosso meio.

Diversos autores vem destacando que as mudanças observadas no perfil da mortalidade infantil parecem indicar o deslocamento dos cenários de enfrentamento do óbito infantil, não mais fortemente relacionados a ações coletivas e sim, no campo dos serviços exclusivos de saúde, especialmente na assistência individual (SZWARCWALD e LEAL, 1997; CAMPOS, CARVALHO e BARCELLOS, 2000).

Ribeiro e Silva (2000) registram que, em São Luiz do Maranhão, detectou-se aumento da mortalidade neonatal, a partir de 1995, as custas do seu componente precoce, relacionando o achado com a queda da qualidade da assistência obstétrica e neonatal. Em um primeiro momento, poder-se-ia questionar que o acréscimo observado na mortalidade neonatal nessa localidade estaria relacionado com a melhoria da captação do evento pelo 
Sistema de Informação ou pela ampliação de cobertura do sistema de saúde. Entretanto, os próprios autores ponderam que, em período anterior a 1995, a proporção de partos hospitalares situava-se acima de $95 \%$ e que, o crescimento do coeficiente coincide com o aumento da proporção de partos cesáreos e com o fechamento de uma maternidade para reforma. Destacam também que, no município, há demanda reprimida por leitos neonatais.

Ainda que não seja adequado à situação acima descrita, a melhoria da qualidade do sistema de informação de nascidos vivos e de mortalidade, a ampliação de cobertura do sistema de saúde e a implantação de ações e serviços materno-infantis de maior complexidade, podem levar a um aumento de números absolutos e/ou coeficientes relacionados aos eventos vitais.

Os dados anteriormente apresentados, de forma inequivoca, mostram a importância que a mortalidade neonatal vem assumindo na situação de morbimortalidade brasileira. O conhecimento dos fatores que estão associados às mortes apontará caminhos para a reversão do quadro.

Dentre os fatores de risco apontados pela literatura brasileira como mais fortemente associados à mortalidade neonatal encontra-se o baixo peso ao nascer - BPN (ALMEIDA, 1992; VICTORA e col, 1989; CESAR, 1990).

Segundo Almeida (1992), em países desenvolvidos, onde a mortalidade neonatal situa-se em niveis inferiores aos de São Paulo, inclusive como resultado da incorporação de tecnologias na assistência ao neonato, observa-se uma atenção crescente à gestação de pré-termo como fator de risco para morte neonatal.

Almeida e Mello Jorge (1998), ao apresentarem os resultados para uma coorte de nascimentos cujos dados foram obtidos a partir de Declarações de Nascimento - DN - e Óbito - DO -, mostram que os recémnascidos pequenos para a idade gestacional - PIG - apresentaram risco de morte significativamente maior que aqueles não PIG. As mesmas autoras verificaram que, para nascimentos ao mesmo tempo prematuros e PIG, é ainda mais elevado o risco de morte. 
Diversos estudos analíticos vêm sendo realizados no Brasil sobre a mortalidade neonatal. Morais Neto e Barros (2000), em uma coorte de 20.981 nascidos vivos em Goiânia, encontraram como fatores de risco para mortalidade neonatal, nascimento em hospital público estadual, prematuridade, BPN e nascidos de gravidez múltipla e, como fator de proteção, nascimento por cesariana. No estudo, as variáveis idade da mãe, gênero do recém-nascido e grau de instrução da mãe não estiveram associadas a um maior risco de mortalidade neonatal.

Em um bem conduzido estudo de caso-controle para identificação de fatores de risco associados à mortalidade infantil, tendo como proposta a construção de instrumentos preditivos para uso em serviços de saúde, César (1990) encontrou associação para as variáveis altura da mãe, número de gestações anteriores, intervalo entre o nascimento da criança em estudo e o nascimento anterior, intervalo interpartal médio, nova gestação após o nascimento da criança em estudo, história prévia de perda fetal, história prévia de perda de filho menor de um ano, cobertura da mãe por serviços de saúde, acompanhamento do pré-natal, sexo da criança, peso ao nascer, doença crônica da criança, migração recente, tempo em que a mãe mora com o atual companheiro e tipo de habitação. Ainda que não tenha havido distinção entre as variáveis associadas à mortalidade neonatal e pósneonatal, é oportuna a citação do trabalho.

Ao estudar a mortalidade neonatal no município de Santo André em São Paulo, através de uma coorte de nascimentos, Almeida (1992) identificou como fator de risco o BPN, não havendo associação entre o risco de morte neonatal e os nascimentos de gestação múltipla, o local de nascimento, o menor grau de instrução da mãe, nascimentos de mães primíparas e grandes multíparas e para os pequenos para idade gestacional simplificados.

Gomes e Santo (1997), analisando a mortalidade infantil em um município da região Centro-Oeste Paulista, no período de 1990 a 1992, encontraram $73 \%$ de óbitos neonatais que, ao serem classificados segundo critério de evitabilidade, apenas $10,9 \%$ foram considerados não evitáveis e 
$18,1 \%$ parcialmente redutiveis por bom controle da gravidez. Os demais óbitos neonatais foram considerados redutíveis, seja por boa atenção ao parto, bom controle da gravidez ou por diagnóstico e tratamento precoces.

Sobre as mortes perinatais evitáveis em Belo Horizonte, Lansky, Franca e Leal (2002) concluíram que $40 \%$ dos óbitos perinatais e $60 \%$ dos neonatais poderiam ter sido evitados, sugerindo falhas na assistência à gestante e ao neonato. $\mathrm{O}$ artigo traz uma nova leitura sobre esta questão, justificável na medida dos avanços possíveis com o SUS, qual seja, a necessidade de responsabilização dos serviços e sistema de saúde sobre esta população.

Em estudo semelhante levado a efeito em São Luís, Ribeiro e Silva (2000) constataram que o aumento da mortalidade neonatal, de forma expressiva devido ao seu componente precoce, quando classificados de acordo com a evitabilidade, mostram participação especial das causas redutíveis por diagnóstico e tratamento precoces e parcialmente redutiveis por bom controle da gravidez.

Conrado (2002), ao estudar a evolução da mortalidade infantil evitável em Ilhéus e Itabuna, na Bahia, no período de 1980 a 1999 refere que os óbitos infantis evitáveis apresentaram diminuição de coeficientes e aumento de participação proporcional dentre os demais óbitos, registrando que, para o último ano de estudo, $56 \%$ e $84 \%$ dos óbitos infantis de llhéus e Itabuna, respectivamente, foram considerados evitáveis. O autor ressalta que a persistência elevada de óbitos infantis por causas mal definidas em llhéus pode estar interferindo nos resultados, incluindo a discussão da questão da qualidade das estatísticas de causas de morte no município, bem como, indiretamente, o acesso e a disponibilidade de serviços de saúde à população menor de um ano.

Os dados apresentados, retirados da literatura brasileira referentes à mortalidade neonatal, mostram de forma inequívoca a importância de se conhecer porque morrem os neonatos para que, com responsabilidade e eficiência, se possa implantar e/ou implementar práticas sanitárias, individuais ou coletivas, voltadas para a promoção da saúde e proteção ao 
grupo etário. Entretanto, anterior ao conhecimento dos fatores de risco associados aos óbitos neonatais, é necessária a garantia de informações relacionadas aos nascimentos vivos e óbitos com conhecida cobertura/captação dos eventos e de boa qualidade. Somente assim poderá ser possivel assegurar indicadores e informações em saúde em consonância com os pressupostos e diretrizes do SUS, capazes de atender às demandas de gestores e população.

\subsection{Histórico e importância dos Sistemas de Informação de Nascidos Vivos e de Mortalidade}

Anterior à discussão sobre o histórico e importância dos sistemas de informação de nascimentos e óbitos no Brasil, mostra-se necessária uma aproximação sobre os eventos vitais e seu valor para a Epidemiologia.

Mello Jorge (1990) define os eventos vitais como sendo

... representados pelos nascimentos vivos, nascimentos mortos, óbitos, casamentos, adoções, separações, legitimações, entre outros que acontecem na vida do indivíduo, alterando, de alguma forma, seu "estado" perante a sociedade e perante o Direito (MELLO JORGE, 1990, p.8).

Apesar de haver definição clara e facilmente aplicável de nascimento vivo e nascido morto, ainda é um importante problema para as estatísticas vitais a classificação errônea destes eventos. Decorre de uma classificação equivocada um duplo efeito: sub-enumeração de nascidos vivos e óbito infantil e superestimativa de nascidos mortos e conseqüentemente distorção de taxas e coeficientes que utilizam estes números nos seus cálculos (FERREIRA, 1982).

A Epidemiologia descritiva ocupa-se em mensurar o estado de saúde de populações e o faz a partir do estudo da distribuição das ocorrências dos eventos vitais em relação ao tempo, espaço e grupos populacionais. $O$ cálculo de indicadores de saúde, coeficientes e índices irá estabelecer parâmetros para o diagnóstico da situação de saúde, permitindo a identificação dos problemas existentes e possibilidades de intervenção. 
Tratando-se de nascimentos e óbitos infantis, o conhecimento e acompanhamento da Taxa de Mortalidade Infantil permite o desenvolvimento de ações concretas voltadas para a modificação do padrão observado. Considerando que, para o cálculo da Taxa referida são utilizados o número de óbitos de menores de um ano e o número de nascidos vivos conforme um lugar e um tempo determinados, a disponibilidade de dados que permitam o estabelecimento do coeficiente com agilidade e qualidade constitui-se objetivo perseguido pelos que trabalham na área.

É assim que pode-se localizar no Brasil uma longa trajetória histórica sobre a produção de dados de eventos vitais, inicialmente no âmbito dos interesses econômicos do Estado e posteriormente na área da saúde.

O trabalho apresentado por Moraes (1994) sistematiza importante resgate histórico das informações referentes às estatísticas vitais no Brasil, retomando as suas origens ao ano de 1585, com o documento "L'information" do Padre José de Anchieta, com registro de 57.000 habitantes no Brasil. A autora utiliza o percurso histórico das estatísticas vitais no Brasil para pontuar características presentes na conformação do quadro das informações em saúde no país: relação burocratizada entre os niveis da Federação, racionalidade organizativa dos dados centralizadora, vinculada aos interesses econômicos, controladora e ideológica. $O$ estudo citado caracteriza a Política de Informações em Saúde no Brasil como ... "fragmentadora da realidade, pouco compatibilizada com o processo decisório, com paralelismo de ações, e demais aspectos discutidos, (...), uma vez que não atende mais às necessidades impostas pela sociedade brasileira." (MORAES, 1994, p.160), fazendo um chamamento claro para o momento de transição em curso naquele periodo. Apesar de entender-se que as características imputadas ao quadro de informações no Brasil apresentadas pela autora citada não estão muito distantes das atuais, para o objeto do presente estudo vamos nos ater à referência histórica mencionada, localizando-a como uma primeira menção às estatísticas de eventos vitais no pais, ainda que circunscrita ao terreno dos interesses do Estado e não relacionadas à saúde. 
Voltando a atenção para a produção e uso de dados sobre as estatísticas vitais na área da saúde, observa-se que, no Brasil, os primeiros estudos e publicações datam da década iniciada em 1940. A publicação de dados de mortalidade por causa ocorreu pela primeira vez em 1944, referindo-se a óbitos ocorridos em municípios de capitais a partir de 1929 (CARVALHO, 1997).

Alguns estudos, desde a primeira metade do século $X X$, já se preocupavam com a cobertura e qualidade dos dados e informações. Saade (1947) refere em seu artigo

Constitui fato reconhecido e debatido entre os cultores da estatística a existência de grandes lacunas no registro de nascimentos em nosso país. Figuram como causas dessa anomalia social a imperfeita legislação, a deficiente rede de cartórios de registro civil, o elevado número de analfabetos e, em conseqüência, a ignorância, incompreensão e falta de civismo de parte do povo. Deixamos de incluir o fator econômico... (SAADE, 1947, p. 449).

Em que pese o uso de termos hoje carregados de desvalor, a discussão principal colocada no texto citado continua bastante atual.

No mesmo período, Scorzelli Júnior (1947), além de discutir a importância do pleno conhecimento dos eventos nascimento e morte pelas "repartições de Saúde Pública", admite que o sistema de registro civil é precário, apresentando críticas e sugestões sobre a coleta de dados a partir de cartórios de registro civil. Propõe alternativas de captação dos dados referentes aos nascimentos e óbitos tais como: vigário ou autoridade religiosa, maternidade, visitadora, serviço de higiene infantil, cemitérios e outros.

Somente vamos encontrar novas publicações referentes a informações sobre eventos vitais em final da década de 1960 e início da seguinte (LAURENTI, SAYÃO e SILVEIRA, 1971; LEVY e Col, 1971; SILVEIRA e SOBOLL, 1973, MILANESI, e SILVA, 1968; SILVA, 1970; SILVEIRA e LAURENTI, 1973; SUAREZ, 1968), quando a maior discussão parecia prender-se aos nascimentos e restringir-se ao estado de São Paulo.

Conforme Mello Jorge (1990), no Brasil, a primeira lei relativa à obrigatoriedade dos registros civis data de 1888, com modificações 
posteriores ocorridas em 1939 e 1969, e finalmente em 1973, com a Lei dos Registros Públicos (Lei 6015 de 31/12/1973), atualmente em vigor. Importante frisar que neste período não havia padronização nacional de modelo de atestado de óbito, existindo e sendo reconhecidos como modelos oficiais mais de 40 tipos diferentes e que iniciativas referentes a dados de mortalidade emergiam de municípios e estados (CARVALHO, 1997). As estatísticas vitais e operações relacionadas ao sistema de informação eram de competência exclusiva do IBGE, calcadas no Sistema de Registro Civil, apresentando dificuldades de diversas ordens para utilização na área de saúde, entre as quais destaca-se a lentidão da divulgação das informações, a baixa cobertura e o pequeno número de variáveis de qualificação dos eventos de importância para a Saúde Pública.

Somente a partir de 1975, com a implantação do primeiro sistema nacional de informação em saúde, o Sistema de Informação sobre Mortalidade - SIM, é que ocorre a padronização da Declaração de Óbito DO, e a concretização de produção de informações sobre mortes no âmbito do setor saúde. As estatísticas referentes aos nascimentos irão permanecer sob a tutela exclusiva do IBGE até a implantação do Sistema de Informação sobre Nascidos Vivos - SINASC, ocorrido em 1990, apesar de o IBGE continuar produzindo informações sobre nascimentos e óbitos.

As bases legais para funcionamento do Sistema de Informação sobre Mortalidade - SIM - estão dadas pelas Leis 6015 de 31 de dezembro de 1973, Lei dos Registros Públicos; Lei 6216/75, a Portaria 130 de 12 de fevereiro de 1999 do Ministério da Saúde e Portaria 474 de 31 de agosto de 2000, da Presidência da FUNASA (FUNASA, 2002; CARVALHO, 1997).

Segundo Carvalho (1997), o SIM tem seu desenvolvimento e implantação ocorridos com envolvimento de alguns estados e todos os municípios de capitais, no bojo de ações básicas e essenciais para a criação do sistema de vigilância epidemiológica do país.

A mesma autora refere que, naquele momento, o Ministério da Saúde estipulou um modelo único de declaração de óbito e declaração de óbito fetal, definiu os fluxos dos documentos e a periodicidade dos dados. 
No período compreendido entre a implantação do SIM até os primeiros anos da década de 90, o sistema foi todo processado em computadores de grande porte, a maior parte tendo sido processada no Ministério da Saúde (SANCHES e col, 2002).

Constituem-se em marcos importantes para o SIM a implantação nas secretarias estaduais de saúde, em 1992, de um sistema destinado a microcomputadores elaborado por técnicos da Fundação Nacional de Saúde e, a partir de 1997, o desenvolvimento de um módulo de automatização de codificação de causa básica a partir da DO, chamado de Seletor de Causa Básica - SCB (CARVALHO, 1997; BRASIL, 2002).

As evoluções do SIM decorreram não somente da consolidação de um processo mas também dos avanços tecnológicos, na área computacional, que ocorreram neste período. Assim é que, em 1998, foi elaborada nova versão da D.O. acompanhada de um novo aplicativo informatizado, os quais entraram em vigor em 1999 (BRASIL, 2002).

$\mathrm{Na}$ segunda metade da década de 90 , considerando o novo contexto, o SIM começa a ser descentralizado para os municípios, como parte e resultado do processo de municipalização do SUS.

A confecção dos formulários de DO é de responsabilidade exclusiva da FUNASAMMS, sendo o documento impresso em três vias pré-numeradas, obedecendo numeração única nacional. As vias são apresentadas em diferentes cores, que destacam finalidades distintas, de acordo com o fluxo preconizado pelo MS. Este pode ser adaptado de acordo com as características do nível operacional do Sistema, garantindo-se o envio das informações às instâncias superiores.

O fluxo e demais procedimentos relacionados ao SIM estão detalhados nos documentos Manual de Procedimentos do Sistema de Informações sobre Mortalidade (BRASIL, 2001a) e Manual de Instruções para o Preenchimento de Declaração de Óbito (BRASIL, 2001b).

De acordo com Antunes (2001), a implantação do SIM não foi homogênea nos diversos estados brasileiros, o que é explicado pelas caracteristicas do sistema, quais sejam, verticalizado, centralizado e 
coerente com o modelo de atenção à saúde hospitalocêntrico e excludente. A autora apresenta uma única e contundente evidência que justifica as afirmações acima: nas regiões Norte e Nordeste a baixa cobertura $e$ deficiente qualidade das informações coincidem com a dificuldade de acesso da população aos serviços de saúde e aos registros em cartório.

Passaremos a discorrer brevemente sobre a história e atualidade das informações referentes ao evento nascimento vivo.

De acordo com Brasil (2001c), a partir da Lei de Registros Públicos o país passou a ter uma fonte oficial de estatísticas sobre nascimentos, constituída pelo Registro Civil de nascidos vivos. Nesse período e até a implantação do SINASC, em 1990, o setor saúde somente dispunha de dados referentes aos nascimentos originados em Cartório de Registro Civil, sendo o sistema de informação operado pelo Instituto Brasileiro de Geografia e Estatística - IBGE (MELLO JORGE e col, 1993). Os mesmos autores referem que o sub-registro de crianças nascidas vivas tinha como conseqüência direta sub-enumeração de nascimentos, o que comprometia a qualidade dos indicadores de saúde que utilizam o número de nascidos vivos. Também é importante acrescentar que os dados coletados pelo IBGE restringiam-se às variáveis de interesse demográfico, relacionadas ao nascimento, o que impedia o uso da fonte de informações para análises mais adequadas ao setor saúde. Acrescente-se que $\circ$ registro de nascimento era feito a partir de informações do Livro de Nascimentos do Cartório e a periodicidade trimestral do fluxo que conjuntamente podem gerar maior número de erros, falta de agilidade e dificuldade de acesso às informações.

Em 1989 foi dado o primeiro passo para a estruturação de um sistema de informação de nascidos vivos, com a criação do Grupo de Estatísticas Vitais - GEVIMS - pela Portaria no 649/GM/MS. O Grupo foi criado para assessorar o Ministério da Saúde quanto à mortalidade e natalidade, avaliação da situação de saúde e de programas básicos de saúde; promoção da utilização de estatísticas vitais em instância federal, regional e local e planejamento e avaliação em saúde (BRASIL, 2001c). 
Em 1990 foi oficialmente criado o Sistema de Informação sobre Nascidos Vivos - SINASC - e o documento-padrão Declaração de Nascido Vivo- DN -, sendo o primeiro sistema de informação em estatísticas vitais desenvolvido para microcomputadores (BRASIL, 2001c).

Sobre o SINASC, Mello Jorge e col (1993) referem que se constitui em sistema alternativo ao do Registro Civil do IBGE e que agrega novas e importantes variáveis, tais como peso ao nascer, duração da gestação e outros, não atendidas pelo sistema anterior.

O desenvolvimento e utilização do formulário de Declaração de Nascido Vivo, amplia a possibilidade de uso das informações relativas ao evento vital, agregando variáveis importantes e possibilitando a desagregação dos dados em análises para pequenas áreas (FERREIRA, 1995).

A implantação do SINASC ocorreu de forma gradual no país, entretanto, desde o ano de 1994 já se observava em muitos municípios um maior número de eventos captados quando comparado ao sistema do IBGE (FUNASA, 2002).

Segundo Sanches e col (2002), em 1999 foi implantado um novo software do SINASC, facilitando o processo de crítica das variáveis, com conseqüente diminuição das inconsistências nas bases de dados.

O SINASC é alimentado a partir da Declaração de Nascido Vivo - DN -, que é emitida por unidade de saúde que realizou o parto ou que recebe o recém nascido logo após o parto ou por cartório de Registro Civil, nos casos de nascimento fora de serviço de saúde e sem atendimento imediatamente posterior (MELLO JORGE e col, 1995).

A confecção dos formulários de DN é de responsabilidade exclusiva da FUNASA/MS, caracterizados por pré-numeração única nacional, apresentando três vias de cores e finalidades distintas, distribuidas gratuitamente às Secretarias Estaduais de Saúde - SES - que os repassam às Secretarias Municipais de Saúde - SMS -, idealmente, ou aos estabelecimentos de saúde e cartórios (SANCHES e col, 2002; FUNASA, 2002). 
O fluxo da DN está normatizado pelo MS, entretanto este pode variar de estado para estado (FUNASA, 2002), e inclusive entre municípios. Variações no fluxo da DN, que não atendam ao recolhimento ativo e planejado pela SMS comprometem principalmente a cobertura do sistema e levam conseqüentemente à sub-enumeração de nascidos vivos.

Os Manuais de Procedimentos do SINASC (BRASIL, 2001c) e de preenchimento da DN (BRASIL, 2001d) detalham conceitos, fluxo, periodicidade de informação, e normas relacionadas ao impresso padrão do Sistema de Informação de Nascidos Vivos.

$\mathrm{Na}$ criação do SIM e do SINASC, a participação do nivel federal, ou seja, do Ministério da Saúde, ocorria em quase todas as fases do processo de produção das informações, estando o poder centralizado. Entretanto, a implantação e consolidação do SUS vem a exigir a descentralização dos SIS, o que ocorreu de forma gradual, inicialmente para os estados e posteriormente para o nivel municipal.

A revisão da produção científica nacional disponível nos mostra que, após a implantação do SIM e até o início da década de 1990, os trabalhos publicados voltavam-se para o estudo de tendência de mortalidade e causas de óbitos, mas pouco foi produzido quanto à avaliação do Sistema.

A partir de 1980 e até início da década seguinte, os trabalhos identificados tinham como objeto principal o sub-registro de nascimentos e óbitos, ainda voltados para a produção de informações sobre os eventos vitais originadas em cartórios de registro civil. (ALMEIDA, 1979; GADELHA, 1982; MELLO JORGE, 1982; GIRALDELLI e WONG, 1984; PORTELA, 1989).

A década de 90 é farta em publicações em periódicos e congressos sobre os sistemas de informação relacionados aos nascimentos e óbitos. Inicialmente discutia-se a cobertura dos sistemas, histórico, aplicações e uso dos dados, limites e vantagens. São exemplos deste período os trabalhos de Mello Jorge e col, 1993; Mello Jorge e col, 1992; Baldijão e col, 1990; Mello Jorge, Baldijão e Gottlieb, 1990; Souza, 1992. 
Após a primeira metade da década de 1990 e até os dias atuais os estudos e publicações diversificam-se e ampliam seus objetos, incorporando discussões sobre qualidade das informações, linkage entre bancos de dados, necessidade de mecanismos de controle de qualidade das informações, desenvolvimento de ferramentas para uso das informações para tomada de decisões em saúde, descentralização, dentre outros. Os estudos de Mello Jorge, Gottlieb e Andrade, 1997; Noronha, Silva e Theme Filha, 1997; Oliveira e Pereira, 1997, Branco, 1996; Schramm e Szwarcwald, 2000; Silva, Ribeiro e Borba Júnior e col, 2001; Almeida e Alencar, 2000, são alguns dos que ilustram a fase atual.

O desenvolvimento e universalização da microinformática, aliados à crescente, porém ainda insuficiente democratização de dados e bancos de dados, trouxeram como conseqüência a possibilidade de acesso e uso ágil das bases de dados dos Sistemas de Informação em Saúde - SIS - no Brasil. Sobre o assunto, Sanches e col (2002) referem que tais bancos de dados representam importante fonte secundária de dados, podendo ser analisados isoladamente ou relacionados, com emprego na pesquisa científica em Saúde Pública ou em vigilância epidemiológica.

Atualmente, grande parte dos municípios brasileiros é responsável pela gestão dos SIS no nível local, o que impõe o desenvolvimento de rotinas e estratégias de acompanhamento e avaliação permanentes dos mesmos, que extrapolem e superem a mera aplicação de instrumentos coercitivos por níveis hierárquicos superiores do SUS.

O III Plano Diretor para o desenvolvimento da epidemiologia no Brasil: 2000-2004 (ABRASCO, 2000), ao analisar questões pertinentes à epidemiologia nas políticas, programas e serviços de saúde, particularmente as relacionadas aos sistemas de informação em saúde e uso das informações para práticas gerenciais, reconhece avanços quanto à facilidade de acesso aos grandes bancos de dados, ampliação de oportunidades de crescimento da área no nível municipal, modificação do padrão de uso da informação epidemiológica, voltando-se para o suporte, a decisão, formulação e implementação de políticas de saúde. $O$ documento referido, 
ao listar problemas referentes aos sistemas de informação de interesse epidemiológico, preocupa-se com a adequada utilização e controle de qualidade do sistema, baixa qualificação e ausência de supervisão na operação dos mesmos e predomínio da lógica centralizada e de processamento de dados em detrimento da análise e uso da informação, dentre outros. As proposições apresentadas no Plano são várias, desde 0 estabelecimento de mecanismos de controle de qualidade, desenvolvimento de estudos de validade e confiabilidade, até a democratização e uso intersetorial dos dados.

De qualquer sorte, fica claro o tratamento da área de informação em saúde como estratégica dentro da epidemiologia, em particular na vertente vinculada aos serviços de saúde.

No processo de democratização dos dados, bases de dados e informações relacionados aos Sistemas de Informação em Saúde no Brasil, a organização da Rede Integrada de Informações para a Saúde - RIPSA constitui-se em marco importante. A RIPSA resulta de criação conjunta do Ministério da Saúde com a OPAS/OMS no Brasil no sentido de, através da articulação interinstitucional propiciar a disponibilidade adequada, oportuna e abrangente de dados, indicadores e análise de situação de saúde e suas tendências, voltados para o uso no estabelecimento de políticas e ações públicas. Integram a Rede entidades representativas dos segmentos técnicos e científicos do cenário nacional, envolvidas na produção e análise dos dados, fundamentando suas ações em problemas da área de informação em saúde no Brasil, assim definidos: - inadequação na utilização da informação no processo de decisão e controle aplicado à gestão de políticas e ações de saúde; - desarticulação, imprecisão e insuficiência dos sistemas de informação, não contemplando a multicausalidade do processo saúde-doença; - inexistência de processos regulares de análise da situação de saúde e tendência, avaliação de serviços e de difusão de informação; fragilidades na sustentação epidemiológica do planejamento, organização e avaliação dos serviços de saúde (RIPSA, 2002). 
No cenário atual em que a informação em saúde se constitui em instrumento de gestão e planejamento de sistemas e serviços de saúde, estudos voltados para a estimativa e conhecimento do sub-registro de nascimentos passam a ter frágil justificativa; entretanto, há um deslocamento das preocupações para a sub-enumeração ou baixa cobertura dos nascimentos pelo SINASC e sub-enumeração ou baixa cobertura de óbitos pelo SIM. A sub-enumeração de nascidos vivos pelo SINASC e de óbitos pelo SIM, dentre outros fatores, parece ter relação com a ainda precária incorporação de normas e rotinas dos SIS estabelecidos pelo nível federal, passividade de recolhimento de DNs e DOs pelas Secretarias Municipais de Saúde - SMS, sub-registro de nascimentos e óbitos domiciliares; inexistência de mecanismos concretos de captura de informações de nascidos vivos de partos domiciliares e de óbitos ocorridos em residências, pelo sistema de saúde; bem como inexistência ou não aplicação de rotinas e instrumentos de acompanhamento e avaliação dos SIS no nivel local. O status que as informações em saúde assumem também parece carecer de importância que justifique $o$ investimento em recursos humanos de qualidade $e$ quantidade suficientes para a operacionalização dos sistemas de informação de forma a atender demandas dos gestores e população.

\subsection{Avaliação dos Sistemas de Informação de Nascidos Vivos e de Mortalidade}

Discussões sobre a utilização dos dados originados no SINASC e SIM para o cálculo de indicadores de saúde, em especial a taxa de mortalidade infantil e seus componentes, estão em curso no país. Parece ser consenso que a qualidade e cobertura dos referidos sistemas sofrem variação de acordo com as regiões, unidades da federação e municípios. Podemos observar no trabalho de Simões (2002) que, quando comparadas as taxas de mortalidade infantil calculadas por método indireto, por estimativas, e pelo método direto, com dados originados no SIM e SINASC, a variação não é homogênea entre regiōes e estados do país. Para a Bahia, a diferença da 
taxa de mortalidade infantil calculada entre os dois métodos para o ano de 1998 é de $109,4 \%$, sendo as taxas 46,3 por mil nascidos vivos e $22,1 \%$, pelos métodos indireto e direto respectivamente. $O$ autor refere que níveis elevados de sub-registro/sub-declaração, de óbitos infantis pelo SIM e de nascidos vivos pelo SINASC justificam a discrepância entre os valores observados.

Ao comparar indicadores de mortalidade calculados a partir de métodos diretos e indiretos em regiões e estados da federação no Brasil, Vasconcelos (2002) menciona que são evidentes as diferenças regionais quanto à qualidade das estatísticas vitais, sendo característica a baixa cobertura dos eventos nos sistemas contínuos de informação nas regiões Norte e Nordeste.

Logo após a implantação do SINASC, Mello Jorge, Gotlieb e Oliveira (1996) realizaram um trabalho voltado para avaliação quantitativa, de cobertura, e qualitativa, de preenchimento da DN, do Sistema em capitais brasileiras e no Distrito Federal. Em que pese a inexistência de dados do SINASC para algumas localidades estudadas, os resultados encontrados apontam para uma cobertura crescente, com o número de nascidos vivos captados sobrepujando o número de nascidos vivos esperados em $60,0 \%$ das áreas com dados disponiveis em 1992, 71,4\% em 93 e 75,0\% em 1994. $A$ análise do preenchimento da DN permitiu verificar uma melhora gradativa da qualidade dos dados, sendo consideradas variáveis de excelente/bom preenchimento sexo, peso ao nascer, duração da gestação, tipo de gravidez, tipo de parto e idade da mãe. As variáveis índice de Apgar, grau de instrução da mãe e paridade mostraram-se de deficiente qualidade, apesar da importância. A título de consideração final, os autores recomendavam que as unidades da federação procedessem avaliação contínua com metodologia uniforme, monitorando os municípios, cabendo ao nível local o controle quali-quantitativo das informações.

A qualidade e confiabilidade dos dados do SINASC passam a ser objeto de estudo a partir de sua implantação, em 1994. Silva e col (2001), ao avaliarem a qualidade dos dados do SINASC, no período de 1997-1998, no 
município de São Luiz no Maranhão, a partir da comparação entre os dados do sistema e dados obtidos de inquérito hospitalar, encontraram que a cobertura estimada do sistema foi de $75,8 \%$, as variáveis peso ao nascer, sexo, hospital de nascimento, tipo de parto e idade materna apresentaram boa confiabilidade, a concordância para as estimativas de BPN foi alta e para prematuridade baixa, sendo mais alta no inquérito do que no SINASC.

Em estudo realizado em Salvador, Bahia, Machado, Ichihara e Aquino (2002) verificaram uma tendência decrescente das informaçöes ignoradas para todas as variáveis no período de 1995 a 1998. O trabalho conclui que o sistema apresenta falhas em relação à qualidade das informações, sendo necessário investir na capacitação de recursos humanos nas etapas de preenchimento, digitação e codificação das DNs.

Em Ribeirão Preto, Mishima, Scochi, Ferro e col (1999) estudaram o fluxo e consistência dos dados da DN de nascidos vivos hospitalares, em um período de 1996, para concluir que o fluxo de preenchimento é heterogêneo entre os hospitais, havendo concordância acima de 90\% em 13 das 18 variáveis avaliadas. Os autores registram que as discordâncias foram maiores em relação às variáveis de paridade e grau de instrução da mãe, número de consultas de pré-natal e nome do pai.

A avaliação da qualidade do preenchimento do campo "Malformação congênita elou anomalia cromossômica" da DN, no ano de 2000 , em Porto Alegre (CUNHA e col, 2002), mostrou que comparando o registro em DN com a prevalência estimada para a ocorrência, houve um subregistro de $49,4 \%$ pelo SINASC, sendo a prevalência estimada de $2 \%$ e a prevalência registrada de $1,0 \%$.

Em Cuiabá, a avaliação do SINASC no período de 1995 a 2000 (MIRANDA e col, 2002) evidenciou que, nos últimos dois anos do estudo, todas as variáveis apresentaram preenchimento em mais de $90,0 \%$, exceto Apgar de $1^{\circ}$ e $5^{\circ}$ minutos, observando-se um incremento qualitativo nas informações no período estudado.

Atualmente são poucos os estudos sobre o registro civil de nascimentos em tempo oportuno, considerando o prazo definido em lei. Ao 
analisar fatores associados ao não registro civil de nascidos vivos em Londrina no Paraná, no ano de 2000, Iwakura e col (2002) encontraram que a taxa média de sub-registro foi de $13,1 \%$ e as variáveis estatisticamente associadas em análise bivariada $(p<0,05)$ ao não registro em 180 dias foram nascimento em hospital público, mãe de baixa escolaridade ou sem companheiro ou adolescente ou multípara, baixo número de consultas prénatais, nascimento por parto vaginal e criança de raça não branca. Em análise multivariada de variáveis com $p<0,20$ na bivariada, mantiveram-se estatisticamente associadas baixa escolaridade da mãe, baixo número de consultas pré-natais e raça não branca, o que, segundo os autores, indica forte associação entre nível sócio-econômico e não registro da criança no prazo legal de 180 dias.

A sub-enumeração de óbitos pelo SIM vem sendo objeto de estudos, principalmente em municípios das regiōes Norte e Nordeste. Frias e col (2002) buscaram quantificar a sub-enumeração de óbitos pelo SIM em município de pequeno porte do agreste de Pernambuco, encontrando uma sub-enumeração de $45,8 \%$ em óbitos de menores de um ano. No estudo foram identificadas como principais e possíveis "fontes notificadoras" dos não enumerados agentes de saúde, cemitérios, unidades de saúde e cartórios, em ordem decrescente. Importante reafirmar que a padronização das rotinas do SIM somente permite a alimentação do sistema a partir de DO preenchida por médico, serviço de verificação de óbito ou em cartório, cabendo aos municípios em situações como a descrita, proporcionar os meios para viabilizar o preenchimento da DO e conseqüente alimentação do SIM.

Estratégias políticas de envolvimento de gestores e técnicos do nivel municipal do Sistema, aliados à capacitação são importantes e podem melhorar a cobertura e qualidade dos dados gerados. Um bom exemplo é o trabalho realizado na microrregional de saúde de Baturité, no Ceará, onde a cobertura do SIM, em 1998, era de $58,8 \%$ em relação ao número de óbitos esperados e elevou-se para $73,8 \%$ no ano seguinte, após intervenção constituída por diagnóstico da situação dos SIS, discussão com secretários 
de saúde e técnicos e descentralização da codificação de causa de óbito (MACHADO e col, 2002).

A qualidade das informações da DO referentes aos óbitos infantis e a possibilidade de resgatar as informações no prontuário médico constituíramse em objeto de estudo de Vanderlei e col (2002). A pesquisa, realizada no Instituto Materno Infantil de Pernambuco, permitiu constatar que as variáveis indispensáveis e essenciais, de acordo com a classificação do Ministério da Saúde, apresentaram omissões de preenchimento variando de 0,7 a 10,9\%, com resgate completo das informações no prontuário médico. Para variáveis exclusivas de menores de um ano, detectou variação de omissão de preenchimento de 27,3 a $47,4 \%$ com resgate de informação a partir do prontuário variando de nula a $50 \%$.

Campos, Carvalho e Barcellos (2000), em estudo sobre áreas de risco para mortalidade infantil e trajetória dos pacientes aos serviços de saúde no município do Rio de Janeiro em 1995, avaliaram a qualidade dos dados do SIM, encontrando que as variáveis idade, sexo, tipo de gestação, residência e local de ocorrência do óbito apresentam alta proporção de preenchimento adequado. As demais variáveis, incluindo as indicadoras de situação sócioeconômica, apresentaram alta proporção de informações ignoradas.

Apesar de estudos e levantamentos concluírem pela boa qualidade e cobertura dos SIS, recomendando o seu uso para estudos epidemiológicos voltados para análise da saúde infantil, isto não é homogêneo para o país como um todo, restringindo-se a áreas concentradas nas regiões Sul e Sudeste.

O contexto atual apresentado para os SIS, em particular SIM e SINASC, em consonância com o processo de consolidação do SUS, justificam e impõem a realização de estudos voltados para a avaliação dos sistemas de informação no nivel local, seja nos aspectos de confiabilidade dos dados, seja nas questões relacionadas à cobertura dos eventos. Considerando municípios de pequeno e médio porte localizados nas regiöes Norte e Nordeste, avaliações de cobertura ainda parecem ser de maior 
importância, colocando-se a confiabilidade e qualidade das informações em plano secundário.

O desenvolvimento de estudos desta natureza, certamente, contribuirá para o direcionamento e re-direcionamento das ações municipais de operacionalização dos sistemas, com vistas à melhoria da qualidade das informações disponiveis, bem como poderá subsidiar decisões normativas em instâncias superiores componentes dos mesmos. 


\section{OBJETIVOS}

\subsection{Objetivo geral}

- Avaliar o Sistema de Informação de Nascido Vivo - SINASC e o Sistema de Informação de Mortalidade - SIM como fontes de dados para obtenção da probabilidade de morte neonatal no município de llhéus, Bahia, em 2001.

\subsection{Objetivos específicos}

- Avaliar a captação de nascimentos pelo SINASC, utilizando uma coorte de nascidos vivos hospitalares com ocorrência e residência no município de llhéus;

- Avaliar a captação pelo SIM de óbitos de menores de 28 dias originados da coorte de nascidos vivos hospitalares com ocorrência e residência no município de llhéus;

- Obter a proporção de nascimentos e óbitos registrados em Cartórios de Registro Civil da Comarca de llhéus originados da coorte de nascidos vivos hospitalares;

- Obter a probabilidade de morte neonatal na coorte de nascidos vivos hospitalares e fator de correção para o cálculo da probabilidade de morte neonatal no município de llhéus;

- Descrever o perfil de nascidos vivos hospitalares da coorte, captados e não captados pelo SINASC, segundo variáveis do neonato, da mãe, do parto e de assistência à saúde;

- Descrever o perfil dos óbitos neonatais da coorte de nascidos vivos hospitalares, captados e não captados pelo SIM, segundo variáveis do neonato, da mãe, do parto e de assistência à saúde. 


\section{MATERIAL E MÉTODO}

\section{1 Área de estudo}

O presente estudo foi realizado tendo como referência a população de crianças nascidas vivas de partos hospitalares realizados no município de llhéus, cujas mães residiam no mesmo município.

llhéus é um município situado na região Sul da Bahia, com uma população recenseada, $\mathrm{n}$ o ano de 2000 , de 222.127 habitantes, dos quais $49,7 \%$ são homens e $50,3 \%$ mulheres, $73 \%$ residindo em zona urbana e $27 \%$ em zona rural (IBGE, 2002).

Considerando a população residente maior ou igual a 10 anos, segundo o Censo Demográfico 2000 do Instituto Brasileiro de Geografia e Estatística - IBGE, a taxa de alfabetização para município é de $80,3 \%$ (IBGE, 2002).

A grande extensão territorial do município é constatada por sua área definida por $1.847,7 \mathrm{Km}^{2}$ (SEI, 2002), com uma densidade demográfica aproximada de 120 habitantes por $\mathrm{km}^{2}$ (IBGE, 2002).

Limita-se a leste com o Oceano Atlântico, a norte com os municípios de Aurelino Leal, Itacaré e Uruçuca, a oeste com municípios de Buerarema, Coaraci, Itabuna, Itajuípe e Itapitanga e ao sul com Una. A maior parte dos municípios circunvizinhos tem a cidade de llhéus como referência para os diversos setores urbanos, incluindo saúde (SEI, 2002).

Historicamente, a colonização e ocupação das terras de llhéus iniciaram-se por volta de $1534 \mathrm{com}$ a fundação da Capitania de São Jorge dos llhéus, sendo criado o município em 1881 (ILHÉUS, 2000).

O município, ao longo de sua história, passou por ciclos econômicos, ligados à produção agrícola, inicialmente de cana de açúcar e posteriormente do cacau. Atualmente vive intensa crise econômica relacionada a pragas na lavoura cacaueira e aos baixos preços do produto no mercado internacional. No segundo semestre de 2002 o mercado internacional sinaliza com uma 
tendência de crescimento dos preços do produto, alcançando os maiores valores dos últimos 13 anos.

De acordo com a Superintendência de Estudos Econômicos da Bahia (SEI, 2002), Ilhéus ocupa o $9^{\circ}$ lugar em Desenvolvimento Econômico e $16^{\circ}$ lugar em Desenvolvimento Social dentre os municipios baianos. A discrepância observada entre os dois indices ilustra as dificuldades no terreno social existentes em llhéus, bem como a não correspondência de investimentos públicos na área e a capacidade econômica gerada. $A$ baixa classificação quanto ao desenvolvimento social permite supor que os indicadores de saúde que compõem o índice podem estar interferindo negativamente na pontuação obtida, o que pode ser exemplificado pela classificação obtida pelo município no Índice de Nível de Saúde, ocupando o $112^{\circ}$ lugar dentre os municipios baianos (SEI, 2002).

Quanto à organização do sistema de saúde, encontra-se na condição de Gestão Plena do Sistema de Saúde.

Segundo Souza (2000), existem no município 80 estabelecimentos de saúde com diversos níveis de complexidade, sendo a rede municipal composta por vinte e oito Unidades Básicas de Saúde - UBS -, nove núcleos de saúde da familia e três unidades móveis médico-odontológicas. A mesma autora refere a existência de seis unidades hospitalares, das quais quatro realizavam assistência obstétrica no periodo de estudo. Não há no município serviços especializados destinados à atenção neonatal.

Vinculadas ao Programa de Atenção à Saúde da Mulher - PAISM -, as atividades de pré-natal, encontram-se implantadas em algumas UBS, tendo sido realizadas 2.858 consultas de pré-natal no ano de 1999 (ILHÉUS, 1999).

O número de nascidos vivos captados pelo Sistema de Informações de Nascidos Vivos - SINASC -, para o ano de 1998, foi de 3.766 (DATASUS, 2000a) e a população residente menor de um ano estimada para o mesmo ano de 4.704 crianças. Para o ano de 1999 foram captados pelo SINASC 2772 nascidos vivos (DATASUS, 2002). 


\subsection{População de estudo}

São estudados os nascidos vivos hospitalares com ocorrência do parto e residência da mãe no município de llhéus e os óbitos neonatais originados desta coorte de nascimentos.

\subsection{Período de referência}

O estudo foi desenvolvido compreendendo o período de $1^{\circ}$. de janeiro a 31 de dezembro de 2001.

\subsection{Delineamento do estudo}

O desenho do estudo, procedimentos utilizados e fonte de dados estão esquematicamente apresentados na figura 1. 
FIGURA 1 - REPRESENTACAO ESQUEMATICA DO DESENHO DO ESTUDO, FON
COLETA E TRATAMENTO DE DADOS

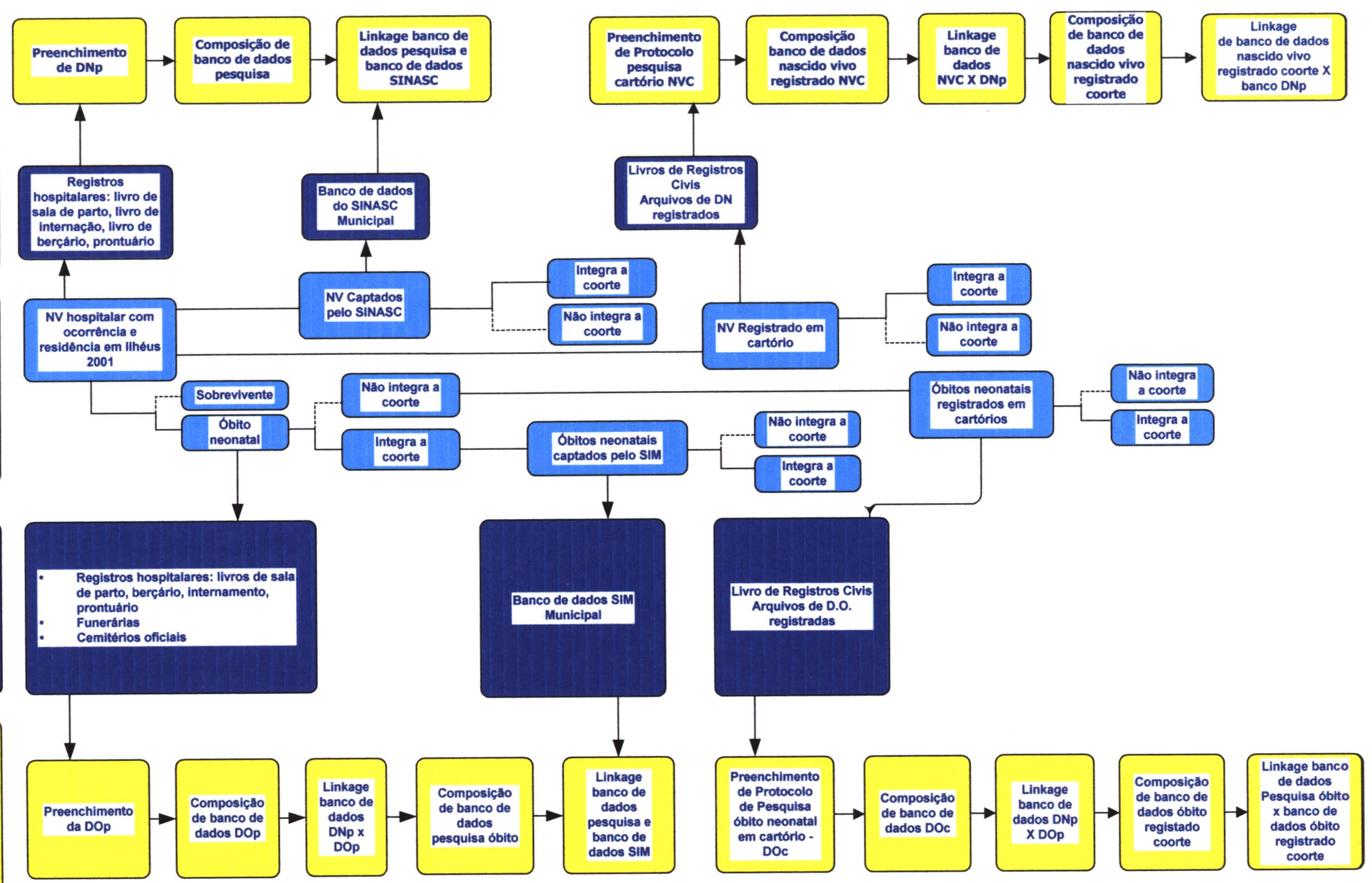




\subsubsection{Nascidos vivos}

\subsubsection{Nascidos vivos hospitalares}

- Fonte de obtenção de dados

As fontes de obtenção dos dados para constituição da coorte de nascidos vivos hospitalares com residência da mãe e ocorrência no município de llhéus estão detalhados no quadro 1 , segundo unidade hospitalar. As variações observadas quanto à fonte de obtenção dos dados justificam-se pela não homogeneidade das formas de registros nos hospitais do município. Para o Hospital e Maternidade Santa Helena, como o livro de sala de parto não continha informações que permitissem a identificação posterior do prontuário da mãe ou do neonato, foram pesquisados todos os prontuários hospitalares do período de estudo, com o objetivo de identificar os internamentos que originaram um nativivo. Nas demais unidades, o livro de sala de parto e berçário permitiram identificar subseqüentemente os prontuários de partos ocorridos com um produto nascido vivo. É importante ainda registrar que, dentre as unidades pesquisadas, apenas o Hospital e Maternidade Santa Helena mantém uma via da DN no prontuário do paciente. As outras unidades registram apenas o número da DN no livro de sala de parto e berçário. 
Quadro 1 - Fontes de coleta utilizadas para obtenção de dados de nascidos vivos e óbitos neonatais, segundo unidade hospitalar, llhéus, 2001

\begin{tabular}{|l|l|}
\hline \multicolumn{1}{|c|}{ Hospital } & \multicolumn{1}{|c|}{ Fonte de coleta } \\
\hline Hospital e Maternidade Santa Helena & $\begin{array}{l}\text { Prontuários hospitalares } \\
\text { Prontuário da mãe } \\
\text { Prontuário do neonato } \\
\text { Declaração de Nascido Vivo }\end{array}$ \\
\hline Hospital e Maternidade Santa Isabel & $\begin{array}{l}\text { Livro de Sala de Parto e Berçário } \\
\text { Livro de internamento } \\
\text { Prontuário da mãe } \\
\text { Prontuário do neonato }\end{array}$ \\
\hline Hospital São Jorge & $\begin{array}{l}\text { Livro de Sala de Parto e Berçário } \\
\text { Sistema informatizado de registro de } \\
\text { internamentos } \\
\text { Prontuário da mãe } \\
\text { Prontuário do neonato }\end{array}$ \\
\hline Hospital e Maternidade Bartolomeu & $\begin{array}{l}\text { Livro de Sala de Parto e Berçário } \\
\text { Prontuário da mãe } \\
\text { Chaves }\end{array}$ \\
\hline
\end{tabular}

\section{- Verificação do local de residência}

A verificação do município de residência da mãe foi realizada a partir do endereço constante no livro ou sistema de registro de internamento e posteriormente confirmado pela consulta à folha de identificação da paciente existente no prontuário. No momento da coleta de dados referente à consulta ao prontuário da mãe e do neonato,o coletador estava treinado para descartar o evento que não atendesse ao critério de inclusão no estudo, qual seja residência no município de llhéus. Caso houvesse dúvida quanto ao município de residência, a coleta do dado deveria prosseguir.

$\mathrm{Na}$ ocorrência de endereços discordantes, o registro da folha de identificação da paciente foi considerado como padrão ouro. Na inexistência 
de registro de municipio de residência foram consultados a relação de logradouros da Listagem de Telefones do município, para a zona urbana, e mapas da Fundação Nacional de Saúde por fazendas e distritos, para a zona rural. Na impossibilidade de localizar o endereço referido ou na inexistência de endereços, o evento foi descartado para efeito deste estudo. Assim, foram descartados 12 nascidos vivos hospitalares por impossibilidade de definição do endereço de residência da mãe.

\section{- Procedimentos utilizados quanto a informações discordantes}

$\mathrm{Na}$ ocorrência de informações discordantes entre as diversas fontes de coleta utilizadas, foi considerada como padrão ouro a informação contida em prontuário da mãe e/ou do neonato.

\subsubsection{Nascidos vivos registrados em cartório}

\section{- Fonte de obtenção de dados}

A obtenção dos dados referentes a nascidos vivos registrados em cartório ocorreu a partir dos Livros de Registros de Pessoais Naturais dos cartórios de Registro Civil do município de llhéus.

Casos de assentamentos de crianças com observação de processo posterior de adoção foram tratados utilizando-se as informações disponiveis sobre a mãe biológica, considerando que o objeto deste estudo está relacionado às condições da gestação, do parto e periodo neonatal.

\section{- Verificação do local de residência}

A verificação do município de residência da mãe da criança registrada foi realizada pela observação dos dados de identificação constantes no Livro de Registros de Nascimentos. Neste momento da coleta de dados, o coletador estava treinado para descartar o evento que não atendesse ao 
critério de inclusão no estudo, qual seja residência no município de llhéus. Caso houvesse dúvida quanto ao município de residência, a coleta do dado deveria prosseguir. Na ocorrência de inexistência de município de residência no assentamento, o endereço foi utilizado para consulta a relação de logradouros da Listagem de Telefones do município, para a zona urbana, e mapas da Fundação Nacional de Saúde por fazendas e distritos, para a zona rural. $\mathrm{Na}$ impossibilidade de localizar o endereço referido ou na inexistência de endereços, o evento foi descartado para efeito deste estudo. Foram descartados 6 registros nos quais não foi possivel identificar 0 município de residência da mãe e um registro decorrente de adoção no qual não havia declaração do endereço da mãe biológica por segredo de justiça.

\subsubsection{Nascidos vivos captados pelo SINASC}

O banco de dados do SINASC municipal foi cedido pelo Setor de Vigilância Epidemiológica da Secretaria Municipal de Saúde de Ilhéus, em formato de planilhas eletrônicas. 


\subsection{2 Óbitos neonatais}

\subsubsection{1 Óbitos neonatais hospitalares}

- Fonte de obtenção de dados

As fontes de obtenção dos dados referentes aos óbitos neonatais hospitalares foram constituídas à semelhança do caminho percorrido para identificar nascidos vivos hospitalares e estão expostos no quadro 1 . É importante registrar que, dentre as unidades pesquisadas, apenas o Hospital e Maternidade Santa Helena mantem uma via da DO no prontuário do paciente. As outras unidades registram apenas o número da DO no livro de sala de parto e berçário.

\section{- Verificação do local de residência}

Os mesmos procedimentos adotados para verificação do município de residência para nascidos vivos hospitalares foram aplicados aos óbitos neonatais identificados estando detalhados anteriormente.

- Procedimentos utilizados quanto a informaçōes discordantes

Em situações de informaçōes discordantes entre as diversas fontes de coleta utilizadas, a informação contida em prontuário da mãe e/ou do neonato foi considerada como padrão ouro. 


\subsubsection{2 Óbitos neonatais registrados em cartórios}

- Fonte de obtenção de dados

A obtenção dos dados referentes a óbitos neonatais registrados em cartório ocorreu a partir dos Livros de Registros de Óbitos dos cartórios de Registro Civil do município de llhéus.

\section{- Verificação do local de residência}

A verificação do município de residência da mãe do óbito neonatal registrado foi realizada pela observação dos dados de identificação constantes no Livro de Registros de Óbitos. Os demais procedimentos foram realizados conforme descrito anteriormente.

\subsubsection{3 Óbitos neonatais captados pelo SIM}

O banco de dados do SIM municipal foi cedido pelo Setor de Vigilância Epidemiológica da Secretaria Municipal de Saúde de llhéus, em formato de planilhas eletrônicas.

\subsection{Variáveis}

Foram compostos seis bancos de dados distintos, com diferentes origens das informações, três deles referentes a nascidos vivos e três referentes a óbitos neonatais. Considerando a diversidade de origem institucional dos dados coletados e respeitando a disponibilidade das informações em cada uma delas, as variáveis estudadas relativas aos nascidos vivos estão expostas no quadro 2 , de acordo com a relação com o evento, categorização utilizada e origem dos dados. 
Quadro 2 - Variáveis estudadas relativas aos nascidos vivos, segundo relação com o evento, categorização e origem dos dados.

\begin{tabular}{|c|c|c|c|c|c|}
\hline \multirow{2}{*}{$\begin{array}{l}\text { Relação com o } \\
\text { evento }\end{array}$} & \multirow[b]{2}{*}{ Variável } & \multirow[b]{2}{*}{ Categorização } & \multicolumn{3}{|c|}{ Origem dos dados } \\
\hline & & & Hospital & Cartório & SINASC \\
\hline \multirow[t]{7}{*}{$\begin{array}{l}\text { De } \\
\text { identificação }\end{array}$} & $\begin{array}{l}\text { Número da } \\
\text { DN }\end{array}$ & & $\bar{X}$ & $\bar{x}$ & $\bar{x}$ \\
\hline & Nome da mãe & Nominal & $\bar{x}$ & $x$ & $x$ \\
\hline & $\begin{array}{l}\text { Endereço da } \\
\text { mäe }\end{array}$ & Nominal & $\mathrm{X}$ & $x$ & $\mathrm{X}$ \\
\hline & $\begin{array}{l}\text { Área de } \\
\text { residência da } \\
\text { mãe }\end{array}$ & $\begin{array}{l}\text { Zona rural } \\
\text { Zona urbana }\end{array}$ & $\bar{X}$ & & - \\
\hline & $\begin{array}{l}\text { Número do } \\
\text { registro }\end{array}$ & & - & $\bar{x}$ & -- \\
\hline & $\begin{array}{l}\text { Data do } \\
\text { registro }\end{array}$ & \begin{tabular}{lll|}
$\begin{array}{l}\text { Dia, } \\
\text { ano }\end{array}$ & mês & e \\
\end{tabular} & - & $\bar{x}$ & - \\
\hline & $\begin{array}{l}\text { Nome da } \\
\text { criança }\end{array}$ & Nominal & -- & $\bar{x}$ & -- \\
\hline \multirow[t]{4}{*}{ Do neonato } & $\begin{array}{l}\text { Data do } \\
\text { nascimento }\end{array}$ & $\begin{array}{lll}\text { Dia, mês e } \\
\text { ano }\end{array}$ & $\bar{x}$ & $\mathrm{X}$ & $\bar{x}$ \\
\hline & $\begin{array}{l}\text { Hora do } \\
\text { nascimento }\end{array}$ & & $\mathrm{X}$ & $\bar{x}$ & $\bar{X}$ \\
\hline & Sexo & $\begin{array}{l}\text { Masculino } \\
\text { Feminino } \\
\text { Ignorado }\end{array}$ & $\mathrm{X}$ & $\bar{x}$ & $\bar{x}$ \\
\hline & $\begin{array}{l}\text { Peso ao } \\
\text { nascer } \\
\text { (em gramas) }\end{array}$ & $\begin{array}{l}<2500 \mathrm{~g} \\
2500 \mathrm{~g} \text { a } 3999 \mathrm{~g} \\
>4000 \mathrm{~g}\end{array}$ & $\bar{x}$ & -- & $\mathrm{X}$ \\
\hline \multirow[t]{2}{*}{ Da mãe } & $\begin{array}{l}\text { Idade } \\
\text { (em anos } \\
\text { completos) }\end{array}$ & & $\bar{X}$ & $\bar{X}$ & $\bar{x}$ \\
\hline & $\begin{array}{l}\text { Paridade } \\
\text { (em número } \\
\text { de filhos) }\end{array}$ & $\begin{array}{l}\text { Nascidos } \\
\text { vivos } \\
\text { Nascidos } \\
\text { mortos } \\
\end{array}$ & $\bar{X}$ & $\bar{X}$ & $\mathrm{X}$ \\
\hline
\end{tabular}

Continua... 
Quadro 2 - Variáveis estudadas relativas aos nascidos vivos, segundo relação com o evento, categorização e origem dos dados.

(Continuação...)

\begin{tabular}{|c|c|c|c|c|c|}
\hline Relação com o & Variável & Categorização & & do & \\
\hline Da gestação & $\begin{array}{l}\text { Duração da } \\
\text { gestação } \\
\text { (em semanas) }\end{array}$ & $\begin{array}{l}0 \text { a } 36 \\
37 \text { a } 41 \\
42 \text { e mais } \\
\text { Ignorada }\end{array}$ & $x$ & - & $\mathrm{x}$ \\
\hline & $\begin{array}{l}\text { Tipo de } \\
\text { gravidez }\end{array}$ & $\begin{array}{l}\text { Única } \\
\text { Dupla } \\
\text { Tripla e mais } \\
\text { Ignorado }\end{array}$ & $x$ & - & $\bar{x}$ \\
\hline & $\begin{array}{l}\text { Número de } \\
\text { consultas de } \\
\text { pré-natal }\end{array}$ & $\begin{array}{l}\text { Nenhuma } \\
1 \text { a } 3 \\
4 \text { a } 6 \\
7 \text { e mais } \\
\text { Ignorado }\end{array}$ & $x$ & -- & $x$ \\
\hline Do parto & $\begin{array}{l}\text { Local de } \\
\text { ocorrência }\end{array}$ & $\begin{array}{l}\text { Hospital } \\
\text { Outros estab. } \\
\text { de saúde } \\
\text { Domicilio } \\
\text { Outros } \\
\text { Ignorado }\end{array}$ & $x$ & $x$ & $x$ \\
\hline & $\begin{array}{l}\text { Hospital de } \\
\text { ocorrência }\end{array}$ & $\begin{array}{l}\text { Santa Helena } \\
\text { Santa Isabel } \\
\text { Bartolomeu } \\
\text { São Jorge }\end{array}$ & $x$ & $x$ & $x$ \\
\hline & Tipo de parto & $\begin{array}{l}\text { Vaginal } \\
\text { Cesáreo } \\
\text { Ignorado }\end{array}$ & $x$ & - & $x$ \\
\hline $\begin{array}{l}\text { Sócio- } \\
\text { econômicas }\end{array}$ & $\begin{array}{l}\text { Estado civil da } \\
\text { mãe }\end{array}$ & $\begin{array}{l}\text { Solteira } \\
\text { Casada } \\
\text { Viúva } \\
\text { Separada } \\
\text { judicialmente } \\
\text { União } \\
\text { consensual } \\
\text { Ignorado }\end{array}$ & $\bar{x}$ & $x$ & $\mathrm{x}$ \\
\hline
\end{tabular}

Continua... 
Quadro 2 - Variáveis estudadas relativas aos nascidos vivos, segundo relação com o evento, categorização e origem dos dados.

(Continuação...)

\begin{tabular}{|l|l|l|l|c|c|}
\hline $\begin{array}{c}\text { Relação com o } \\
\text { evento }\end{array}$ & Variável & Categorização & \multicolumn{3}{|c|}{ Origem dos dados } \\
\hline Sócio- & Escolaridade & Nenhuma & $\mathrm{X}$ & $\mathrm{X}$ & $\mathrm{X}$ \\
econômicas & da mãe (em & 1 a 3 & & & \\
& anos de & 4 a 7 & & & \\
& estudo) & 8 a 11 & & & \\
& & 12 e mais & & & \\
\hline
\end{tabular}

As variáveis relacionadas aos óbitos neonatais estão expostas no quadro 3, segundo relação com o evento em estudo, categorização utilizada e origem dos dados. Algumas variáveis utilizadas para nascidos vivos foram repetidas na coleta dos dados referentes aos óbitos neonatais, com a finalidade de permitir e confirmar a linkage entre os bancos de dados, as quais não apresentaremos no quadro 3 .

Quadro 3 - Variáveis estudadas relativas aos óbitos neonatais, segundo relação com o evento, categorização e origem dos dados

\begin{tabular}{|l|l|l|c|c|c|}
\hline \multirow{2}{*}{$\begin{array}{c}\text { Relação com } \\
\text { o evento }\end{array}$} & Variável & Categorização & \multicolumn{3}{|c|}{ Origem dos dados } \\
\cline { 4 - 6 } & & Hospital & Cartório & SIM \\
\hline $\begin{array}{l}\text { De } \\
\text { identificação }\end{array}$ & $\begin{array}{l}\text { Número da } \\
\text { DN }\end{array}$ & & $X$ & $X$ & $X$ \\
\cline { 2 - 6 } & $\begin{array}{l}\text { Número da } \\
\text { DO }\end{array}$ & & $X$ & $X$ & $X$ \\
\cline { 2 - 6 } & $\begin{array}{l}\text { Nome da } \\
\text { mãe }\end{array}$ & Nominal & $X$ & $X$ & $X$ \\
\cline { 2 - 6 } & $\begin{array}{l}\text { Endereço da } \\
\text { mãe }\end{array}$ & Nominal & $X$ & $X$ & $X$ \\
\hline
\end{tabular}

Continua... 
Quadro 3 - Variáveis estudadas relativas aos óbitos neonatais, segundo relação com o evento, categorização e origem dos dados

(Continuação...)

\begin{tabular}{|c|c|c|c|c|c|}
\hline \multirow{2}{*}{\begin{tabular}{|l|}
$\begin{array}{c}\text { Relação com } \\
\text { o evento }\end{array}$ \\
$\begin{array}{l}\text { De } \\
\text { identificação }\end{array}$
\end{tabular}} & \multirow{2}{*}{\begin{tabular}{|l|} 
Variável \\
$\begin{array}{l}\text { Cartório de } \\
\text { registro do } \\
\text { óbito }\end{array}$
\end{tabular}} & \multirow[b]{2}{*}{$\begin{array}{l}\text { Categorização } \\
1^{\circ} \text {. Ofício } \\
2^{\circ} \text {. Ofício } \\
\text { Japú e Banco } \\
\text { da Vitória } \\
\text { Pontal } \\
\text { Castelo Novo } \\
\text { Rio do Braço } \\
\text { Aritaguá } \\
\text { Banco Central } \\
\text { Olivença }\end{array}$} & \multicolumn{3}{|c|}{ Origem dos dados } \\
\hline & & & -- & $x$ & -- \\
\hline & $\begin{array}{l}\text { Número do } \\
\text { registro do } \\
\text { óbito }\end{array}$ & & -- & $\bar{x}$ & - \\
\hline & $\begin{array}{l}\text { Data do } \\
\text { registro do } \\
\text { óbito }\end{array}$ & Dia, mês e ano & -- & $\bar{x}$ & - \\
\hline & $\begin{array}{l}\text { Nome da } \\
\text { crianca }\end{array}$ & Nominal & -- & $x$ & $\bar{x}$ \\
\hline & Data do óbito & Dia, mês e ano & $x$ & $x$ & $\bar{x}$ \\
\hline & Hora do óbito & Hora e minuto & $x$ & $x$ & $\bar{x}$ \\
\hline & $\begin{array}{l}\text { Idade ao } \\
\text { morrer }\end{array}$ & $\begin{array}{l}\text { Mês, dia, horas } \\
\text { e minutos }\end{array}$ & $x$ & $x$ & $\bar{x}$ \\
\hline & \begin{tabular}{|l} 
Data do \\
nascimento
\end{tabular} & Dia, mês e ano & $\bar{x}$ & $x$ & $\bar{x}$ \\
\hline & $\begin{array}{l}\text { Hora do } \\
\text { nascimento }\end{array}$ & Hora e minutos & $x$ & $x$ & $\bar{x}$ \\
\hline & $\begin{array}{l}\text { Óbito em } \\
\text { relação ao } \\
\text { parto }\end{array}$ & $\begin{array}{l}\text { Antes } \\
\text { Durante } \\
\text { Depois } \\
\text { lgnorado }\end{array}$ & $x$ & $\mathrm{X}$ & $x$ \\
\hline
\end{tabular}

Continua... 
Quadro 3 - Variáveis estudadas relativas aos óbitos neonatais, segundo relação com o evento, categorização e origem dos dados

(Continuação...)

\begin{tabular}{|l|l|l|c|c|c|}
\hline $\begin{array}{l}\text { Relação com } \\
\text { o evento }\end{array}$ & \multicolumn{1}{|c|}{ Variável } & Categorização & \multicolumn{3}{|c|}{ Origem dos dados } \\
\hline $\begin{array}{l}\text { Da } \\
\text { assistência } \\
\text { ao óbito } \\
\text { neonatal }\end{array}$ & $\begin{array}{l}\text { Assistência } \\
\text { médica na } \\
\text { doença que } \\
\text { levou ao } \\
\text { óbito }\end{array}$ & $\begin{array}{l}\text { Sim } \\
\text { Não }\end{array}$ & \begin{tabular}{l} 
Ignorado \\
\cline { 2 - 6 }
\end{tabular} & Local de \\
ocorrência do & óbito & $\begin{array}{l}\text { Hospital } \\
\text { Outros estab. } \\
\text { de saúde } \\
\text { Domicílio } \\
\text { Via pública } \\
\text { Outros } \\
\text { Ignorado }\end{array}$ & $\mathrm{X}$ & $\mathrm{X}$ & $\mathrm{X}$ \\
\hline
\end{tabular}

\subsection{Coleta de dados}

A coleta de dados foi desenvolvida no periodo de maio a setembro de 2002 , por equipe de quatro coletadores, previamente treinados com vistas à padronização de procedimentos.

Os dados hospitalares foram coletados a partir da consulta aos arquivos de hospitais que prestam assistência obstétrica e pediátrica no municipio de llhéus. No município existem 4 hospitais que prestam assistência obstétrica, sendo três conveniados ao SUS e um não conveniado. A assistência pediátrica é prestada por 6 hospitais, sendo quatro conveniados ao SUS, um não conveniado e um da rede própria do SUS.

A coleta de dados em hospitais foi precedida de visita ao diretor médico do estabelecimento hospitalar, com apresentação da pesquisadora e da pesquisa e assinatura, por ambos, do Termo de Consentimento (Anexo 3).

Os dados de registro civil foram coletados a partir da consulta aos assentamentos de Cartórios de Registros Civis da Comarca de Ilhéus. No 
município funcionam 09 Cartórios de Registro Civil, 08 localizados no Fórum Epaminondas Berbet de Castro e um localizado na Estância Hidromineral de Olivença, conforme detalhado em quadro 4.

A coleta dos dados em cartórios de registro civil foi precedida de autorização pelo Juiz da Vara de Registro de Pessoas Naturais de llhéus (Anexo 4), e realizada após decorridos 180 dias do último dia do ano calendário de 2001, dando oportunidade a todos os nascidos vivos o prazo legal máximo para efetivação do Registro Civil.

Quadro 4- Cartórios de Registro Civil da comarca de llhéus, maio de 2002.

\begin{tabular}{|l|l|}
\hline \multicolumn{1}{|c|}{ CARTÓRIO } & \multicolumn{1}{c|}{ LOCALIZAÇÃO } \\
\hline Cartório do $1^{\circ}$. Ofício & Fórum Epaminondas Berbet de Castro \\
\hline Cartório do $2^{\circ}$. Ofício & Fórum Epaminondas Berbet de Castro \\
\hline Cartório do Japú e Banco da Vitória & Fórum Epaminondas Berbet de Castro \\
\hline Cartório do Pontal & Fórum Epaminondas Berbet de Castro \\
\hline Cartório de Castelo Novo & Fórum Epaminondas Berbet de Castro \\
\hline Cartório do Rio do Braço & Fórum Epaminondas Berbet de Castro \\
\hline Cartório de Aritaguá & Fórum Epaminondas Berbet de Castro \\
\hline Cartório do Banco Central & Fórum Epaminondas Berbet de Castro \\
\hline Cartório de Olivença & Estância Hidromineral de Olivença \\
\hline
\end{tabular}

Os bancos de dados do SIM e SINASC do municipio de llhéus foram cedidos pelo Setor de Vigilância Epidemiológica da Secretaria Municipal de Saúde de llhéus, após encerramento do ano estatístico de 2001.

O trabalho de campo somente foi iniciado após apresentação da proposta de pesquisa ao gestor municipal do Sistema de Saúde, com assinatura de Termo de Consentimento (Anexo 5). 


\subsection{Instrumentos de coleta de dados}

Foram utilizados quatro diferentes instrumentos para coleta de dados, elaborados a partir da simplificação da DO e DN padronizadas pelo Ministério da Saúde, mantendo-se a mesma codificação.

Os dados hospitalares para nascidos vivos foram coletados através de instrumento denominado Declaração de Nascido Vivo Hospitalar - DNh (anexo 6). Os dados para nascido vivo registrado em cartório foram coletados através de instrumento denominado Declaração de Nascido Vivo Cartório - DNc (anexo 7).

As informações sobre óbitos neonatais hospitalares foram colhidas através do preenchimento de instrumento denominado Declaração de Óbito Hospitalar - DOh (anexo 8). As informações referentes a óbitos neonatais registrados em cartórios foram coletadas através de instrumento de coleta denominado Declaração de Óbito Cartório - DOc (anexo 9).

\subsection{Consolidação dos dados}

A consolidação dos dados foi realizada através da digitação em planilha eletrônicas do Excel Microsoft.

\subsection{Análise dos dados}

A probabilidade de morte neonatal foi calculada:

$$
\hat{q}=\frac{d}{E} \times 1000 \text {, onde: }
$$

$\wedge$

$q$ = estimativa da probabilidade de morte neonatal em um período de tempo definido;

$d=$ óbitos neonatais ocorridos no período de tempo definido;

$E=$ número de nascidos vivos no período de tempo definido. 
Assim, a probabilidade de morte neonatal será:

$$
\hat{q}=\frac{\text { número de óbitos de }<\text { de } 28 \text { dias }}{\text { número de nascidos vivos }} \times 1000
$$

\section{- $\quad$ Linkage}

Segundo Almeida (1994), a técnica de linkage consiste "na ligação de dois ou mais bancos de dados independentes, que possuam variáveis comuns entre si e que, por meio de uma ou mais delas seja possivel identificar os indivíduos que fazem parte dos dois bancos de dados". (ALMEIDA, 1994, p.25)

Para realizar a linkage entre os bancos de dados foram utilizadas as variáveis data de nascimento (dia/mês/ano) e sexo. Após obtenção de um conjunto de DN e DO com a mesma data de nascimento e sexo, para cada caso foram utilizadas as variáveis de nome da mãe, horário de nascimento e peso como confirmatórias do pareamento.

As operaçōes acima descritas foram repetidas entre os seis bancos de dados estudados: DN hospital, DN cartório, SINASC, DO hospital, DO cartório e SIM.

Após o pareamento, foram construídos dois bancos de dados um de nascidos vivos e um de óbitos neonatais.

Após a linkage, detectou-se a ocorrência de nascidos vivos que tinham registro no SINASC ou DN cartório como nascimento hospitalar com ocorrência e residência em llhéus que não constavam no banco de dados DN hospital. Para estes procedeu-se uma coleta dirigida em arquivos hospitalares.

\section{- Procedimentos estatísticos utilizados}

Para análise do perfil de nascidos vivos e de óbitos neonatais segundo captação pelo SINASC e SIM, respectivamente, foram utilizados os $\chi^{2}$, com a finalidade de estudar a distribuição dos eventos captação e não- 
captação segundo variáveis e possibilidade de associação (SIEGEL,1975). Verificou-se a significância estatística das associações entre variáveis considerando-se um erro $\alpha$ de 0,05 (5\%).

\subsection{Aspectos éticos}

Foram realizados contatos prévios à coleta de dados com autoridade judicial competente, gestor municipal de saúde e diretores de unidades hospitalares tipo maternidade visando a autorização de consulta a dados secundários, sendo apresentados objetivos da pesquisa, os métodos e procedimentos da investigação, benefícios esperados, possíveis incômodos resultantes da presença e inquirição dos pesquisadores em arquivos hospitalares e cartórios de registro civil, a importância da autorização; a garantia de sigilo e impossibilidade de individualização dos dados em publicações e por fim, a garantia de esclarecimentos durante 0 desenvolvimento da pesquisa. Os anexos 3 a 5 constituem-se nos documentos de autorização da coleta de dados.

Somente após a obtenção da autorização de consulta a dados secundários por autoridade competente foram iniciadas a coleta de dados nos hospitais e cartórios.

Após a apresentação da tese em cumprimento às exigências acadêmicas para conclusão do curso de Doutorado em Saúde Pública, os resultados serão divulgados em linguagem acessível à comunidade estudada, bem como diretores dos hospitais, autoridade judicial de defesa dos direitos da criança e Secretário Municipal de Saúde. 


\section{RESULTADOS E DISCUSSÃO}

Apesar de não estar incluído nos objetivos do presente trabalho, para melhor contextualização dos resultados decorrentes da pesquisa proposta, optou-se por apresentar inicialmente os dados secundários disponiveis no site do DATASUS (2002) e CD ROM (FUNASA, 2002) do SINASC e SIM de Ilhéus, bem como aplicação dos critérios para avaliação de SIS propostos por Szwarcwald e col (2002). Assim, os dois primeiros itens deste capítulo atem-se a esta análise, e somente a partir do terceiro item passaremos à apresentação e discussão dos resultados obtidos com os dados primários.

\subsection{Os dados do SINASC e SIM em Ilhéus}

A qualidade dos dados do SINASC e SIM no Brasil, por regiōes e na Bahia em particular, conforme referido anteriormente, apresenta variação. Segundo Simões (1999), a região Nordeste e a Bahia, de acordo com os parâmetros utilizados para avaliação dos dados, têm características que apontam para importante sub-enumeração de nascimentos e óbitos nos respectivos sistemas de informação. Em tal situação, problemas existentes na captação e fluxo dos instrumentos de alimentação do SINASC e SIM devem estar justificando a sub-enumeração mencionada.

Ilhéus constitui-se no terceiro município em população do estado da Bahia, de porte médio, caracterizado por grande extensão territorial e aproximadamente $1 / 3$ dos seus habitantes residindo em zona rural, estando em Gestão Plena do Sistema de Saúde. As características enunciadas colocam o SINASC e SIM deste município em situação privilegiada para a realização de estudos voltados para o conhecimento dos seus fluxos e captação dos eventos nascimento e morte aí ocorridos.

A importância das informações relacionadas aos nascidos vivos e óbitos infantis reside no fato de que os eventos vitais compõem coeficientes, como denominador e numerador, respectivamente, relevantes para a 
epidemiologia e a saúde pública, em particular a taxa de mortalidade infantil. A ocorrência de nascidos vivos e óbitos segundo idade ao morrer, peso ao nascer e outras variáveis são utilizados não somente para a definição de ações e práticas de profissionais de saúde, mas também para 0 estabelecimento de políticas voltadas para atenção ao grupo maternoinfantil.

Considerando a situação atual do SINASC e SIM na região e na Bahia, a importância das informações geradas pelos sistemas para o setor saúde e as características do município em tela, busca-se estudar os mesmos, com ênfase na captação dos eventos nascimentos vivos hospitalares com ocorrência e residência em llhéus e óbitos neonatais originados no grupo.

O fluxo de alimentação do SINASC, conforme normatizado pelo MS (BRASIL, 2001c), prevê como fontes de DN, estabelecimentos hospitalares, unidades de saúde e cartórios de registro civil, os dois últimos para partos domiciliares. A baixa freqüência de nascimentos domiciliares em llhéus, 5,2\% em 1997 (IBGE, 2003) e a inexistência de demanda reprimida por leitos de obstetrícia no município, justificam a realização do presente estudo a partir de nascimentos hospitalares. Assim, constituem-se em limites do desenho metodológico utilizado, para efeito de avaliação do SINASC, nascimentos domiciliares, principalmente aqueles não registrados em cartório.

O comportamento epidemiológico atualmente observado da mortalidade infantil no Brasil, com diminuição da probabilidade de morte em todos os grupos etários e aumento da mortalidade proporcional neonatal, notadamente em menores de 07 dias (BARROS e col,1996; LEAL e SZWARCWALD, 1996; MENEZES e col,1996; RIBEIRO e SILVA, 2000) destacam e justificam uma maior atenção a estudos para o grupo neonatal.

O fluxo da DO, conforme preconizado pelo MS (BRASIL, 2001a) para alimentação do SIM prevê como fontes emissoras e notificadoras para óbitos hospitalares, hospitais e médicos, para óbitos por causas acidentais ou violentas o legista do Instituto Médico Legal - IML ou na inexistência deste, 
perito designado e para óbitos naturais ocorridos em domicilio, médico assistente, Serviço de Verificação de Óbito ou cartórios de registro civil, de acordo com a situação do falecimento e contexto local. Pressupôs-se que a maior parte dos óbitos neonatais em llhéus ocorre em ambiente hospitalar, o que justifica o desenho proposto para o estudo.

Configuram-se limites do desenho metodológico utilizado óbitos neonatais domiciliares e não registrados em cartórios de registro civil de llhéus, bem como os ocorridos em outros municípios.

Os dados do SINASC disponibilizados pelo DATASUS (DATASUS, 2002) permitiram as análises que se seguem.

Tabela 01 - Número de nascidos vivos segundo residência, captados pelo SINASC e percentual de variação anual, Ilhéus, 1994 a 2000

\begin{tabular}{ccc}
\hline Ano & Número de nascidos vivos & $\%$ de variação \\
\hline 1994 & 2716 & - \\
1995 & 2479 & $-8,7$ \\
1996 & 3080 & $+24,2$ \\
1997 & 3766 & $+22,3$ \\
1998 & 3766 & 0,0 \\
1999 & 2772 & $-26,4$ \\
2000 & 3686 & $+33,0$ \\
\hline
\end{tabular}

Fonte: Dados brutos Datasus e FUNASA

O número absoluto de nascidos vivos captados pelo SINASC mostra variação ao longo dos anos apresentados (Tabela 01), sendo negativa em 1995 e 1999 e positiva no período entre 1996 a 98 e 2000. Considerando que 1994 foi o primeiro ano de operacionalização do Sistema, seria esperada uma variação do número de nascimentos captados crescente, positiva, até o alcance do pleno funcionamento de normas e rotinas adequadas a garantia da qualidade dos dados. A variação negativa observada em 1999, após seis anos da implantação, chama a atenção, impondo a busca de possíveis explicações. É plausivel supor que a queda na captação de dados pelo sistema tenha decorrido do processo de descentralização do SINASC para o nivel municipal, iniciado em final de 1998 e concluído em 1999. 
Tabela 02 - Número de nascidos vivos captados pelo SINASC, segundo município de residência, população residente menor de um ano (dados oficiais IBGE e DATASUS), população menor de um ano (calculado por extrapolação a partir de dados censitários) e proporções de captação de nascidos vivos pelo SINASC, Ilhéus, 1994 a 2000

\begin{tabular}{cccccc}
\hline Ano & $\begin{array}{c}\text { Número de } \\
\text { nascidos } \\
\text { vivos - } \\
\text { SINASC }\end{array}$ & $\begin{array}{c}\text { Menor de } \\
\text { um ano } \\
\text { (IBGE) }\end{array}$ & $\begin{array}{c}\text { Proporção de } \\
\text { captação do } \\
\text { SINASC (\%) }\end{array}$ & $\begin{array}{c}\text { Menor de um } \\
\text { ano (por } \\
\text { extrapolação) }\end{array}$ & $\begin{array}{c}\text { Proporção de } \\
\text { captação do } \\
\text { SINASC (\%) }\end{array}$ \\
\hline 1994 & 2716 & 4804 & 56,6 & 4382 & 62,0 \\
1995 & 2479 & 4874 & 50,9 & 4369 & 56,7 \\
1996 & 3080 & 4543 & 67,8 & 4356 & 70,7 \\
1997 & 3766 & 4630 & 81,3 & 4343 & 86,7 \\
1998 & 3766 & 4704 & 80,0 & 4330 & 87,0 \\
1999 & 2772 & 4778 & 58,0 & 4317 & 64,2 \\
2000 & 3686 & 4304 & 85,6 & 4304 & 85,6 \\
\hline
\end{tabular}

Fonte: Dados brutos SINASC - Datasus e SESAB

Menor de um ano - IBGE - Censos Demográficos e Contagem Populacional e MS/SE/Datasus para anos intercensitários.

Menor de um ano por extrapolação - Censos Demográficos 1991 e 2000, IBGE.

A tabela 02 apresenta o número de nascidos vivos captados pelo SINASC, a população residente menor de um ano, segundo duas fontes distintas, e as proporções de captação pelo SINASC em relação à população residente para o período de 1994 a 2000, considerando os menores de um ano calculados por diferentes técnicas. Era de se esperar que o número de nascimentos fosse ligeiramente superior ao da população menor de um ano pois, desta última estão excluídos os nascidos vivos que faleceram no primeiro ano de vida. Utilizando como denominador a população menor de um ano oficialmente divulgada pelo DATASUS/IBGE, chama atenção a proporção de captação crescente no período 1994 a 97, discretamente decrescente em 98 e fortemente decrescente em 1999. A variação observada no número de menores de um ano divulgado pelo DATASUS a partir de dados censitários e contagem populacional do IBGE, levou ao cálculo por extrapolação do número de menores de um ano, a partir dos Censos Demográficos de 1991 e 2000. A proporção de captação do SINASC, usando como denominador esta última população mostra-se com um padrão mais constante, destacando-se uma tendência de crescimento no 
periodo de 1994 a 1998, seguida de queda brusca em 1999 e retomada do patamar anterior no ano seguinte. Conforme comentado anteriormente, em 1999 ocorreu a descentralização do SINASC para o município, o que pode explicar a queda na proporção de captação observada. Para o último ano em análise, observa-se um crescimento da proporção de captação, o que pode refletir intervenções específicas na dinâmica de alimentação do Sistema. Destaca-se também a diminuição lenta, porém constante, no número de residentes menores de um ano.

Tabela 03 - Número de nascidos vivos captados pelo SINASC e Taxa de Natalidade (\%o habitantes), llhéus, 1994 a 2000

\begin{tabular}{ccc}
\hline Ano & Número de nascidos vivos & Taxa de Natalidade \\
\hline 1994 & 2716 & 11,2 \\
1995 & 2479 & 10,0 \\
1996 & 3080 & 12,7 \\
1997 & 3766 & 15,2 \\
1998 & 3766 & 15,0 \\
1999 & 2772 & 10,8 \\
2000 & 3686 & 16,6 \\
\hline
\end{tabular}

Fonte: Dados brutos Datasus e FUNASA

A tabela 03 expõe o número de nascidos vivos captados pelo SINASC, no período de 1994 a 2000 e a taxa de natalidade. Observa-se que a taxa de natalidade assumiu valores crescentes para o período de 1994 a 1998, excetuando 1995, e grande queda em 1999, com posterior crescimento em 2000. O comportamento dos dados apresentados mais uma vez aponta para problemas relacionados à alimentação do SINASC. Corroboram esta análise a comparação com as taxas de natalidade encontradas para o Brasil, região Nordeste e Bahia. Segundo o IDB 2001 (DATASUS, 2002), as taxas de natalidade padronizadas, calculadas combinando método direto e estimativa, para o Brasil, região Nordeste e Bahia para o ano de 1999 são respectivamente, 21,16; 22,40 e 20,68 \% habitantes. Ao comparar a taxa de natalidade de llhéus no ano de 1999 $(10,8 \%$ habitantes) à média nacional, regional e estadual observa-se a 
grande distância entre os valores do indicador, reafirmando problemas importantes relacionados à cobertura do Sistema de Informação.

Para finalizar a avaliação quanto à cobertura do SINASC, foram calculados os desvios da taxa de natalidade em relação à taxa média, para o período de 1994 a 2000 (Gráfico 01). Considerando-se um sistema de informação com as características do SINASC, com normas e rotinas estabelecidas, incluindo o fluxo e acompanhamento contínuo, espera-se uma melhoria das informações dele decorrentes, principalmente quanto à cobertura, através da demonstração de tendência crescente. Os valores dos desvios apresentados mostram grande variação, positiva e negativa, sem tendência definida e sem vinculação ano a ano. É cabível imputar o comportamento observado à irregularidade de alimentação do SINASC no município, podendo-se ainda depreender, que ao longo do período estudado, nenhuma medida técnica foi adotada ou capaz de modificar a situação.

O gráfico 1 apresenta os desvios da taxa de natalidade no periodo de 1994 a 2000, em relação à taxa média do mesmo período. Considerando-se o cálculo do indicador a partir de dados de nascidos vivos captados pelo SINASC e população total informada pelo IBGE, e que esta última varia pouco nos anos estudados, depreende-se que o comportamento dos desvios deva-se à variações do número de nascidos vivos. Observam-se desvios negativos no período de 1994 a 1996, positivos em 1997 e 98, volta a ser negativo em 1999, para tornar-se positivo em 2000. Se por um lado, a magnitude do coeficiente está relacionada à captação dos eventos, os desvio deste em relação a média em um período deve ser um índice de regularidade das informações. Assim, parece plausível supor que a mudança no comportamento do desvio no ano de 1999 deva ser relacionada à descentralização da gestão do SINASC para o nível municipal. 
Gráfico 1 - Desvios da Taxa de Natalidade em relação à média, Ilhéus, 1994 a 2000

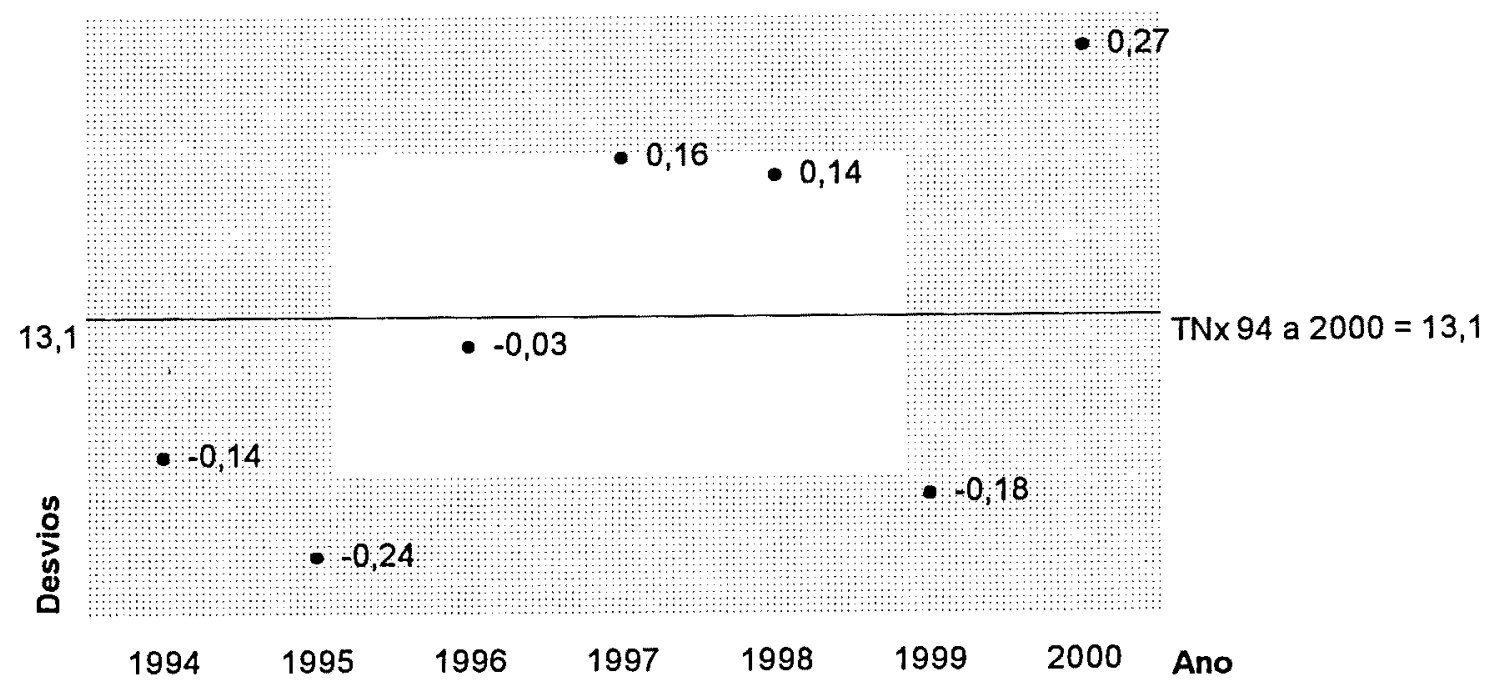

Fonte: Datasus

Com relação aos óbitos ocorridos em menores de um ano, sua distribuição de acordo com os componentes etários em llhéus (Tabela 04) de forma geral, permite observar que o número de óbitos infantis totais e por faixa etária vem diminuindo ao longo dos anos em estudo. Os óbitos totais passaram de $341 \mathrm{em} 1986$ para $98 \mathrm{em} 2000$, os óbitos neonatais passaram de 111 para 63 e os pós-neonatais de 230 para 35. 
Tabela 04 - Número de óbitos infantis segundo idade ao morrer, llhéus, 1986 a 2000

\begin{tabular}{ccccc}
\hline Ano & $\begin{array}{c}\text { Menores de } \\
\text { 28dias }\end{array}$ & $\begin{array}{c}\text { 28 dias a 11 } \\
\text { meses e 29 } \\
\text { dias }\end{array}$ & Ignorada & Total \\
\hline 1986 & 111 & 230 & - & 341 \\
1987 & 122 & 205 & -- & 327 \\
1988 & 101 & 173 & -- & 274 \\
1989 & 70 & 170 & -- & 240 \\
1990 & 78 & 135 & 1 & 214 \\
1991 & 77 & 97 & 24 & 198 \\
1992 & 67 & 143 & 14 & 224 \\
1993 & 73 & 113 & 26 & 212 \\
1994 & 114 & 114 & -- & 228 \\
1995 & 68 & 70 & -- & 138 \\
1996 & 68 & 53 & -- & 121 \\
1997 & 95 & 53 & -- & 148 \\
1998 & 95 & 55 & -- & 150 \\
1999 & 63 & 31 & 1 & 95 \\
2000 & 63 & 35 & -- & 98 \\
\hline
\end{tabular}

Fonte:Dados brutos Datasus, 2002

A variação percentual ano a ano do número de óbitos infantis captados pelo SIM (Tabela 05) demonstra um comportamento global decrescente, entretanto não homogêneo e constante para os anos em estudo. O comportamento e flutuação positiva e negativa da variação do número de óbitos de menores de um ano apresentada para o município, apontam para irregularidade de alimentação do sistema de informação. 
Tabela 05 - Variação anual (\%) do número de óbitos infantis segundo idade ao morrer, llhéus, 1986 a 2000

\begin{tabular}{cccc}
\hline Ano & $\begin{array}{c}\Delta \% \text { dos óbitos } \\
\text { neonatais }\end{array}$ & $\begin{array}{c}\Delta \% \text { dos óbitos } \\
\text { pós-neonatais }\end{array}$ & $\begin{array}{c}\Delta \% \text { dos óbitos } \\
\text { totais }\end{array}$ \\
\hline 1986 & -- & -- & - \\
1987 & $+9,9$ & $-10,9$ & $-4,1$ \\
1988 & $-17,2$ & $-15,6$ & $-16,2$ \\
1989 & $-30,7$ & $-1,7$ & $-12,4$ \\
1990 & $+11,4$ & $-20,6$ & $-10,8$ \\
1991 & $-1,3$ & $-28,1$ & $-7,5$ \\
1992 & $-13,0$ & $+47,4$ & $+13,1$ \\
1993 & $+9,0$ & $-21,0$ & $-5,7$ \\
1994 & $+56,2$ & $+0,9$ & $+7,5$ \\
1995 & $-40,4$ & $-38,6$ & $-39,5$ \\
1996 & 0,0 & $-24,3$ & $-12,3$ \\
1997 & $+39,7$ & 0,0 & $+22,3$ \\
1998 & 0,0 & $+3,8$ & $-1,3$ \\
1999 & $-33,7$ & $-43,6$ & $-36,7$ \\
2000 & 0,0 & $+12,9$ & $+3,2$ \\
\hline
\end{tabular}

Fonte: Dados brutos Datasus e FUNASA

A tabela 06 apresenta a variação por período do número de óbitos infantis segundo idade ao morrer em llhéus. O comportamento global da variação é negativo nos periodos analisados. Observa-se que a variação dos óbitos infantis é maior no período compreendido entre 90 e 99 do que no periodo anterior (80-89), o mesmo ocorrendo para os óbitos pós-neonatais. A variação do número de óbitos neonatais assume comportamento inverso nos períodos estudados, sendo menor em 90-99 quando comparado ao período anterior.

Tabela 06 - Variação por período(\%) do número de óbitos infantis segundo idade ao morrer, llhéus, 1980-89 e 1990-99

\begin{tabular}{ccc}
\hline \multirow{2}{*}{ Variação } & \multicolumn{2}{c}{ Período } \\
\cline { 2 - 3 } ny & $80-89$ & $90-99$ \\
\hline$\Delta \%$ óbitos infantis & $-18,6$ & $-55,6$ \\
$\Delta \%$ óbitos neonatais & $-37,5$ & $-19,2$ \\
$\Delta \%$ óbitos pós-neonatais & $-3,4$ & $-77,0$ \\
\hline
\end{tabular}

Fonte: Dados brutos Datasus e FUNASA

A tabela 07 apresenta a taxa de mortalidade infantil, neonatal e pósneonatal para o período de 1989 a 2000, em lihéus, calculada por diferentes 
métodos. Dentre os dados apresentados, constitui-se em unanimidade a diminuição da probabilidade de morte em menores de um ano e nas faixas etárias neonatal e pós-neonatal, entretanto, chama atenção a divergência existente entre os indicadores de acordo com a forma de cálculo utilizada. Em anos mais próximos parece haver uma tendência à convergência dos valores dos coeficientes. As taxas calculadas utilizando-se como denominador a população menor de um ano e os dados oriundos do SINASC (nascidos vivos) demonstram maiores distâncias, devido ao número de nascidos vivos captados pelo SINASC ser inferior à população menor de um ano informada pelo Datasus e IBGE. Destaca-se que ao calcular os coeficientes com dados do SIM e SINASC, há interferência de fatores relacionados à qualidade dos dados dos dois Sistemas. Quanto à Taxa de Mortalidade Infantil estimada para o municipio de llhéus para os anos de 1989, 1990, 1994 e 1998, observa-se uma queda no período, passando de 39,17/1000 NV em 1989 para 30,73/1000 NV em 1998, correspondendo, segundo o autor (SIMÕES, 1999), a uma variação negativa de $21,53 \%$.

Para efeito de análise comparativa, a Taxa de Mortalidade Infantil para o Brasil, região Nordeste e Bahia em 1998 assumem respectivamente os valores de 36,$10 ; 57,91$ e 50,36 por mil nascidos vivos (SIMÕES, 1999), apresentando-se superiores ao observado em llhéus no mesmo ano.

A despeito de estar fartamente documentada na literatura a diminuição da mortalidade infantil no Brasil, estados e municípios, os coeficientes encontrados para llhéus no ano de 1999 encontram-se abaixo da média nacional, apresentando uma queda acentuada em relação aos anos anteriores. Considerando que nenhuma medida específica foi adotada ou implementada neste período, é plausível questionar a qualidade/captação do evento morte infantil pelo SIM. É importante frisar que ao final do ano de 1998, o SIM foi descentralizado para o nível municipal, o que pode ter interferido grandemente nos fluxos e rotinas do sistema, com conseqüente impacto sobre sua cobertura. 
Tabela 07 - Taxa de Mortalidade Infantil segundo idade ao morrer calculada por diferentes métodos, llhéus, 1989 a 2000

\begin{tabular}{ccccccccc}
\hline \multirow{2}{*}{ Ano } & \multicolumn{3}{c}{ Por 1000 menores de um } & \multicolumn{3}{c}{ Por 1000 nascidos vivos } & Estimativa \\
\cline { 2 - 7 } & \multicolumn{4}{c}{ ano } & \multicolumn{4}{c}{ TMI } \\
\hline 1989 & -- & -- & - & - & -- & - & -- & 39,17 \\
1990 & -- & - & - & - & -- & -- & 37,03 \\
1991 & 44,7 & 17,4 & 21,9 & - & -- & -- & n.d \\
1992 & -- & - & -- & - & -- & -- & n.d \\
1993 & 44,8 & 15,4 & 23,8 & - & -- & - & n.d \\
1994 & 47,4 & 23,7 & 23,7 & 84,0 & 42,0 & 42,0 & 32,32 \\
1995 & 28,3 & 13,9 & 14,3 & 55,7 & 28,3 & 27,4 & n.d \\
1996 & 26,6 & 14,9 & 11,6 & 39,3 & 17,2 & 22,1 & n.d \\
1997 & 31,9 & 20,5 & 11,4 & 39,3 & 14,1 & 15,2 & n.d \\
1998 & 31,8 & 20,1 & 11,6 & 39,8 & 14,6 & 25,2 & 30,73 \\
1999 & 19,8 & 13,1 & 6,4 & 34,3 & 11,2 & 22,7 & n.d \\
2000 & 22,7 & 14,6 & 8,1 & 26,6 & 17,1 & 9,5 & n.d \\
\hline
\end{tabular}

Fonte: Dados brutos Datasus e FUNASA para a TMI, TMI e TMI $_{P}$ por 1000 menores de um ano e por 1000 nascidos vivos.

Simões (1999) para estimativa

A variação anual do coeficiente de mortalidade infantil, neonatal e pós-neonatal pode ser utilizada para análises da dinâmica assumida pelo indicador ao longo de um período. Tratando-se neste momento de avaliação dos dados do SIM, optamos por calcular a variação do coeficiente por mil menores de um ano, já que o cálculo por mil nascidos vivos, além de sofrer variações relativas à qualidade do SIM, também estaria sujeito às questões relacionadas à qualidade do SINASC. Conforme pode ser observado na tabela 08 , a variação anual da taxa de mortalidade infantil e da neonatal apresenta valores positivos e negativos para o período compreendido entre os anos de 1993 e 2000. O mesmo comportamento não é observado para a variação da taxa de mortalidade pós-neonatal, que excetuando os anos de 1998 e $2000 \mathrm{com}$ variações positivas, todos os demais anos apresentam variação negativa, demonstrando um padrão contínuo descendente. 
Tabela 08 - Variação anual (\%) da taxa de mortalidade Infantil -TMI, neonatal -TMN e pós-neonatal - TMP (por 1000 menores de um ano), llhéus, 1993 a 2000

\begin{tabular}{cccc}
\hline Ano & $\Delta \%$ TMI & $\Delta \%$ TMN & $\Delta \%$ TMP \\
\hline 1993 & -- & -- & - \\
1994 & $+5,8$ & $+53,9$ & $-0,4$ \\
1995 & $-40,3$ & $-41,4$ & $-39,7$ \\
1996 & $-7,4$ & $+7,2$ & $-18,9$ \\
1997 & $+20,0$ & $+37,6$ & $-1,7$ \\
1998 & $-0,3$ & $-2,0$ & $+1,8$ \\
1999 & $-37,7$ & $-34,8$ & $-44,8$ \\
2000 & $+14,6$ & $+11,4$ & $+26,6$ \\
\hline
\end{tabular}

Fonte: Dados brutos Datasus e FUNASA

A tabela 09 apresenta a variação da taxa de mortalidade infantil, neonatal e pós-neonatal, considerando o período de 91 a 1999. Observa-se que a variação dos coeficientes é negativa, sendo maior para o risco de morrer em maiores de 27 dias do que no primeiros 27 dias de vida.

Tabela 09 - Variação por período(\%) da taxa de mortalidade infantil (TMI), neonatal (TMN) e pós-neonatal (TMP), llhéus, 1991-99
Variação
$91-99$

\begin{tabular}{cc}
\hline$\Delta \%$ TMI & $-55,7$ \\
$\Delta \%$ TMN & $-24,7$ \\
$\Delta \%$ TMP & $-70,8$ \\
\hline
\end{tabular}

Fonte: Dados brutos Datasus e FUNASA

Tratando-se de uma avaliação do SIM e para evitar interferências decorrentes da qualidade dos dados do SINASC, para o cálculo dos desvios das taxas de mortalidade infantil, neonatal e pós-neonatal (gráficos 2 a 4) optou-se por utilizar como denominador a população de menores de um ano.

O gráfico 2 apresenta os desvios da taxa de mortalidade infantil para o período de 1993 a 2000, em relação à média do mesmo período. Observa-se que o comportamento dos desvios obedece a um padrão, positivo nos dois primeiros anos em análise, negativo mos dois seguintes, aproximando-se da média em 97 e 98 e volta a afastar-se para menos da média nos anos de 1999 e 2000. Considerando que a população menor de 
um ano sofre pequenas alterações no período, o cálculo dos desvios apresenta-se como um índice de regularidade das informações do SIM. Assim, a princípio, a regularidade dos fluxos de alimentação do Sistema parece ser razoável.

Gráfico 2 - Desvios da Taxa de Mortalidade Infantil (por 1000 menores de 1 ano) em relação à média, llhéus, 1993 a 2000

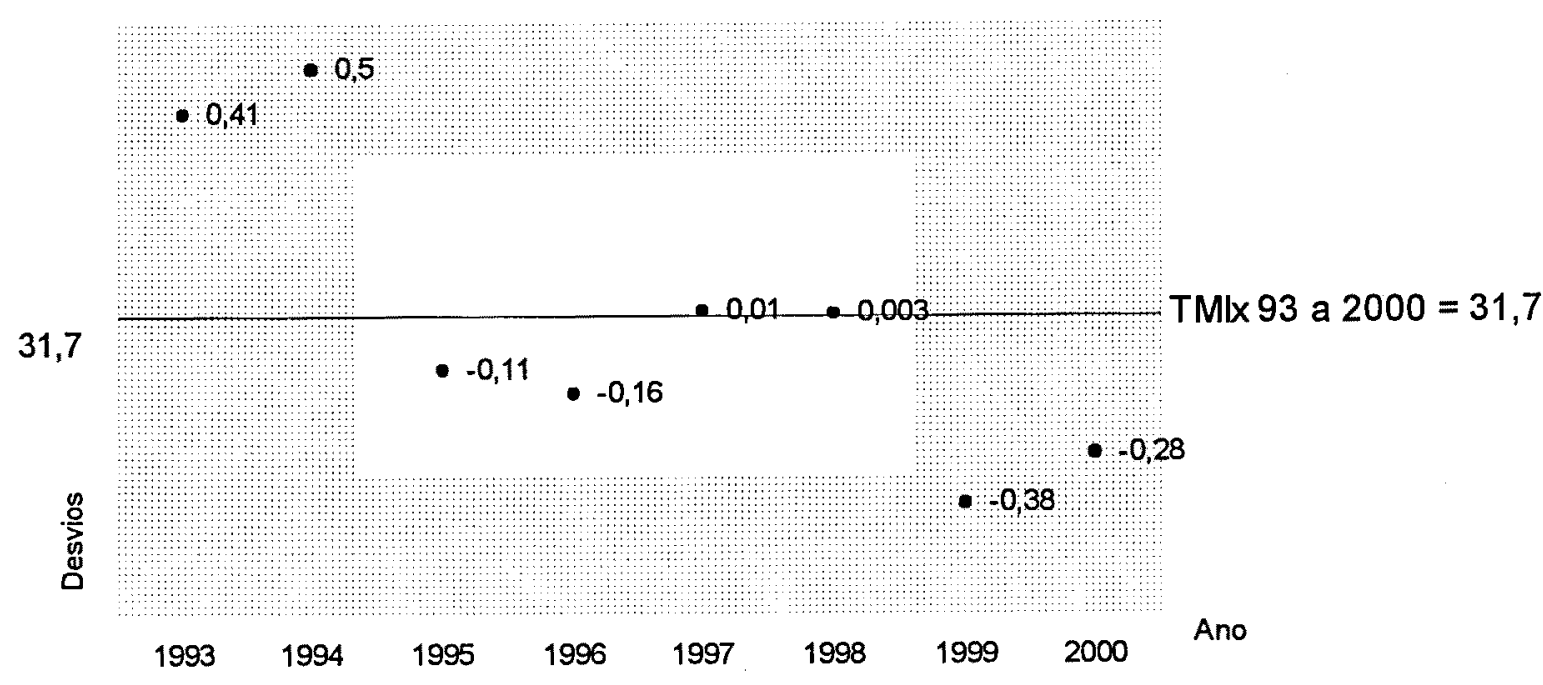

Fonte: Datasus

Os desvios da taxa de mortalidade neonatal em relação à média do periodo de 1993 a 2000 (gráfico 3) apresentam comportamento por blocos, com afastamentos para mais e para menos da taxa média. Nos anos de 93 e 94 mostram-se positivos, em 95 e 96 são negativos, em 97 e 98 são positivos e em 99 e 2000 negativos. A partir destes dados, pode-se questionar a adequação da regularidade da captação do evento óbito neonatal pelo SIM. 
Gráfico 3 - Desvios da Taxa de Mortalidade Neonatal (por 1000 memores de um ano) em relação à média, llhéus, 1993 a 2000.

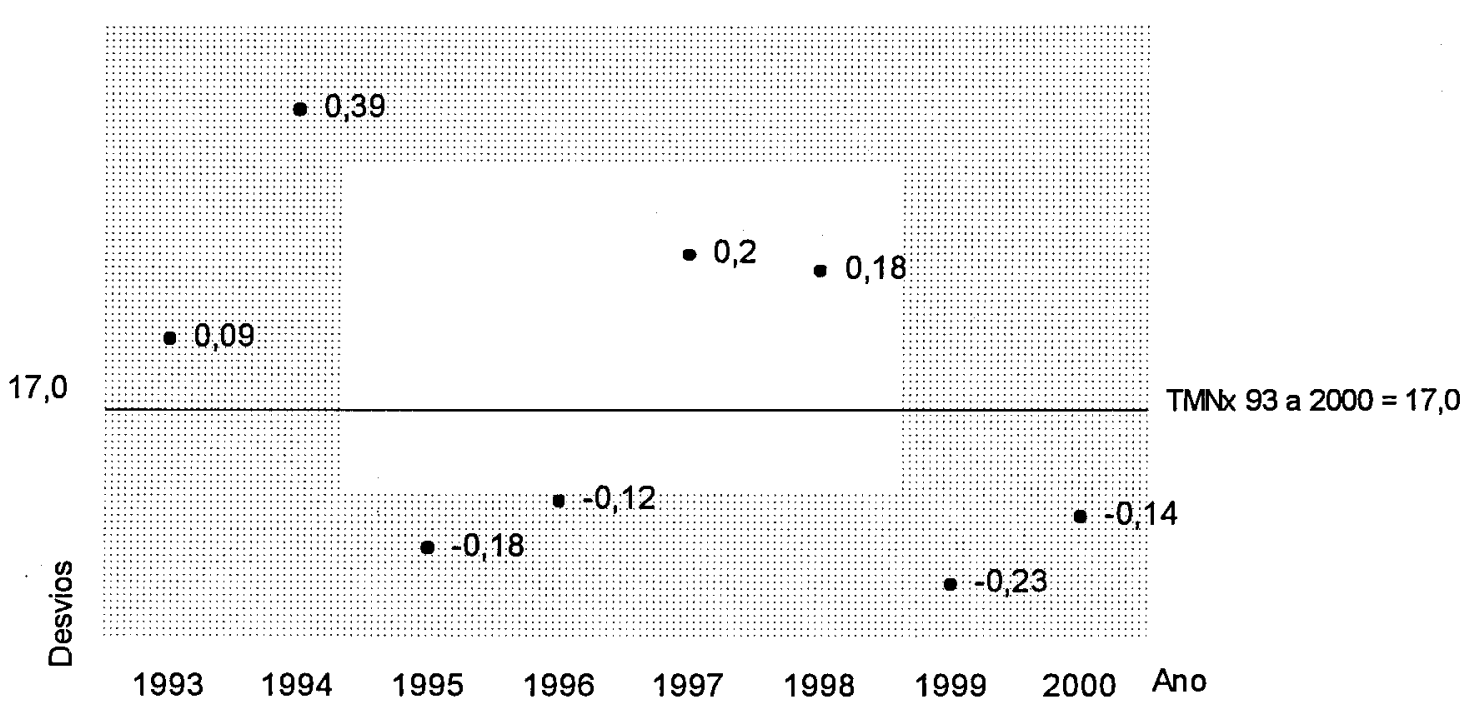

Fonte: Datasus

O gráfico 4 mostra os desvios assumidos pela taxa de mortalidade pós-neonatal em relação a média do período de 1993 a 2000. Observa-se um comportamento claro que inicia com valores positivos distantes da média, seguido de aproximação e posterior afastamento em valores negativos. Os problemas apontados quanto a regularidade do evento morte neonatal, parece não estar interferindo na captação dos óbitos pósneonatais. 
Gráfico 4 - Desvios da Taxa de Mortalidade Pós-Neonatal (por 1000 menores di um ano) em relação à média, Ilhéus, 1993 a 2000

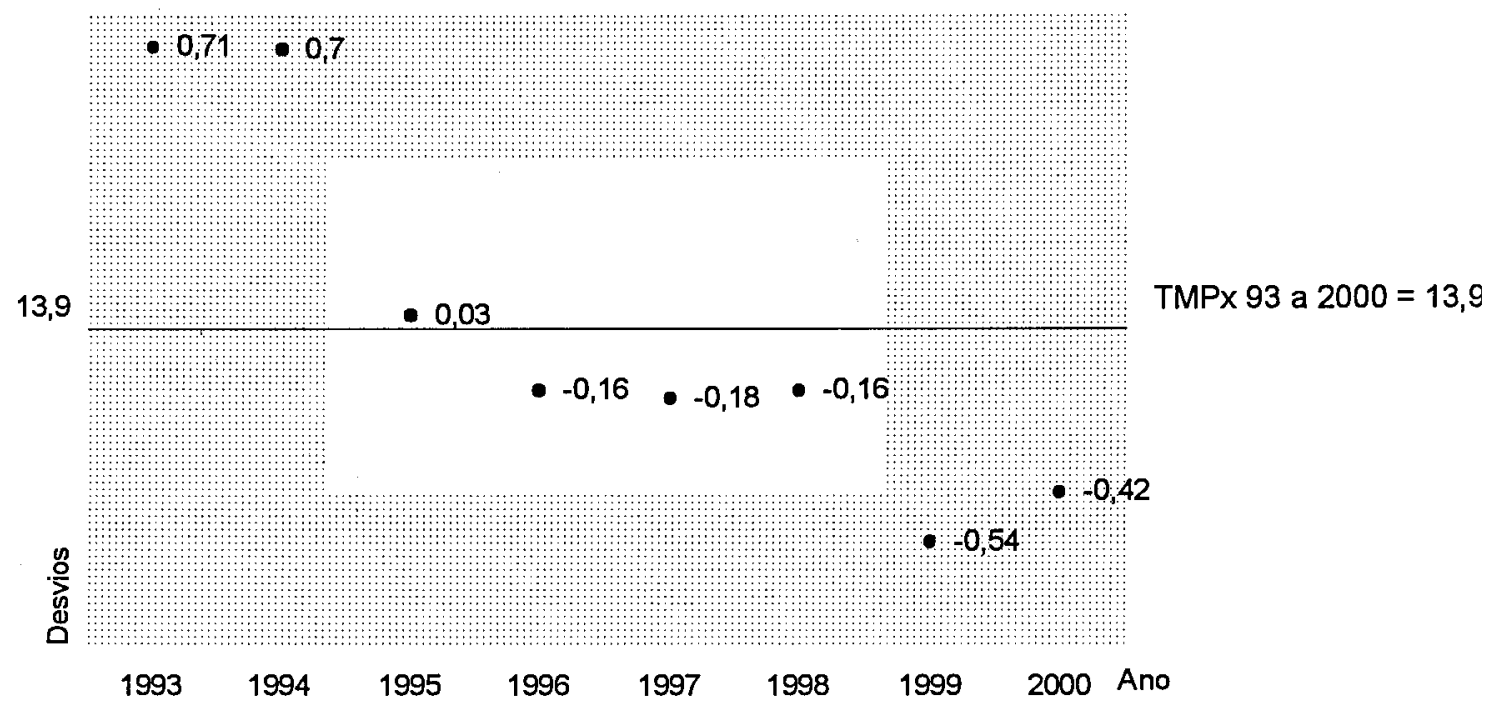

Fonte: Datasus

Os dados apresentados apontam para a necessidade de monitorar e avaliar os sistemas de informação em llhéus. A boa cobertura, regularidade de alimentação e qualidade dos dados dos Sistema de Informação de Nascido Vivo - SINASC e Sistema de Informação sobre Mortalidade - SIM assumem importância estratégica no contexto atual do SUS, proporcionando o desenvolvimento ágil e de baixo custo de estudos voltados para a análise oportuna e contínua da situação de saúde no grupo etário de menores de um ano, com ênfase nos menores de 28 dias. 


\subsection{Os Sistemas de Informação em Saúde em llhéus}

Szwarcwald e cols. (2002) elaboraram critérios para classificar municípios segundo a adequação das informações do SIM e SINASC. Nesta proposta, os indicadores utilizados são Coeficiente Geral de Mortalidade padronizado por idade, o Desvio Médio do Coeficiente Geral de Mortalidade, a Taxa de Natalidade, o Desvio Médio da Taxa de Natalidade e a proporção de óbitos em menores de um ano sem definição de causa básica. Utilizando dados do SIM e SINASC referentes ao municipio de llhéus para o periodo de 1997 a 99 (Datasus, 2002) e a população padrão do Rio de Janeiro para cálculo do coeficiente geral de mortalidade padronizado por idade, procedemos a análise de adequação das informações conforme metodologia proposta pela autora supra referida.

O Coeficiente Geral de Mortalidade padronizado por idade (CGMp) no ano de 1999 em llhéus foi de 4,43 por 1000 habitantes. Segundo Szwarcwald e cols (2002), este coeficiente pode ser utilizado para identificar falhas na cobertura das informações referentes aos óbitos, geralmente variando entre 7 e 10 por mil habitantes. Becker (1991) apud Szwarcwald e cols (2002) considera que valores inferiores a 4 por 1000 habitantes indicam grande precariedade na captação dos óbitos ocorridos. Observa-se que o CGMp de Ilhéus em 1999 aproxima-se bastante do valor crítico, o que aponta para precariedade na captação de óbitos ocorridos.

O Desvio Médio do CGM (DMCGM) para o período de 1997 a 99 foi de 0,12 , o que representa $2,96 \%$ do Coeficiente de Mortalidade Médio. Segundo a autora da proposta, valores superiores a $10 \%$ são críticos, refletindo irregularidade das informaçōes de óbito. Neste item, os dados do SIM para o período analisado apontam para regularidade das informações de óbito. Tratando-se de curto espaço de tempo, não é esperado que ocorram grandes variações do coeficiente geral de mortalidade, o que justifica o emprego do índice para avaliar a regularidade das informações referentes aos óbitos. Destaca-se que, como regra geral, o indicador não é 
adequado para avaliações relacionadas à situação de saúde de uma população.

A análise da taxa de natalidade e comparação com o mesmo indicador de distintas localidades permite avaliar a cobertura das informações referentes aos nascimentos. No estudo de Szwarcwald e cols. (2002), para o Brasil, uma taxa de natalidade de 16 por 1000 habitantes foi considerado o limite crítico inferior. Em llhéus, a taxa de natalidade referente ao ano de 1999 foi de 10,87 por 1000 habitantes, apontando importante subenumeração de nascimentos.

O quarto indicador proposto pelos autores citados é o Desvio Médio da Taxa de Natalidade(DM $\mathrm{DN}_{\mathrm{TN}}$ ). Para análise das informações de llhéus, foi utilizado o período de 1997 a 99, sendo o $\mathrm{DM}_{\mathrm{TN}}$ 0,14, correspondendo a $1,0 \%$ da taxa de natalidade média para o período em análise. Segundo os autores da metodologia, valores superiores a $10 \%$ são considerados críticos, refletindo irregularidade das informações referentes a nascimentos. Constata-se que, de acordo com os parâmetros propostos, o município apresenta regularidade das informações referentes a nascimentos.

A proporção de óbitos em menores de um ano sem definição da causa básica em llhéus foi de 12,8\%,12\% e 25,26\% para os anos de 1997 , 98 e 99 , respectivamente. Os autores da metodologia adotaram que valores maiores que $20 \%$ são excessivos e expressam irregularidades do registro das informações de óbitos. É importante destacar a grande variação do índice nos anos estudados, o que sugere a ocorrência ou agudização de problemas nos sistemas de informação.

Com base nos resultados encontrados para os cinco critérios, e ainda conforme a mesma metodologia, o município de llhéus classifica-se na categoria II, ou seja, não satisfaz a algum dos critérios, mas apresenta CGM padronizado maior ou igual a 4 por 1000 habitantes. Chama atenção que nos critérios referentes à regularidade de informações o município apresenta bom desempenho, o que não ocorre quanto aos critérios relacionados à cobertura, entretanto, considerando que em situação de baixa cobertura constante, a regularidade dos dados se mantenha o que não significa 
decerto boa qualidade do SIS. As análises apresentadas quanto às variações por período e ano a ano das taxas de natalidade, e de mortalidade neonatal, principalmente, a partir de dados do SINASC e SIM para uma série histórica maior, demonstram claramente que também a regularidade das informações dos sistemas não é de boa qualidade.

Diante do exposto acreditamos que no momento atual é premente o desenvolvimento de estudos voltados para a avaliação de cobertura e qualidade dos Sistemas de Informação em Saúde no município de Ilhéus, não somente para que possamos compreender melhor as variações observadas nos indicadores de saúde do município, principalmente aquelas referentes aos menores de um ano, mas também para avaliarmos a situação das informações em saúde em cidade de médio porte do Nordeste do Brasil.

\subsection{Os nascidos vivos em Ilhéus, segundo fonte de dados.}

\section{- Hospital}

A coorte de nascidos vivos hospitalares é composta por 3.426 indivíduos com ocorrência de nascimento e residência no município de Ilhéus. Considerando a metodologia proposta para o estudo, não foi possivel definir a residência no município de 12 neonatos, os quais foram descartados para efeito deste trabalho, portanto, não compõem a coorte.

\section{- SINASC}

A figura 2 representa o fluxograma dos dados obtidos através do banco de dados do SINASC municipal. Destacamos que dos 3.510 nascidos vivos captados, 68, apesar de terem informações de residência em llhéus, pela linkage e conferência de informações no prontuário, residem em outros municípios. Dos restantes, 11 foram nascimentos domiciliares captados pelo SINASC e um nascimento em outro município de residente em llhéus. Chama atenção a duplicação de dados que alimentam o Sistema, o que foi 
detectado para 87 nascidos vivos, tendo-se o cuidado de descartar a possibilidade de gravidez múltipla.

Para efeito da análise comparativa entre os bancos de dados da coorte hospitalar e do SINASC, consideraremos como nascidos vivos captados pelo Sistema 3.423 eventos, resultado do total de captados (3.510), excluídos os eventos duplicados (87).

Figura 2 - Representação dos dados do SINASC, Ilhéus, 2001

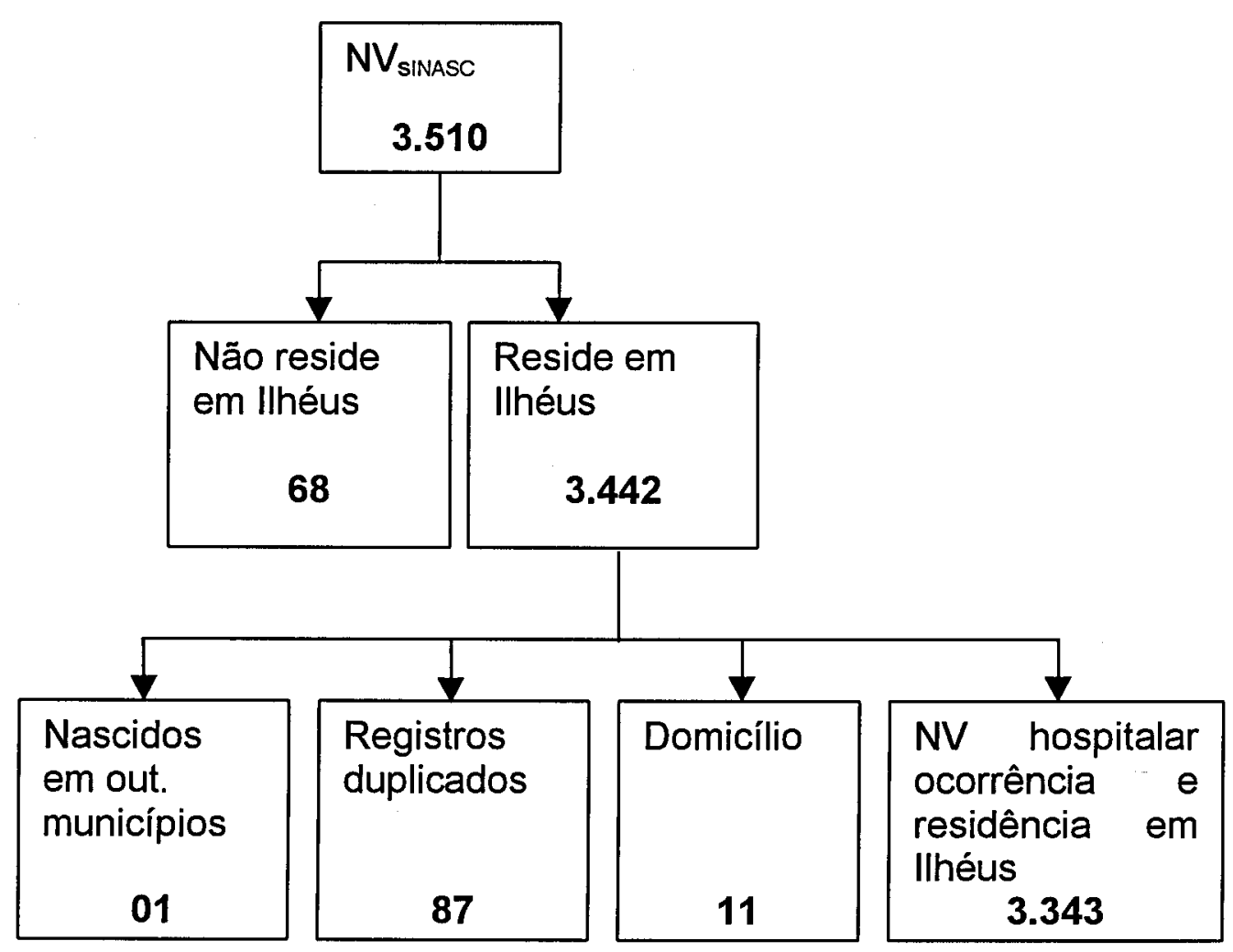

\section{- Cartório}

Os nascidos vivos no ano de 2001 em llhéus, registrados até 180 dias do ano de 2002, foram em número de 3.105. Detectou-se dois registros feitos em duplicidade, tendo-se excluído o segundo de cada um deles do banco de dados, ficando então o banco de dados com 3.103 nascidos vivos. 


\subsection{Avaliação da captação pelo SINASC dos nascidos vivos hospitalares com ocorrência e residência em llhéus}

A figura 3 apresenta o resultado da linkage entre os bancos de dados de NV da coorte e nascidos vivos captados pelo SINASC. Dos 3.426 nascidos vivos da coorte, 3.308 foram captados pelo Sistema, correspondendo a $96,6 \%$ dos eventos. Deixaram de ser captados 118 nascidos vivos, o que corresponde a $3,4 \%$. Dos nascidos vivos captados pelo SINASC, 115 não integram a coorte, sendo 01 nascimento em outro município, 11 em domicilio, 68 não residentes em llhéus e 35 nascimentos hospitalares com ocorrência e residência em llhéus, porém não localizados em arquivos hospitalares. Para estes últimos foi realizada uma segunda coleta de dados nas unidades hospitalares, com o objetivo de confirmar as informações, entretanto não foram localizados os registros e/ou os prontuários.

A proporção de captação pelo SINASC dos nascidos vivos da coorte foi alta, porém, tratando-se de eventos hospitalares, seria esperado ou ideal uma concordância de $100 \%$. Cabe destacar a existência de captados pelo Sistema que não compõem a coorte, apesar de constar em DN a informação do evento ter ocorrido em um hospital. Podem estar justificando o achado a baixa qualidade dos processos de guarda e arquivamento das informações hospitalares, o que impossibilita o resgate posterior de informações, ou ainda questões ligadas a naturalidade de filhos, estas no terreno da justiça. É importante chamar atenção para os 68 nascidos vivos captados pelo SINASC como residentes em Ilhéus e que após a linkage e confirmação em prontuários foram reclassificados como residentes em outros municípios. Tal fato superestima o número de nascidos vivos e pode subestimar a taxa de mortalidade infantil. Sendo o município uma referência para média e alta complexidade no sistema de saúde, mecanismos devem ser estabelecidos para evitar esta situação. $O$ controle de numeração das $D N$ distribuídas às unidades hospitalares, a auditoria permanente dos SIS, o cumprimento dos fluxos preconizados pelo MS e o cruzamento de informações com outros 
Sistemas, como o Sistema de Informações Hospitalares - SIH, são estratégias que tendem a minimizar tais ocorrências.

Figura 3 - Representação esquemática do procedimento de linkage entre os bancos de dados de Nascidos Vivos da Coorte (NVcoorte ) e nascidos vivos captados pelo SINASC (NVsinasc), Ilhéus, 2001

\section{Linkage}

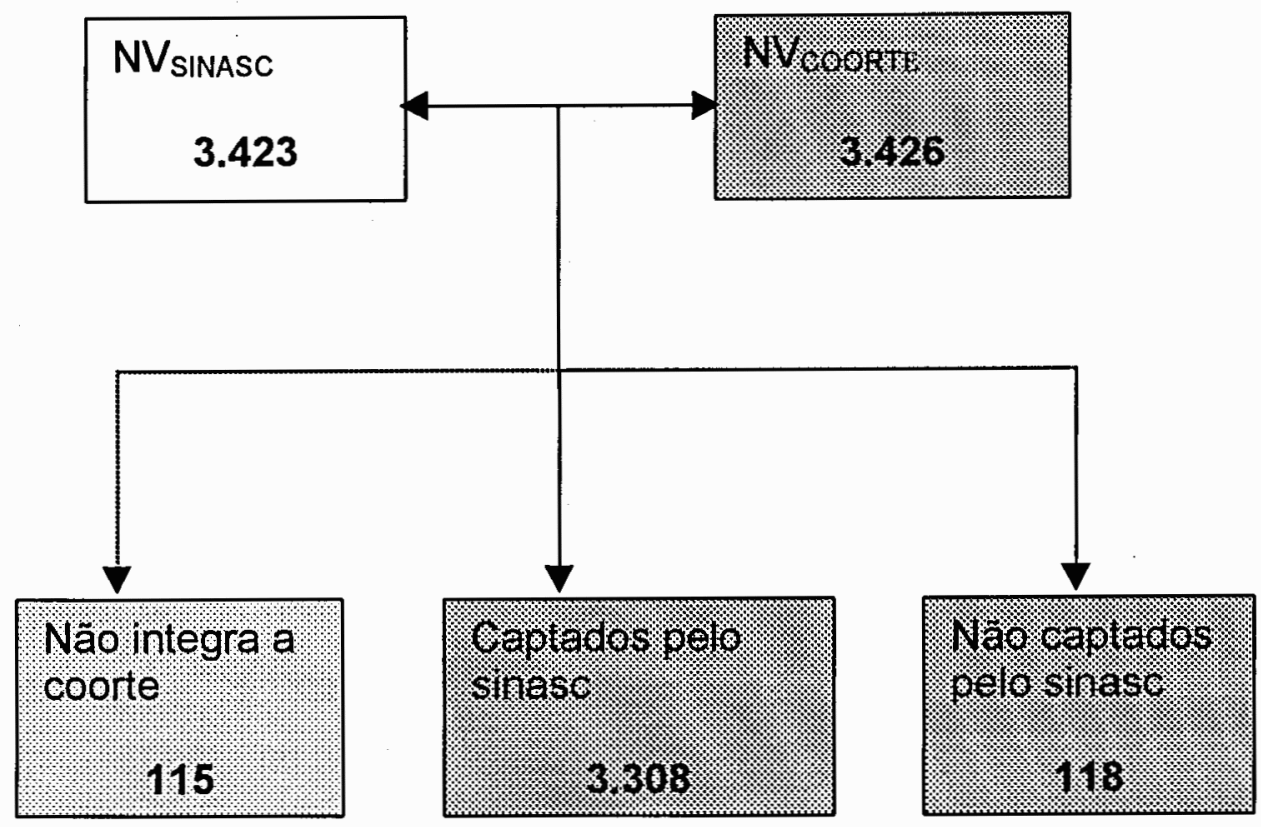

\subsection{Avaliação do registro em cartório dos nascidos vivos} hospitalares com ocorrência e residência em Ilhéus

A figura 4 apresenta de forma esquemática, os resultados da linkage realizada entre os bancos de dados DN cartório e DN coorte. Observa-se que dos 3.426 nascidos vivos da coorte, 2.934 foram registrados, correspondendo a uma proporção de registro de $85,6 \%$ e 492 não foram registrados $(14,4 \%)$, até 180 dias após o nascimento. São poucos os 
estudos na atualidade sobre oportunidade de registro civil de crianças, o que dificulta a comparação com achados da literatura. Em Londrina, no Paraná, Iwakura e cols. (2002) encontraram uma taxa média de subregistro de $13,1 \%$ nesse prazo.

Destaca-se que 169 nascidos vivos registrados não integram a coorte, sendo 94 nascimentos domiciliares, 09 nascimentos em outros locais, $01 \mathrm{em}$ outros estabelecimentos de saúde de município ignorado, 14 residentes em Ilhéus nascidos em outros municípios, 25 registrados como residentes em Ilhéus, porém com residência em outros municipios segundo os prontuários hospitalares e 26 nascimentos hospitalares com ocorrência e residência em llhéus, porém sem correspondência nos registros e/ou prontuários hospitalares. À semelhança dos procedimentos adotados para a situação no SINASC, para estes últimos foi realizada nova coleta dirigida nas unidades hospitalares, com o objetivo de confirmar as informações, entretanto, não foi possivel localizar os dados nos hospitais. Chama a atenção a discordância entre as informações para nascimentos domiciliares entre os dados do SINASC e dos registrados em cartórios. Conforme mencionado anteriormente, o SINASC captou 11 nascimentos domiciliares e os cartórios registraram 94. A discordância pode dever-se à perda, por familiares, das DN emitidas pelos hospitais, sem que seja providenciada uma segunda via, e conseqüentemente feito o registro por declaração de ocorrência domiciliar. 
Figura 4 - Representação esquemática dos procedimentos de linkage entre os bancos de dados de nascidos vivos registrados em cartório ( $\left(\mathrm{NN}_{\text {cartório }}\right)$ e nascidos vivos da coorte ( $\left.\mathrm{DN}_{\text {coorte }}\right)$, llhéus, 2001

\section{Linkage}

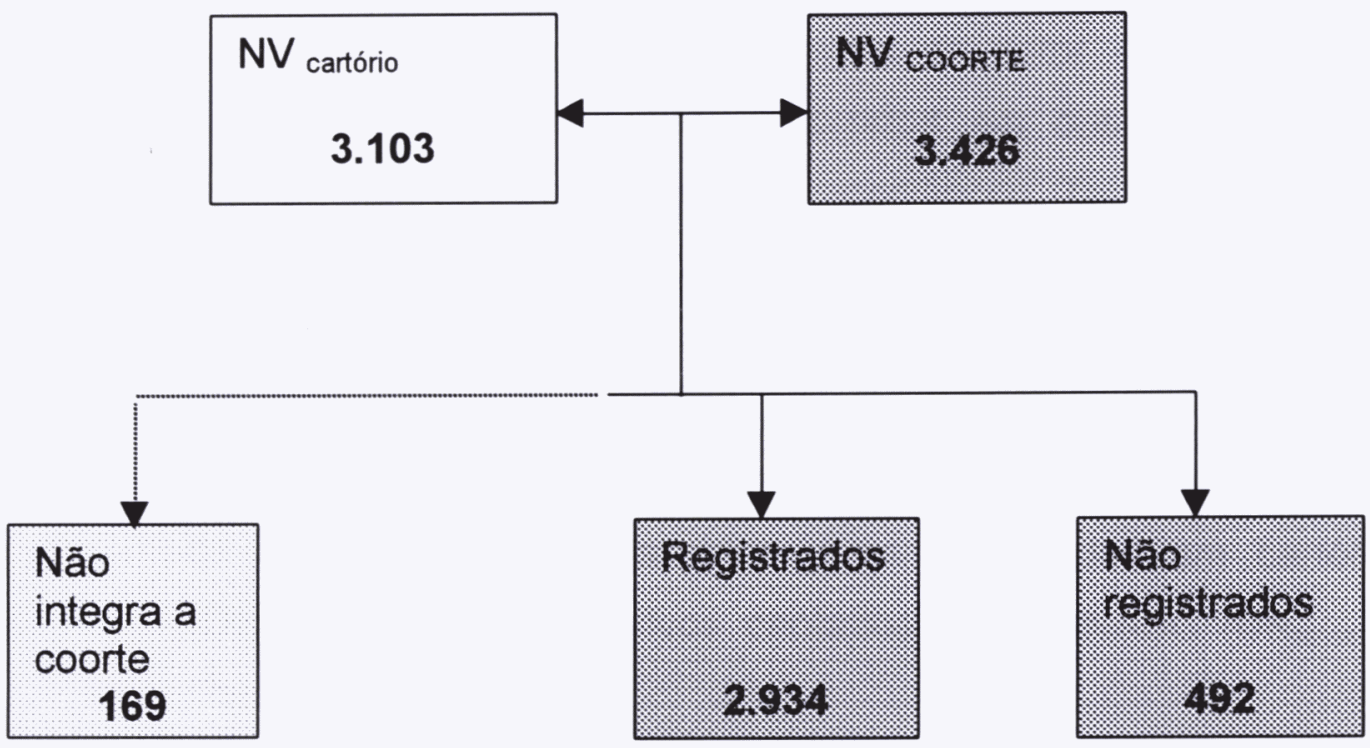

\subsection{Avaliação da captação pelo SINASC dos nascidos Vivos hospitalares originados na coorte e dos NV registrados em cartório de llhéus}

A figura 5 apresenta a síntese da linkage realizada entre os três bancos de dados: da coorte, de nascidos vivos registrados em cartórios e do SINASC. O número total de nascidos vivos ocorridos e de mães residentes em llhéus e captados pelas três fontes de dados foi de 2857 . Aqueles que foram captados por pelo menos uma das possiveis entradas consideradas foi de 3.680 , excluindo-se os erros de município de residência e duplicação de dados. Dos membros da coorte, 2857 foram captados pelo SINASC e registrados em cartórios, 41 não foram captados pelo SINASC nem registrados em cartórios, 77 foram somente registrados em cartórios e não 
captados pelo SINASC e 451 foram captados pelo SINASC e não registrados em cartórios. A proporção de registrados em cartórios e captados pelo SINASC foi de $93,0 \%$ e de registrados em cartórios não captados pelo SINASC de $7,0 \%$. A proporção de nascidos vivos residentes em Ilhéus membros da coorte ou registrados em cartórios que não foram captados pelo SINASC municipal foi de $7,1 \%$, entretanto há que se ressaltar que, de acordo com informações de técnicos do setor no nivel local, nascimentos de residentes em I/héus ocorridos em outros municípios deverão ser digitados pelo município de ocorrência. Tal procedimento operacional do sistema pode estar justificando pequena parte dos nascimentos registrados em cartório não encontrados no SINASC.

Figura 5 - Síntese da linkage entre os bancos de dados de nascidos vivos da coorte ( $\left(\mathrm{DN}_{\text {coorte}}\right.$ ), nascidos vivos registrados em cartório ( $\mathrm{DN}_{\text {cartório }}$ ) e nascidos vivos captados pelo SINASC ( $D N_{\text {sinasc }}$ ), lihéus, 2001

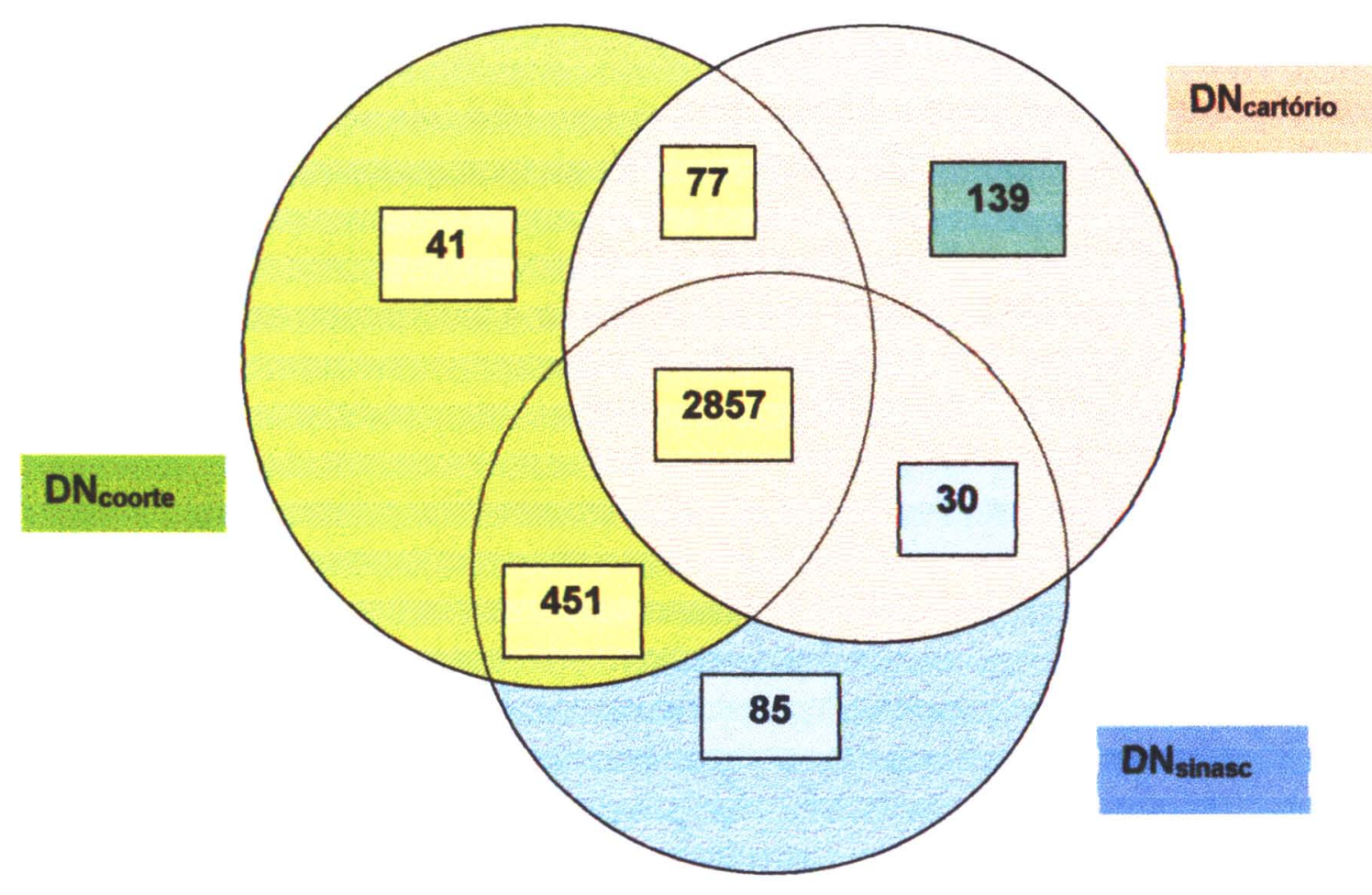




\subsection{Perfil dos nascidos vivos hospitalares, segundo captação ou não pelo SINASC}

Nas tabelas 10 a 17 estão apresentados os dados obtidos através de consulta aos arquivos hospitalares, após a linkage entre os bancos de dados e referem-se ao perfil de nascidos vivos hospitalares com residência e ocorrência em Ilhéus, segundo captação pelo SINASC e algumas variáveis do neonato, da mãe, da gestação, do parto e da assistência.

A análise dos nascimentos da coorte segundo mês de ocorrência (tabela10) mostra uma pequena variação ao longo do ano, sendo outubro 0 mês com menor proporção de nascidos vivos $(7,2 \%)$ e março o de maior proporção $(9,8 \%)$. Dentre nascidos vivos não captados, chama atenção uma maior concentração nos meses de janeiro $(34,0 \%)$, junho $(10,2 \%)$ e julho $(12,0 \%)$, o que pode estar apontando para algum fator que altere a rotina dos serviços neste periodo. Conhecendo a estrutura organizacional do sistema, é plausível supor que, nestes meses, ocorre uma maior concentração de férias de funcionários, o que poderia estar interferindo na emissão, encaminhamento, recepção ou digitação das DN. Considerando que a alimentação do SIM é responsabilidade exclusiva de um único funcionário, talvez isto esteja na origem de tão grande variação. Destaca-se que há associação estatisticamente significante $\left(\chi_{(11)}^{2}=114,678 ; p=0,000\right)$ entre o mês de nascimento e a captação ou não pelo SINASC. 
Tabela 10 - Número de nascidos vivos segundo captação pelo SINASC e mês de nascimento, llhéus, 2001

\begin{tabular}{|c|c|c|c|c|c|c|}
\hline \multirow{3}{*}{$\begin{array}{c}\text { MÊS DE } \\
\text { NASCIMENTO }\end{array}$} & \multicolumn{4}{|c|}{ SINASC } & \multirow{2}{*}{\multicolumn{2}{|c|}{ TOTAL }} \\
\hline & \multicolumn{2}{|c|}{ CAPTADOS } & \multicolumn{2}{|c|}{ NÄO CAPTADOS } & & \\
\hline & $\mathbf{N}$ & $\%$ & $\mathbf{N}$ & $\%$ & $\mathrm{~N}$ & $\%$ \\
\hline Janeiro & 244 & 7,4 & 40 & 34,0 & 284 & 8,3 \\
\hline Fevereiro & 282 & 8,5 & 7 & 5,9 & 289 & 8,4 \\
\hline Março & 325 & 9,9 & 7 & 5,9 & 332 & 9,8 \\
\hline Abril & 295 & 8,9 & 4 & 3,3 & 299 & 8,7 \\
\hline Maio & 315 & 9,6 & 8 & 6,8 & 323 & 9,4 \\
\hline Junho & 275 & 8,3 & 12 & 10,2 & 287 & 8,4 \\
\hline Julho & 274 & 8,3 & 14 & 12,0 & 288 & 8,4 \\
\hline Agosto & 255 & 7,7 & 4 & 3,3 & 259 & 7,6 \\
\hline Setembro & 273 & 8,2 & 1 & 0,8 & 274 & 8,0 \\
\hline Outubro & 242 & 7,3 & 6 & 5,1 & 248 & 7,2 \\
\hline Novembro & 255 & 7,7 & 6 & 5,1 & 261 & 7,6 \\
\hline Dezembro & 273 & 8,2 & 9 & 7,6 & 282 & 8,2 \\
\hline TOTAL & 3308 & 100,0 & 118 & 100,0 & 3426 & 100,0 \\
\hline
\end{tabular}

$\chi^{2}(11)=114,678 ; p=0,000$

A tabela 11 apresenta a distribuição de nascidos vivos da coorte segundo zona de residência e captação pelo SINASC. A grande maioria dos nascidos vivos da coorte $(88,8 \%)$ reside na zona urbana. Observa-se que a proporção de residentes em zona rural é superior no grupo dos não captados pelo SINASC do que entre os captados, entretanto, não há associação estatisticamente significante entre as variáveis apresentadas $\left(\chi_{(1)}^{2}=3,36 ; p=0,066\right.$; excluídos os de área de residência ignorada).

Tabela 11 - Número de nascidos vivos segundo captação pelo SINASC e área de residência, llhéus, 2001

\begin{tabular}{lcccccc}
\hline \multirow{2}{*}{ ÁREA } & \multicolumn{4}{c}{ SINASC } & \multicolumn{2}{c}{ TOTAL } \\
\cline { 2 - 6 } & \multicolumn{2}{c}{ CAPTADOS } & NÃO CAPTADOS & \multicolumn{2}{c}{} \\
\cline { 2 - 6 } & $\mathbf{N}$ & $\%$ & $\mathbf{N}$ & $\%$ & $\mathbf{N}$ & $\%$ \\
\hline Urbana & 2944 & 89,0 & 98 & 83,0 & 3042 & 88,8 \\
Rural & 358 & 10,8 & 19 & 16,1 & 377 & 11,0 \\
lgnorada & 6 & 0,2 & 1 & 0,9 & 7 & 0,2 \\
\hline \multicolumn{1}{c}{ TOTAL } & 3308 & 100,0 & 118 & 100,0 & 3426 & 100,0 \\
\hline$\chi^{2}(1)=3,36 ; p=0,066 ;$ & excluídos os de área de residencia ignorada. &
\end{tabular}

A tabela 12 apresenta a distribuição dos nascidos vivos da coorte segundo hospital de ocorrência do parto e captação pelo SINASC. O maior 
número de nascimentos ocorreu no hospital e maternidade Santa Helena e a maior proporção de nascimentos não captados pelo SINASC ocorreu no hospital Santa Isabel, $50 \%$ dos não captados. É importante destacar que o hospital e maternidade Santa Helena apresenta a segunda maior proporção de nascimentos não captados pelo Sistema. Observa-se que, apesar da pequena proporção de nascimentos da coorte terem ocorrido no hospital São Jorge $(1,2 \%)$, dentre os não captados, $7,6 \%$ dos nascimentos ocorreram neste hospital. As diferenças de captação segundo hospital de ocorrência do nascimento mostraram-se estatisticamente significantes $\left(\chi_{(3)}^{2}=58,235\right.$; $p=0,000$ ). Discute-se a necessidade de padronização de fluxo do documento de alimentação do SINASC, com desenvolvimento de instrumentos de acompanhamento e controle do mesmo, principalmente em relação aos hospitais Santa Helena e Santa Isabel.

Tabela 12 - Número de nascidos vivos segundo captação pelo SINASC e hospital de ocorrência, llhéus, 2001

\begin{tabular}{|c|c|c|c|c|c|c|}
\hline \multirow{3}{*}{ HOSPITAL } & \multicolumn{4}{|c|}{ SINASC } & \multirow{2}{*}{\multicolumn{2}{|c|}{ TOTAL }} \\
\hline & \multicolumn{2}{|c|}{ CAPTADOS } & \multicolumn{2}{|c|}{ NÃO CAPTADOS } & & \\
\hline & $\mathrm{N}$ & $\%$ & $\mathrm{~N}$ & $\%$ & $\bar{N}$ & $\%$ \\
\hline Bartolomeu & 156 & 4,7 & 7 & 5,9 & 163 & 4,8 \\
\hline Santa Helena & 1955 & 59,1 & 43 & 36,5 & 1998 & 58,3 \\
\hline São Jorge & 33 & 1,0 & 9 & 7,6 & 42 & 1,2 \\
\hline Santa Isabel & 1164 & 35,2 & 59 & 50,0 & 1223 & 35,7 \\
\hline TOTAL & 3308 & 100,0 & 118 & 100,0 & 3426 & 100,0 \\
\hline
\end{tabular}

A distribuição dos nascidos vivos da coorte segundo idade da mãe (tabela 13) mostra concentração de nascidos de mães na faixa etária de 20 a 34 anos $(62,4 \%)$, seguidos da faixa etária de 15 a 19 anos (30,5\%). A proporção de captados e não captados por faixa etária da mãe não é muito diferente nos dois grupos. Não há associação estatisticamente significante entre idade da mãe e captação pelo $\operatorname{SINASC}\left(\chi^{2}{ }_{(3)}=0,06 ; p=0,996\right.$, excluídos os de idade da mãe ignorada). 
Tabela 13 - Número de nascidos vivos segundo captação pelo SINASC e idade da mãe, llhéus, 2001

\begin{tabular}{|c|c|c|c|c|c|c|}
\hline \multirow{3}{*}{$\begin{array}{l}\text { IDADE DA } \\
\text { MÄE (em } \\
\text { anos) }\end{array}$} & \multicolumn{4}{|c|}{ SINASC } & \multirow{2}{*}{\multicolumn{2}{|c|}{ TOTAL }} \\
\hline & \multicolumn{2}{|c|}{ CAPTADOS } & \multicolumn{2}{|c|}{ NĂO CAPTADOS } & & \\
\hline & $\mathrm{N}$ & $\%$ & $\mathrm{~N}$ & $\%$ & $\mathbf{N}$ & $\%$ \\
\hline$<15$ & 51 & 1,5 & 2 & 1,7 & 53 & 1,6 \\
\hline 15 a 19 & 1008 & 30,5 & 37 & 31,3 & 1045 & 30,5 \\
\hline 20 a 34 & 2065 & 62,4 & 73 & 61,9 & 2138 & 62,4 \\
\hline 35 e mais & 174 & 5,3 & 6 & 5,1 & 180 & 5,2 \\
\hline Ignorada & 10 & 100,0 & 0 & 0 & 10 & 0,3 \\
\hline TOTAL & 3308 & 100,0 & 118 & 100,0 & 3426 & 100,0 \\
\hline
\end{tabular}

Na tabela 14 está apresentado o número e percentual de nascidos vivos da coorte segundo situação familiar da mãe e captação pelo SINASC. A distribuição da situação familiar da mãe é semelhante nos dois grupos, captados e não captados, não havendo associação estatisticamente significante entre as variáveis $\left(\chi^{2}(1)=1,17 ; p=0,28\right.$, cálculo excluindo-se os nascidos vivos de situação familiar ignorada). Chama atenção a alta proporção de situação familiar ignorada no grupo de estudo, reafirmando a importância da busca de informações no curso do internamento. Esta é uma das variáveis constantes da DN de difícil resgate posterior no prontuário ou outros registros hospitalares.

Tabela 14 - Número de nascidos vivos segundo captação pelo SINASC e situação familiar da mãe, llhéus, 2001

\begin{tabular}{|c|c|c|c|c|c|c|}
\hline \multirow{3}{*}{ ESTADO CIVIL } & \multicolumn{4}{|c|}{ SINASC } & \multirow{2}{*}{\multicolumn{2}{|c|}{ TOTAL }} \\
\hline & \multicolumn{2}{|c|}{ CAPTADOS } & \multicolumn{2}{|c|}{ NẢO CAPTADOS } & & \\
\hline & $\mathrm{N}$ & $\%$ & $\mathrm{~N}$ & $\%$ & $\mathbf{N}$ & $\%$ \\
\hline $\begin{array}{l}\text { Mãe com } \\
\text { companheiro }\end{array}$ & 1069 & 32,3 & 44 & 37,3 & 1113 & 32,5 \\
\hline $\begin{array}{l}\text { Mãe sem } \\
\text { companheiro }\end{array}$ & 1957 & 59,2 & 65 & 55,1 & 2022 & 59,0 \\
\hline Ignorado & 282 & 8,5 & 9 & 7,6 & 291 & 8,5 \\
\hline TOTAL & 3308 & 100,0 & 118 & 100,0 & 3426 & 100,0 \\
\hline
\end{tabular}

$\chi^{2}(1)=1,17 ; p=0,28$; excluidos os de situação familiar ignorada.

Para 91,6\% dos nascidos vivos da coorte a escolaridade da mãe é ignorada, sendo $91,4 \%$ no grupo da coorte captado pelo SINASC e $97,5 \%$ 
no grupo não captado. Este achado dificulta a análise dos dados e coloca a necessidade de buscar a informação no momento em que a mãe está internada. Considerando que esta informação não é registrada nos impressos hospitalares, mostra-se impossível resgata-la posteriormente. Ressalta-se que se trata de uma das poucas variáveis constantes da DN indicadora de nível socio-econômico da criança, portanto, de extrema importância para intervenções que objetivem a modificação do risco de morte em menores de um ano.

Tabela 15 - Número de nascidos vivos segundo captação pelo SINASC e duração da gestação, llhéus, 2001

\begin{tabular}{|c|c|c|c|c|c|c|}
\hline \multirow{3}{*}{$\begin{array}{c}\text { DURAÇÃO DA } \\
\text { GESTAÇÃO }\end{array}$} & \multicolumn{4}{|c|}{ SINASC } & \multirow{2}{*}{\multicolumn{2}{|c|}{ TOTAL }} \\
\hline & \multicolumn{2}{|c|}{ CAPTADOS } & \multicolumn{2}{|c|}{ NÅO CAPTADOS } & & \\
\hline & $\mathrm{N}$ & $\%$ & $\mathrm{~N}$ & $\%$ & $\mathrm{~N}$ & $\%$ \\
\hline Pré-termo & 114 & 3,5 & 5 & 4,2 & 119 & 3,5 \\
\hline Não pré-termo & 3130 & 94,6 & 105 & 89,0 & 3235 & 94,4 \\
\hline Ignorada & 64 & 1,9 & 8 & 6,8 & 72 & 2,1 \\
\hline TOTAL & 3308 & 100,0 & 118 & 100,0 & 3426 & 100,0 \\
\hline
\end{tabular}

$\mathrm{p}=0,351$; excluídos os nascidos vivos de duração da gestação ignorada.

A distribuição da coorte segundo duração da gestação e captação pelo SINASC (tabela 15) mostra que as gestações de termo (37 a 41 semanas) constituem-se maioria dos nascimentos, entretanto, a proporção de nascimentos de pré-termo entre os não captados é ligeiramente superior à dos captados. Chama atenção que para $2,1 \%$ dos nascimentos da coorte não foi possível identificar a duração da gravidez, sendo maior a proporção de duração da gravidez ignorada entre os não captados $(6,8 \%)$ do que entre os captados $(1,9 \%)$ pelo Sistema. A maior proporção de nascimentos de prétermo entre os não captados não se mostrou estatisticamente significante ( $p=0,351$; excluídos os nascidos vivos de duração da gestação ignorada). 
Tabela 16 - Número de nascidos vivos segundo captação pelo SINASC e peso ao nascer, llhéus, 2001

\begin{tabular}{|c|c|c|c|c|c|c|}
\hline \multirow{3}{*}{ PESO } & \multicolumn{4}{|c|}{ SINASC } & \multirow{2}{*}{\multicolumn{2}{|c|}{ TOTAL }} \\
\hline & \multicolumn{2}{|c|}{ CAPTADOS } & \multicolumn{2}{|c|}{ NÂO CAPTADOS } & & \\
\hline & $\mathbf{N}$ & $\%$ & $\mathbf{N}$ & $\%$ & $\mathbf{N}$ & $\%$ \\
\hline Baixo peso & 330 & 10,0 & 18 & 15,3 & 348 & 10,2 \\
\hline Não baixo & 2934 & 88,7 & 95 & 80,5 & 3029 & 88,4 \\
\hline peso & & & & & & \\
\hline Ignorado & 44 & 1,3 & 5 & 4,2 & 49 & 1,4 \\
\hline TOTAL & 3308 & 100,0 & 118 & 100,0 & 3426 & 100,0 \\
\hline
\end{tabular}

O peso ao nascer é um dos principais fatores de risco para morte neonatal e, consequentemente, um importante indicador para desencadear ações de intervenção para redução do risco de morte neste grupo etário. A tabela 16 mostra a distribuição do peso ao nascer dos nascidos vivos da coorte, segundo captação pelo SINASC. Houve maior freqüência de neonatos de baixo peso ao nascer entre os não captados do que entre os captados, sendo que os resultados mostraram-se estatisticamente significantes $\left(\chi^{2}(1)=4,00 ; p=0,045\right.$; excluídos os nascidos vivos de peso ao nascer ignorado). Destaca-se que a proporção de baixo peso e peso ignorado entre os não captados foi superior à observada no grupo de captados. Pode-se questionar que o SINASC estaria deixando de captar recém nascidos com pequena viabilidade, e em conseqüência subestimando o número de nascidos vivos e a taxa de mortalidade neonatal.

Tabela 17 - Número de nascidos vivos segundo captação pelo SINASC e registro civil, llhéus, 2001

\begin{tabular}{|c|c|c|c|c|c|c|}
\hline \multirow{3}{*}{$\begin{array}{l}\text { REGISTRO } \\
\text { CIVIL }\end{array}$} & \multicolumn{4}{|c|}{ SINASC } & \multirow{2}{*}{\multicolumn{2}{|c|}{ TOTAL }} \\
\hline & \multicolumn{2}{|c|}{ CAPTADOS } & \multicolumn{2}{|c|}{ NÄO CAPTADOS } & & \\
\hline & $\mathrm{N}$ & $\%$ & $\mathrm{~N}$ & $\%$ & $\mathbf{N}$ & $\%$ \\
\hline Sim & 2857 & 86,4 & 77 & 65,3 & 2934 & 85,6 \\
\hline Não & 451 & 13,6 & 41 & 34,7 & 492 & 14,4 \\
\hline TOTAL & 3308 & 100,0 & 118 & 100,0 & 3426 & 100,0 \\
\hline
\end{tabular}

Para os 3426 neonatos da coorte a proporção de registro civil foi de $85,6 \%$. Esta proporção foi de $65,3 \%$ entre os não captados pelo SINASC e 
de $86,4 \%$ entre os captados, ou seja, dentre os não captados, $34,7 \%$ não foram registrados. Os resultados mostraram-se estatisticamente significantes $\left(\chi^{2}(1)=41,293 ; p=0,000\right)$ indicando que o não registro dos nascidos vivos encontra-se associado à não captação destes eventos pelo SINASC, fato já esperado, considerando que uma DN de nascido vivo de parto hospitalar e registrado em cartório tem dupla chance de ser captada pelo SINASC. O fluxo da DN preconizado pelo MS inclui o envio do documento dos hospitais e dos cartórios para o nível municipal. Assim, tratando-se de nascimentos hospitalares, há uma ampliação da possibilidade de captação destes pelo SINASC. Na eventualidade do fluxo dos hospitais para o nível municipal ser inadequado, o cartório seria a principal via de alimentação do sistema. Assim, os achados encontrados apontam para a necessidade de definição e controle dos fluxos da DN tanto de cartórios como de hospitais.

\section{8 Óbitos neonatais segundo fonte de obtenção dos dados}

\section{- SIM}

A figura 6 apresenta os resultados da linkage entre os bancos de dados de nascidos vivos hospitalares com ocorrência e residência em llhéus e os óbitos neonatais captados pelo SIM como óbitos neonatais. Dos 35 óbitos neonatais captados pelo SIM, 34 fazem parte da coorte hospitalar. 0 único óbito neonatal que não integra a coorte é de nascimento domiciliar e óbito hospitalar. 
Figura 6 - Representação esquemática do procedimento de linkage entre os bancos de dados de Nascidos Vivos da Coorte ( $\left.\mathrm{NV}_{\text {coorte }}\right)$ e óbitos neonatais captados pelo SIM (SIM neonatal), Ilhéus, 2001

\section{Linkage}

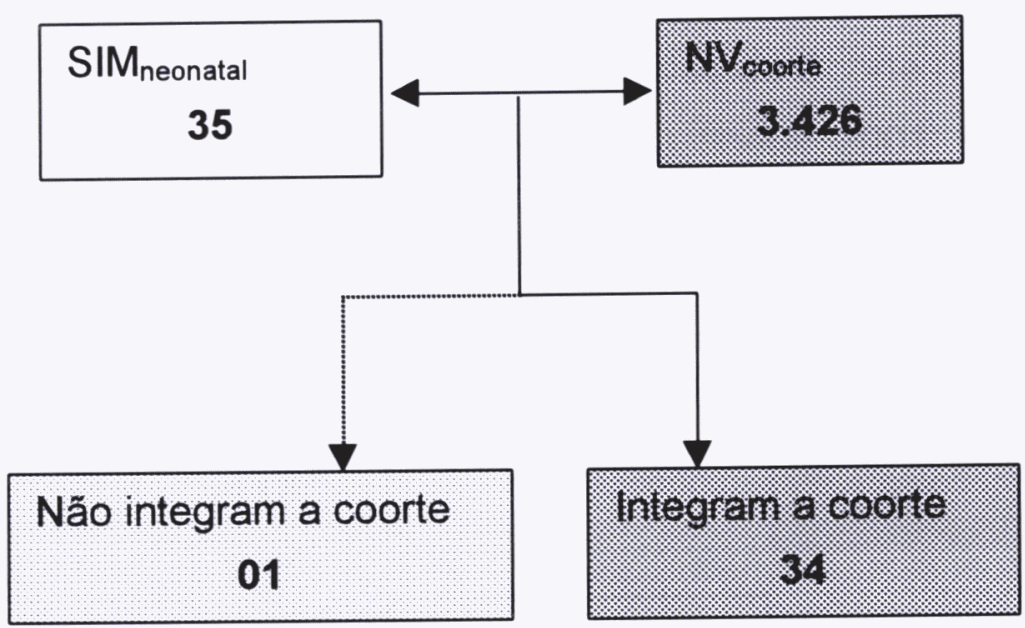

Dada a possibilidade de existir erro de classificação de evento no SIM, isto é, óbitos neonatais para os quais foi incorretamente preenchido o campo de número 7 (tipo de óbito) da DO, e dessa maneira estes passariam a ser identificados como óbitos fetais, decidiu-se promover a linkage das DNh com os óbitos captados como fetais pelo SIM.

Ao realizar a linkage entre os bancos de dados do SIM e da coorte de nascidos vivos detectou-se que parte dos óbitos captados pelo SIM como fetais diziam respeito a nascidos vivos da coorte, ou seja, do conjunto de óbitos fetais, $24,8 \%$ eram em verdade óbitos neonatais e $75,2 \% \%$ eram de fato óbitos fetais. Assim, optou-se por também inclui-los na avaliação do SIM.

A figura 7 apresenta os resultados da linkage realizada entre os bancos de dados da coorte e dos óbitos captados pelo SIM como fetais. Observa-se que, dos 117 óbitos fetais captados pelo SIM, 29 correspondem a nascidos vivos da coorte e 88 não integram a coorte. É importante ressaltar que o critério utilizado para composição do banco de dados da coorte foi a existência de informações nos registros hospitalares de 
nascimento vivo, sendo que em apenas um neonato foi constatado emissão de DO declarando natimorto, apesar de no prontuário constar "nativivo encaminhado ao berçário" .

Figura 7 - Representação esquemática do procedimento de linkage entre os bancos de dados de Nascidos Vivos da Coorte $\left(\mathrm{NV}_{\text {coorte }}\right)$ e óbitos fetais captados pelo SIM (SIM fetal), Ilhéus, 2001

\section{Linkage}

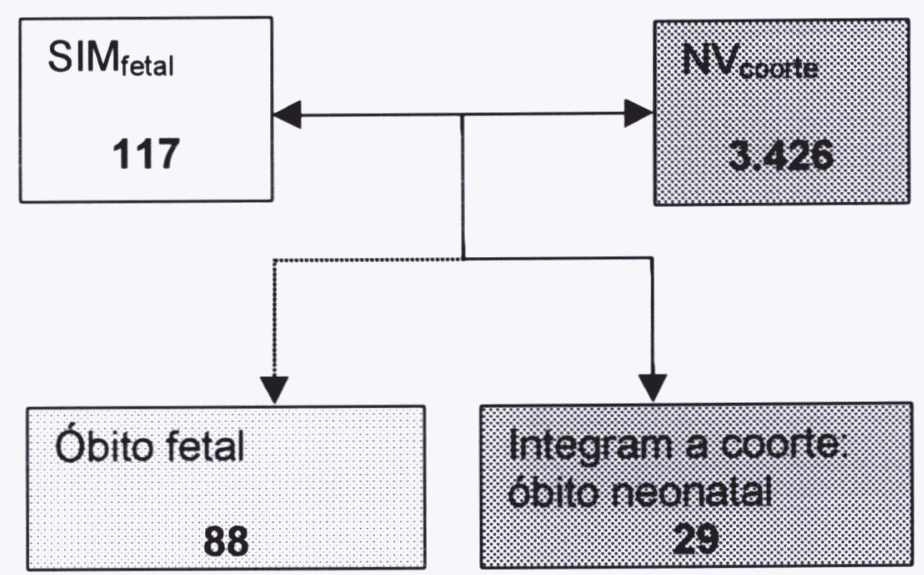

\section{- Cartórios}

A figura 8 apresenta os resultados da linkage realizada entre os bancos de dados de óbitos neonatais registrados em cartórios do município e o da coorte. Observa-se que dos 61 óbitos neonatais registrados em cartórios, 57 integram e 4 não integram a coorte. Os quatro óbitos que não integram a coorte são: um nascimento domiciliar, 02 nascimentos hospitalares registrados como tendo ocorrido em llhéus, porém não encontrados nos arquivos hospitalares, e um cujo local de nascimento era ignorado. 
Figura 8 - Representação dos procedimentos de linkage entre os bancos de dados de óbitos neonatais registrados em cartório ( $\left(\mathrm{DO}_{\text {cartório }}\right)$ e nascidos vivos da coorte ( $\mathrm{DN}_{\text {coorte }}$ ), llhéus, 2001

\section{Linkage}

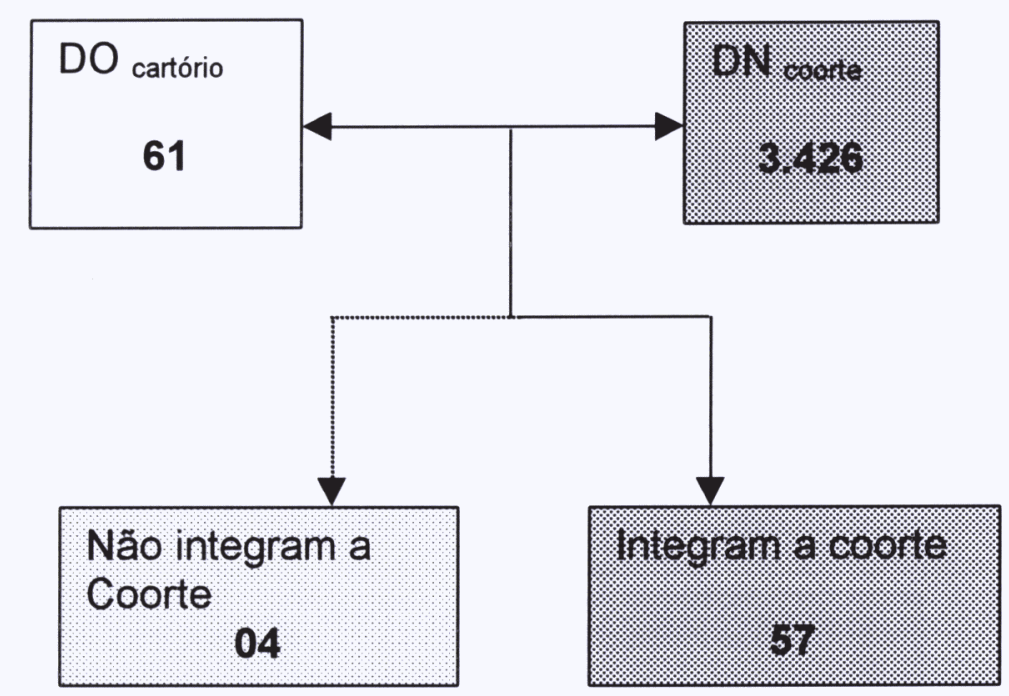

- Hospitalares

A figura 9 apresenta esquematicamente os resultados da linkage realizada entre os bancos de dados da coorte e óbitos neonatais captados em registros hospitalares. Observa-se que dos 65 óbitos neonatais com registros hospitalares 63 integram a coorte e dois não fazem parte dela. Dos dois óbitos neonatais que não integram a coorte, 01 corresponde a nascimento em domicílio e 01 a nascimento ocorrido em local ignorado, não fazendo parte de nenhum dos bancos de dados de nascidos vivos. 
Figura 9 - Representação do procedimento de linkage entre os bancos de dados de Nascidos Vivos da Coorte ( $\left.\mathrm{NV}_{\text {coorte }}\right)$ e óbitos neonatais captados em registros hospitalares $\left(\mathrm{DO}_{\text {hospital }}\right)$, Ilhéus, 2001

Linkage

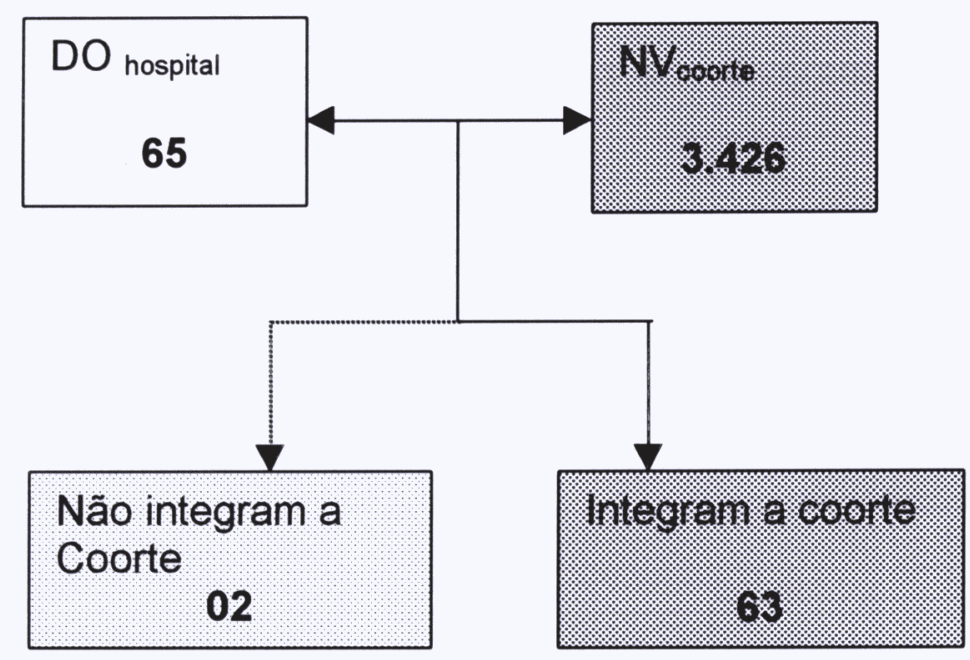

\subsection{Avaliação da captação pelo SIM de óbitos neonatais originados na coorte de NV hospitalares}

Os resultados da linkage entre os bancos de dados de nascidos vivos hospitalares com ocorrência e residência em llhéus e os óbitos neonatais obtidos por diversas fontes segundo captação pelo SIM estão expostos na figura 10. Observa-se que foram captados 68 óbitos neonatais na coorte. Destes, 34 foram captados pelo SIM como neonatais, 29 foram captados pelo SIM como fetais e 5 não foram captados pelo SIM.

A proporção de óbitos de menores de 28 dias ocorridos na coorte captados pelo SIM neonatal foi de 50,0\%. Agregando-se os óbitos fetais captados pelo SIM que em realidade são neonatais, a proporção de 
captação passa a ser de 92,6\%. A proporção de não captação pelo SIM sob nenhuma forma foi de $7,4 \%$.

Tratando-se de uma coorte hospitalar, onde a maior parte dos óbitos neonatais ocorre antes da alta após o nascimento, e considerando o fluxo da DO preconizado pelo MS, seria esperado uma proporção de captação de $100 \%$.

Figura 10 - Representação esquemática do procedimento de linkage entre os bancos de dados de nascidos vivos da coorte ( $\left.N V_{\text {coorte }}\right)$ e óbitos neonatais identificados por diversas fontes e captados pelo SIM (SIM), Ilhéus, 2001

\section{Linkage}

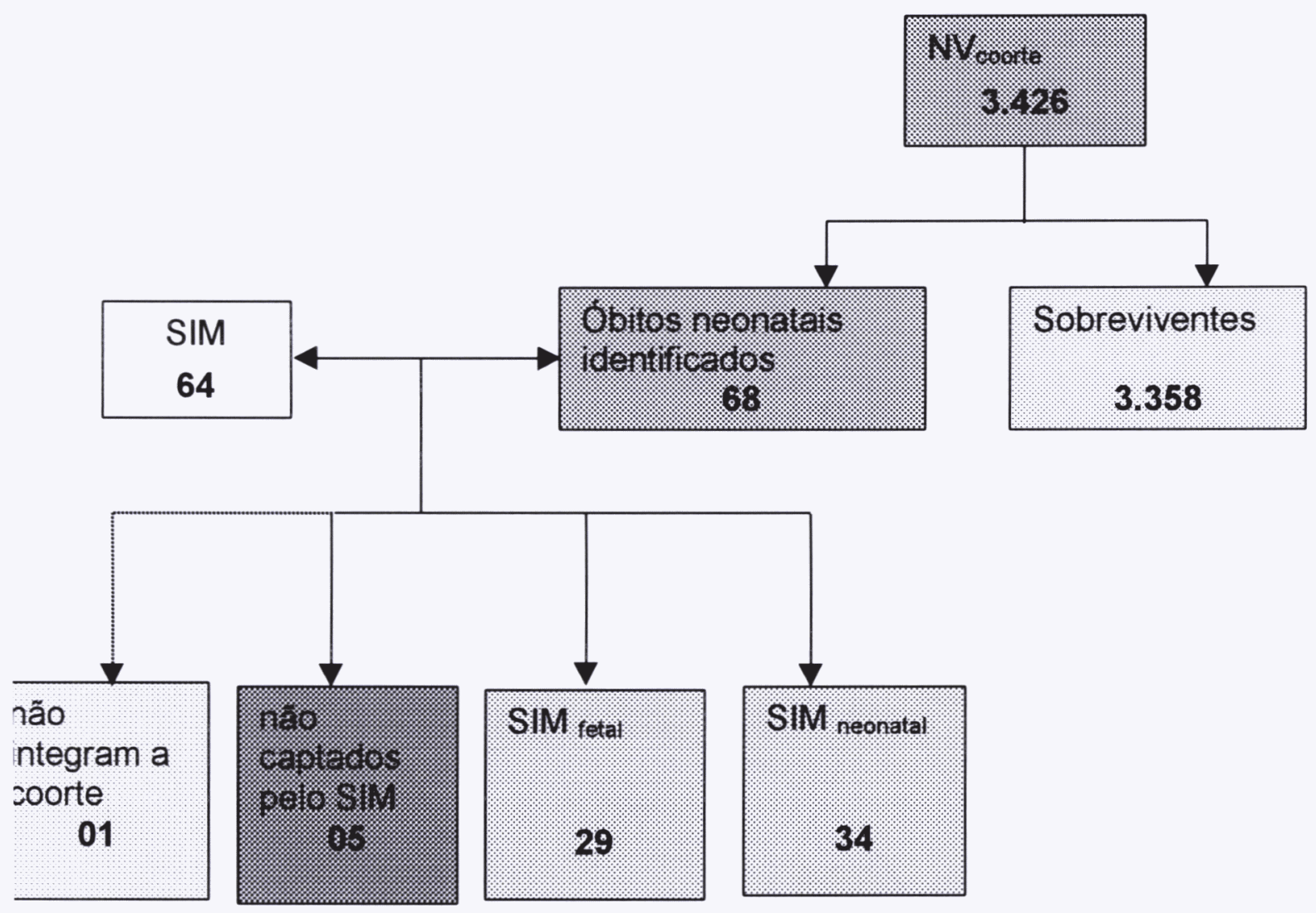

Os óbitos neonatais da coorte de nascidos vivos com residência e ocorrência em llhéus, segundo fonte de obtenção dos dados, estão expostos na figura 11 . 
Os sessenta e oito óbitos neonatais ocorridos na coorte estão assim distribuídos segundo fonte de captação: 27 captados por Doh, SIM neonatal e DOc; 23 captados por DOh, SIM fetal e DOC; 2 captados por DOh e DOc; 5 captados por DOc e SIM neonatal; 2 captados por DOh e SIM neonatal 6 captados por DOh e SIM fetal e 3 captados exclusivamente por DOh. Observa-se que dos óbitos encontrados somente 3 tiveram apenas uma fonte de captação, os registros hospitalares e caracterizam-se por: 1 baixo peso (870g), óbito com 6 horas de vida, residente na zona urbana; 1 óbito com um dia de vida, peso de $3580 \mathrm{~g}$, residente na zona rural; 1 óbito com 1 hora de vida, peso de $1240 \mathrm{~g}$, residente na zona urbana. Os demais 65 óbitos neonatais foram captados por pelo menos duas fontes de dados.

Figura 11 - Síntese dos óbitos neonatais pertencentes à coorte de nascidos vivos hospitalares com residência e ocorrência em llhéus, segundo fonte de

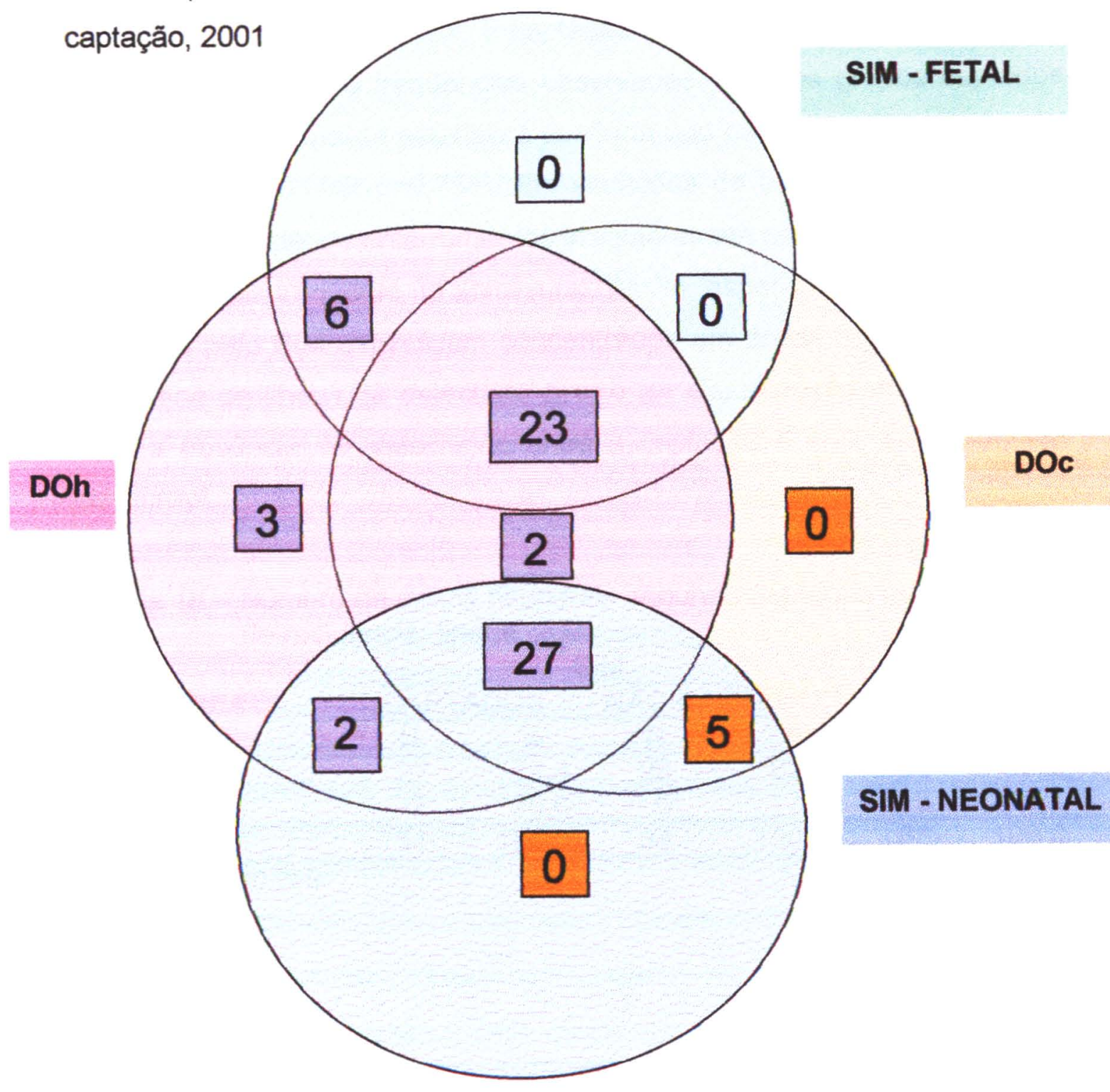


4.10 Perfil dos óbitos neonatais originados na coorte de NV hospitalares com ocorrência e residência em Ilhéus, segundo captação pelo SIM

As tabelas 18 a 25 apresentam os resultados decorrentes da avaliação de captação pelo SIM dos óbitos neonatais identificados na coorte de nascidos vivos com residência e ocorrência hospitalar no município de Ilhéus, segundo algumas variáveis da criança, da gestação, do parto, da mãe e da assistência.

Considerando tratar-se de análise descritiva com objetivo de avaliar o SIM e buscar indicativos de possíveis falhas no sistema, optou-se por não incluir os óbitos neonatais captados equivocadamente como fetais na categoria de captados pelo SIM.

A distribuição dos óbitos neonatais ocorridos na coorte segundo zona de residência, urbana e rural, e captação pelo SIM (tabela 18) mostra que não há diferença nas freqüências observadas entre os grupos captados $e$ não captados. $A$ análise estatística confirma que não há associação entre as variáveis $\left(\chi_{(1)}^{2}=0,095 ; p=0,758\right)$. Em situações de baixa cobertura do SIM, discute-se o papel de enterramentos irregulares em cemitérios não oficiais, o que seria mais freqüente na zona rural. Assim, esperar-se-ia que óbitos não captados pelo SIM estivessem concentrados em áreas rurais. Na situação especifica de llhéus, já detectado o erro de classificação do evento morte fetal, a ausência de associação entre a captação e área de residência é justificável.

Tabela 18 - Número de óbitos neonatais segundo captação pelo SIM e área de residência, llhéus, 2001

\begin{tabular}{lrrrrrr}
\hline \multirow{2}{*}{ ÁREA } & \multicolumn{4}{c}{ SIM } & \multicolumn{2}{c}{ TOTAL } \\
\cline { 2 - 7 } & \multicolumn{2}{c}{ CAPTADOS } & NÃO CAPTADOS & \multicolumn{1}{c}{ CAL } \\
\cline { 2 - 7 } & $\mathrm{N}$ & $\%$ & $\mathrm{~N}$ & $\%$ & $\mathrm{~N}$ & $\%$ \\
\hline Urbana & 27 & 79,4 & 28 & 82,4 & 55 & 80,9 \\
Rural & 7 & 20,6 & 6 & 17,6 & 13 & 19,1 \\
\hline TOTAL & 34 & 100,0 & 34 & 100,0 & 68 & 100,0 \\
\hline$\chi^{2}{ }_{(1)}=0,095 ; p=0,758$ & & & & & &
\end{tabular}


Os óbitos da coorte, segundo hospital de ocorrência e captação pelo SIM, estão expostos na tabela 19. Os dados mostram que a maior parte dos óbitos ocorreu no hospital e maternidade Santa Helena, o que pode ser justificado por ser a unidade hospitalar com o maior número de nascidos vivos $(58,3 \%)$, conforme pode ser visto na tabela 12 . Entretanto, chama atenção que $82,4 \%$ dos óbitos não captados pelo SIM tenham acontecido neste hospital. Caso o erro de classificação do evento morte fetal seja decorrente de equívoco na emissão da DO, sem dúvida, a ocorrência concentra-se no hospital e maternidade Santa Helena. No hospital São Jorge não houve nenhum óbito neonatal, destacando-se que o número de nascidos vivos nesta unidade foi muito pequeno. Os resultados mostram que a diferença de captação segundo hospital de ocorrência dos óbitos é estatisticamente significante $\left(\chi_{(1)}^{2}=6,49 ; p=0,01\right.$; excluídos categorias com freqüência igual ou menor que 1).

Tabela 19 - Número de óbitos neonatais segundo captação pelo SIM e hospital de ocorrência do óbito, llhéus, 2001

\begin{tabular}{|c|c|c|c|c|c|c|}
\hline \multirow{3}{*}{ HOSPITAL } & \multicolumn{4}{|c|}{ SIM } & \multirow{2}{*}{\multicolumn{2}{|c|}{ TOTAL }} \\
\hline & \multicolumn{2}{|c|}{ CAPTADOS } & \multicolumn{2}{|c|}{ NÃO CAPTADOS } & & \\
\hline & $\bar{N}$ & $\%$ & $\mathrm{~N}$ & $\%$ & $\mathrm{~N}$ & $\%$ \\
\hline Bartolomeu & 1 & 2,9 & 0 & 0,0 & 1 & 1,5 \\
\hline Sta. Helena & 17 & 50,0 & 28 & 82,4 & 45 & 66,2 \\
\hline Santa Isabel & 15 & 44,2 & 6 & 17,6 & 21 & 30,8 \\
\hline Ignorado & 1 & 2,9 & 0 & 0,0 & 1 & 1,5 \\
\hline TOTAL & 34 & 100,0 & 34 & 100,0 & 68 & 100,0 \\
\hline
\end{tabular}

$\chi^{2}{ }_{(1)}=6,49 ; p=0,01$; excluídos categorias com freqüência igual ou menor que 1 .

Na maior parte dos óbitos neonatais ocorridos na coorte, a idade da mãe situou-se na faixa etária de 20 a 34 anos $(60,3 \%)$, repetindo-se este comportamento nos grupos captados e não captados pelo SIM. A proporção de mães menores de 15 anos é maior no grupo de óbitos neonatais não captados pelo SIM do que no grupo dos óbitos captados, entretanto, dado o pequeno número, tal resultado deve ser interpretado com cautela. Não houve diferença estatisticamente significante $(p=0,334)$ entre as variáveis idade da mãe e captação pelo SIM. 
Tabela 20 - Número de óbitos neonatais segundo captação pelo SIM e idade da mãe, llhéus, 2001

\begin{tabular}{lrrrrrr}
\hline \multirow{2}{*}{$\begin{array}{l}\text { IDADE DA MÄE } \\
\text { (em anos) }\end{array}$} & \multicolumn{4}{c}{ CAPTADOS } & NÄO CAPTADOS & \multicolumn{2}{c}{ TOTAL } \\
\cline { 2 - 6 } & \multicolumn{1}{c}{$\mathrm{N}$} & $\%$ & $\mathrm{~N}$ & $\%$ & $\mathrm{~N}$ & \multicolumn{1}{c}{$\%$} \\
\hline$<15$ & 0 & 0,0 & 2 & 5,9 & 2 & 2,9 \\
15 a 19 & 9 & 26,5 & 11 & 32,4 & 20 & 29,4 \\
20 a 34 & 21 & 61,7 & 20 & 58,8 & 41 & 60,3 \\
35 e mais & 4 & 11,8 & 1 & 2,9 & 5 & 7,4 \\
\hline TOTAL & 34 & 100,0 & 34 & 100,0 & 68 & 100,0 \\
\hline p=0,334 & & & & & &
\end{tabular}

A alta proporção de informações ignoradas para a variável escolaridade da mãe dificulta a sua análise por categorias. Para todos os óbitos neonatais da coorte a proporção de escolaridade da mãe ignorada foi de $86,8 \%$, no grupo de óbitos captados foi de $85,3 \%$ e no grupo de não captados $88,2 \%$. É importante destacar o valor desta variável para o desenvolvimento de ações e práticas de saúde que objetivem o enfrentamento do problema morte neonatal, bem como, a impossibilidade de resgatar a informação em momento posterior ao internamento.

$\mathrm{Na}$ tabela 21 está apresentada a distribuição dos óbitos neonatais ocorridos na coorte segundo duração da gravidez e captação pelo SIM. Conforme é de se esperar, a maior proporção dos óbitos neonatais ocorre em gestações pré-termo. Entretanto, ressalta-se que a proporção de gestações de prétermo no grupo de óbitos não captados pelo SIM é maior do que no grupo dos óbitos captados. Este achado poderia estar apontando para que o sistema está deixando de captar neonatos com menor viabilidade, porém ao analisar os dados da tabela 22, observa-se que a freqüência de baixo peso ao nascer é menor no grupo dos óbitos não captados do que entre os captados. Chama atenção a alta proporção de gestação de duração ignorada no grupo de óbitos neonatais captados pelo SIM, o que pode estar justificando a incoerência entre os dados das tabelas 21 e 22 . De acordo com a análise estatística dos dados, não há associação entre as variáveis duração da gestação e captação pelo $\operatorname{SIM}\left(\chi_{(1)}^{2}=0,06 ; p=0,812\right.$; excluídos os óbitos neonatais de duração da gestação ignorada). 
Tabela 21 - Número de óbitos neonatais segundo captação pelo SIM e duração da gestação, llhéus, 2001

\begin{tabular}{|c|c|c|c|c|c|c|}
\hline \multirow{3}{*}{$\begin{array}{l}\text { DURAÇÂO DA } \\
\text { GESTAÇÂO (em } \\
\text { semanas) }\end{array}$} & \multicolumn{4}{|c|}{ SIM } & \multirow{2}{*}{\multicolumn{2}{|c|}{ TOTAL }} \\
\hline & \multicolumn{2}{|c|}{ CAPTADOS } & \multicolumn{2}{|c|}{ NÄO CAPTADOS } & & \\
\hline & $\mathrm{N}$ & $\%$ & $\mathrm{~N}$ & $\%$ & $\mathrm{~N}$ & $\%$ \\
\hline Pré-termo & 16 & 47,1 & 21 & 61,8 & 37 & 54,4 \\
\hline Não pré-termo & 8 & 23,5 & 12 & 35,3 & 20 & 29,4 \\
\hline Ignorada & 10 & 29,4 & 1 & 2,9 & 11 & 16,2 \\
\hline TOTAL & 34 & 100,0 & 34 & 100,0 & 68 & 100,0 \\
\hline
\end{tabular}

A distribuição dos óbitos neonatais da coorte segundo peso ao nascer (tabela22) mostra que há uma concentração de óbitos classificados como de baixo peso, correspondendo a $67,7 \%$ do total. Destaca-se que dentre os óbitos não captados pelo SIM, 38,2\% foram categorizados como não baixo peso, e que esta proporção é superior àquela observada nos óbitos neonatais captados pelo SIM. Não há associação entre a proporção de baixo peso ao nascer e o óbito ter sido ou não captado pelo Sistema $\left(\chi_{(1)}^{2}=2,09\right.$; $p=0,148$; excluídos os óbitos neonatais de peso ao nascer ignorado).

Tabela 22 - Número de óbitos neonatais segundo captação pelo SIM e peso ao nascer, llhéus, 2001

\begin{tabular}{|c|c|c|c|c|c|c|}
\hline \multirow{3}{*}{ PESO } & \multicolumn{4}{|c|}{ SIM } & \multirow{2}{*}{\multicolumn{2}{|c|}{ TOTAL }} \\
\hline & \multicolumn{2}{|c|}{ CAPTADOS } & \multicolumn{2}{|c|}{ NÅO CAPTADOS } & & \\
\hline & $\mathrm{N}$ & $\%$ & $\mathrm{~N}$ & $\%$ & $\mathbf{N}$ & $\%$ \\
\hline Baixo peso & 25 & 73,5 & 21 & 61,8 & 46 & 67,7 \\
\hline Não baixo & 7 & 20,6 & 13 & 38,2 & 20 & 29,4 \\
\hline ignorado & 2 & 5,9 & 0 & 0,0 & 2 & 2,9 \\
\hline TOTAL & 34 & 100,0 & 34 & 100,0 & 68 & 100,0 \\
\hline
\end{tabular}

$\chi^{2}{ }_{(1)}=2,09 ; p=0,148$; excluídos os óbitos neonatais de peso ao nascer ignorado.

A análise da distribuição da idade ao morrer nos óbitos ocorridos na coorte (tabela 23) mostra que $79,1 \%$ dos óbitos ocorreram nas primeiras 24 horas de vida. A freqüência de óbitos em menores de 24 horas no grupo não captado pelo SIM $(97,1 \%)$ é bastante superior à encontrada no grupo dos óbitos captados (61,8\%). A morte de neonatos logo nas primeiras horas de vida pode facilitar equívocos no preenchimento da DO e da emissão de DN. 
É lícito supor que este achado explica o erro de classificação do evento morte fetal, apontando para sua origem no momento do preenchimento da DO. Existe associação entre as variáveis captação pelo SIM e idade ao morrer $(p=0,001)$, indicando que há menor captação para os óbitos ocorridos nas primeiras 24 horas de vida.

Tabela 23 - Número de óbitos neonatais segundo captação pelo SIM e idade ao morrer, llhéus, 2001

\begin{tabular}{|c|c|c|c|c|c|c|}
\hline \multirow{3}{*}{$\begin{array}{l}\text { IDADE AO } \\
\text { MORRER }\end{array}$} & \multicolumn{4}{|c|}{ SIM } & \multirow{2}{*}{\multicolumn{2}{|c|}{ TOTAL }} \\
\hline & \multicolumn{2}{|c|}{ CAPTADOS } & \multicolumn{2}{|c|}{ NÃO CAPTADOS } & & \\
\hline & $\mathrm{N}$ & $\%$ & $\mathrm{~N}$ & $\%$ & $\mathrm{~N}$ & $\%$ \\
\hline$<24$ horas & 21 & 61,8 & 33 & 97,1 & 54 & 79,4 \\
\hline 1 a 6 dias & 10 & 29,4 & 1 & 2,9 & 11 & 16,2 \\
\hline 7 a 27 dias & 3 & 8,8 & 0 & 0,0 & 3 & 4,4 \\
\hline TOTAL & 34 & 100,0 & 34 & 100,0 & 68 & 100,0 \\
\hline
\end{tabular}
$\mathrm{p}=0,001$

A distribuição dos óbitos neonatais ocorridos na coorte, segundo registro civil e captação pelo SIM (tabela24), mostra que a freqüência de registro civil entre os óbitos não captados pelo SIM é menor do que a observada no grupo de captados. Conforme descrito, a proporção de óbitos registrados na coorte foi de $83,8 \%$ e de não registrados de $16,2 \%$. Os resultados mostram que há associação estatisticamente significante $\left(\chi^{2}(1)=5,314 ; p=0,021\right)$ entre as variáveis captação pelo SIM e registro civil do óbito neonatal. Os achados descritos permitem apontar a necessidade de definição de fluxos e rotinas do SIM no nível municipal, acompanhados de mecanismos de controle e acompanhamento, tanto para hospitais quanto para cartórios.

Tabela 24 - Número de óbitos neonatais segundo captação pelo SIM e registro civil, llhéus, 2001

\begin{tabular}{|c|c|c|c|c|c|c|}
\hline \multirow{3}{*}{$\begin{array}{l}\text { REGISTRO } \\
\text { CIVIL }\end{array}$} & \multicolumn{4}{|c|}{ SIM } & \multirow{2}{*}{\multicolumn{2}{|c|}{ TOTAL }} \\
\hline & \multicolumn{2}{|c|}{ CAPTADOS } & \multicolumn{2}{|c|}{ NÅO CAPTADOS } & & \\
\hline & $\mathrm{N}$ & $\%$ & $\bar{N}$ & $\%$ & $\mathbf{N}$ & $\%$ \\
\hline Sim & 32 & 94,1 & 25 & 73,5 & 57 & 83,8 \\
\hline Não & 2 & 5,9 & 9 & 26,5 & 11 & 16,2 \\
\hline TOTAL & 34 & 100,0 & 34 & 100,0 & 68 & 100,0 \\
\hline
\end{tabular}




\subsection{Probabilidade de morte neonatal}

- Probabilidade de morte neonatal no SIM/SINASC

Considerando-se os dados do SINASC e SIM expostos na figura 13, pode-se calcular a probabilidade de morte neonatal. Ressalta-se que para 0 cálculo foram considerados os dados brutos dos sistemas de informação, sem ajustes decorrentes das constatações deste estudo.

Figura 12 - Representação dos eventos nascimentos e óbitos neonatais segundo captação pelo SINASC e SIM, llhéus, 2001

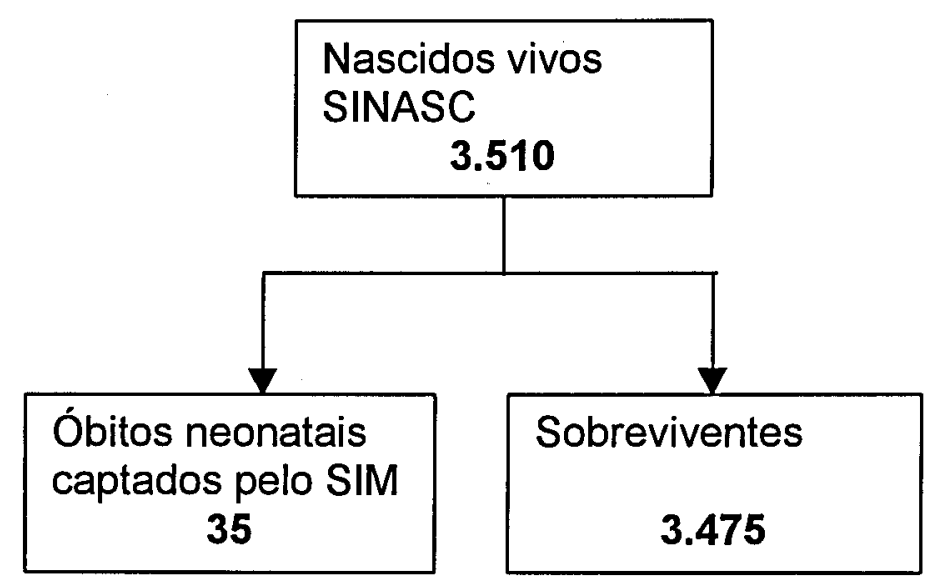

Considerando os dados do SIM/SINASC, a probabilidade de morte neonatal será:

$$
\hat{q}=\frac{\text { óbitos de }<\text { de } 28 \text { dias }}{\text { nascidos vivos }} \times 1000
$$

$$
\hat{q}=\frac{35}{3.510} \times 1000
$$

$\boldsymbol{\Lambda}$

$$
q=9,97 \% \text { nascidos vivos }
$$


Para o município de Itararé, São Paulo, em estudo realizado com dados do SIM/SINASC de 1993, Bohland e Mello Jorge (1999) encontraram uma mortalidade neonatal de $16,8 \%$ nascidos vivos. Em Pelotas, para o mesmo ano, Menezes e cols (1996) encontraram taxa de mortalidade neonatal de 14,3\%. Em estudo mais recente, Szwarcwald, Bastos e Andrade (2002), encontraram taxa de mortalidade neonatal para o município do Rio de Janeiro de $15,0 \%$ nascidos vivos. Não bastando a análise da captação dos eventos nascimento e morte neonatal em llhéus anteriormente apresentada, a comparação com os dados da literatura, mesmo que para outras localidades, permite colocar em discussão a baixa probabilidade de morte neste grupo etário no município, usando-se como fonte o SIM e SINASC.

Agregando-se os óbitos neonatais captados como fetais identificados pelo estudo teriamos uma probabilidade de morte neonatal de $18,2 \%$ nascidos vivos, ainda assim, baixa, considerando tratar-se de município do Nordeste brasileiro, em crise econômica e com condições de assistência ao neonato insuficientes. Deve-se destacar que para o ano de 2000, utilizandose dados do SIM e SINASC, a taxa de mortalidade neonatal foi de $17,1 \%$ nascidos vivos (tabela 07 ).

\section{- Probabilidade de morte neonatal na coorte}

Foram identificados 68 óbitos neonatais na coorte, conforme exposto abaixo:

\begin{tabular}{|c|c|c|c|c|c|c|c|c|}
\hline $\begin{array}{l}\text { Óbitos } \\
\text { captados } \\
\text { pelo SIM } \\
\text { neonatal } \\
34\end{array}$ & + & \begin{tabular}{l} 
Óbitos \\
captados \\
pelo SIM \\
fetal \\
\multicolumn{2}{c}{29}
\end{tabular} & + & $\begin{array}{l}\text { Óbitos } \\
\text { captados } \\
\text { pelos } \\
\text { cartórios } \\
\quad 02\end{array}$ & + & $\begin{array}{l}\text { Óbitos } \\
\text { captados } \\
\text { nos } \\
\text { hospitais } \\
03\end{array}$ & $=$ & $\begin{array}{c}\text { Óbitos } \\
\text { neonatais } \\
\text { da coorte } \\
68\end{array}$ \\
\hline
\end{tabular}


Assim, a probabilidade de morte neonatal na coorte será:

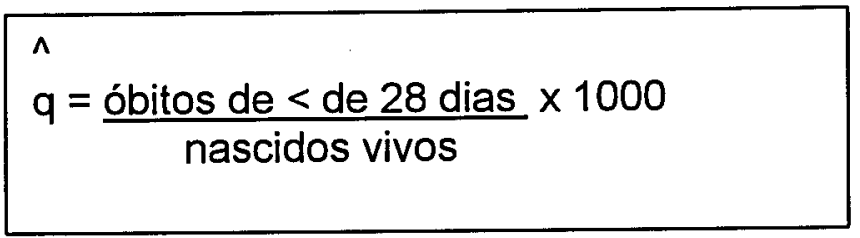

$$
\hat{q}=\frac{68}{3.426} \times 1000
$$

$\wedge$

$$
q=19,84 \% \text { nascidos vivos }
$$

Assim, a probabilidade de morte neonatal encontrada na coorte foi de $19,84 \%$ nascidos vivos, aproximadamente 2 vezes aquela calculada com dados do SIM/SINASC.

Calculando-se um fator de correção a ser aplicado a taxa de mortalidade infantil encontrada com dados do SIM/SINASC, teríamos:

$$
\mathrm{FC}=\frac{\mathrm{Pr}-\mathrm{Psim} / \text { sinasc }}{\mathrm{Pr}}
$$

$$
F C=\frac{19,84-9,97}{19,84}
$$

$$
\mathrm{FC}=0,497
$$




\section{CONSIDERAÇÕES FINAIS E CONCLUSÕES}

\section{Qualidade dos SIS em Ilhéus}

A análise dos dados do SINASC para os anos de 1994 a 2000 demonstra que o número de eventos captados apresenta importante variação no período, positiva e negativa, não sendo possível estabelecer ou observar um padrão. A proporção de captação de nascidos vivos pelo sistema, calculada em relação à população estimada a partir dos Censos Demográficos, mostra um crescimento no periodo de 1994 a 98, seguido de brusco decréscimo em 1999, voltando a crescer em seguida. A taxa de natalidade para o mesmo período apresenta comportamento idêntico. Constata-se que a taxa de natalidade em llhéus é inferior à observada para outras localidades brasileiras. $O$ desvio da taxa de natalidade em relação à média do período (1994 a 2000) apresenta-se negativo nos primeiros três anos e positivo nos seguintes, exceto em 1999. Os dados apresentados permitem concluir que a cobertura e a regularidade dos dados são de baixa qualidade e que algum fator interferiu grandemente sobre o sistema no ano de 1999, com impacto negativo. Observa-se uma melhora da cobertura no ano de 2000; entretanto, considerando a irregularidade dos dados, constatada durante os anos analisados, não há nenhuma garantia que este fato seja resultante de ações efetivas sobre os processos inerentes ao sistema.

O número de óbitos de menores de um ano e por grupo etário em Ilhéus diminuiu ao longo dos anos estudados (1986 a 2000). A variação anual para o mesmo período mostra que, o decréscimo observado não é homogêneo entre os componentes etários, nem constante ao longo do tempo. A variação do número de óbitos infantis e pós-neonatais, para o periodo 90-99, é negativa e mais expressiva que no periodo anterior (80-89). A variação do número de óbitos neonatais, apesar de também negativa, apresenta comportamento inverso, sendo maior no período de 80 a 89 . As taxas de mortalidade infantil, neonatal e pós-neonatal, calculadas por 
diferentes métodos e/ou origem de dados, mostram diminuição nos anos estudados, entretanto, divergem em magnitude. A variação da taxa de mortalidade em menores de um ano e menores de 28 dias apresenta valores positivos e negativos, sem um padrão definido. A variação da taxa de mortalidade pós-neonatal é negativa ou levemente positiva, apontando para um decréscimo contínuo. Os desvios das taxas de mortalidade neonatal, em relação à média do período (1993 a 2000), apresentam comportamentos por blocos de dois anos consecutivos, alternando resultados positivos $e$ negativos. O mesmo não acontece com os desvios da taxa de mortalidade pós-neonatal, que é positiva e distante da média no primeiro ano em estudo, aproxima-se progressivamente da média e em seguida afasta-se, tornandose negativo. Assim, conclui-se que a grande variação do número de óbitos infantis e das taxas de mortalidade infantil e por grupo etário, bem como dos desvios das taxas de mortalidade em relação às médias do período, apontam para baixa regularidade dos fluxos e da cobertura do SIM. Este achado é mais pronunciado entre os menores de 28 dias, apontando para maior irregularidade e menor cobertura neste grupo etário.

Considerando os resultados encontrados para os cinco critérios de avaliação propostos por Szwarcwald e col (2002), o município de llhéus classifica-se na categoria II, ou seja, não satisfaz a algum dos critérios, mas apresenta CGM padronizado maior ou igual a 4 por 1000 habitantes. Podese concluir que nos critérios referentes à regularidade de informações o município apresenta bom desempenho, o que não ocorre quanto aos critérios relacionados à cobertura. Todavia, deve-se destacar que, havendo baixa cobertura constante, a regularidade dos dados se mantém, o que não significa decerto boa qualidade do SIS. As análises apresentadas quanto aos desvios das taxas de natalidade, e de mortalidade neonatal, principalmente, a partir de dados do SINASC e SIM para uma série histórica maior, demonstram claramente que também a regularidade das informações dos sistemas não é de boa qualidade. 


\section{* A avaliação do SINASC de llhéus a partir da coorte hospitalar em 2001}

A comparação entre os bancos de dados de nascidos vivos da coorte hospitalar e o SINASC permite concluir que a cobertura do Sistema em relação à coorte de nascidos vivos hospitalares com residência e ocorrência em llhéus foi superior a $95 \%$, portanto, uma boa cobertura.

A proporção de membros da coorte hospitalar registrados em cartórios foi de $85,6 \%$, inferior à captação pelo SINASC. Assim, pode-se concluir que os fluxos das DN dos hospitais para o setor responsável pela alimentação do sistema deve ser preservado, já que, tradicionalmente, é mais difícil reverter a magnitude do subregistro civil.

É importante destacar a duplicação de informações de nascidos vivos no SINASC, o que foi detectado para 87 nascimentos, e a classificação equivocada de município de residência. Tal fato, ainda que em pequena monta, acrescenta um viés às estatísticas vitais.

\section{* O perfil de nascidos vivos da coorte hospitalar segundo captação pelo SINASC}

A distribuição dos membros da coorte segundo mês de ocorrência do parto mostra uma concentração de nascidos vivos não captados nos meses de janeiro, junho e julho, diferenças estas estatisticamente significantes.

A captação pelo SINASC conforme zona de residência da mãe não apresenta diferenças entre os nascidos vivos captados e não captados.

A análise dos nascimentos por hospital de ocorrência mostra que a maior proporção de partos ocorre no Santa Helena e que a maior proporção de não captados nasceram no Santa Isabel, seguido do Santa Helena. As diferenças observadas são estatisticamente significantes.

A distribuição dos nascidos vivos da coorte por idade da mãe e situação familiar, segundo captação pelo SINASC é semelhante nos captados e não captados. 
A observação da duração da gestação em relação à captação pelo sistema mostra que, a proporção de nascimentos de pré-termo é pouco maior entre os não captados, entretanto, isto não é estatisticamente significante.

O baixo peso ao nascer e o peso ignorado foram mais freqüentes no grupo de nascidos vivos não captados do que entre os captados, diferenças estas estatisticamente significantes.

A distribuição dos nascidos vivos da coorte por registro civil demonstrou que a proporção de não registrados é maior entre os não captados do que nos captados, sendo estatisticamente significante.

Conclui-se que os grupos captados e não captados pelo SINASC são diferentes quanto ao mês de nascimento, hospital de ocorrência do parto, peso ao nascer e registro civil.

É importante destacar que a escolaridade materna foi ignorada para $91,6 \%$ dos nascidos vivos da coorte. Tratando-se de variável importante para intervenções que modifiquem o risco de morte infantil, o achado demonstra a necessidade de esforços para a coleta da informação, no curso do internamento, considerando a impossibilidade de resgata-la a partir de registros hospitalares.

Os resultados encontrados permitem direcionar açöes que objetivem melhorar a cobertura e a qualidade do SINASC.

\section{* A avaliação do SIM de llhéus a partir da coorte hospitalar em 2001}

Sobre a avaliação do SIM exclusivamente relacionado à captação dos óbitos neonatais ocorridos na coorte hospitalar, conclui-se que há erro de classificação do evento morte fetal. Dos natimortos captados pelo sistema, $26,8 \%$ eram em verdade nascidos vivos que se tornaram óbitos neonatais. $A$ forma de coleta de dados utilizada não permite definir se o equívoco de classificação ocorre na digitação ou na emissão das DO, entretanto, a alta concentração de não captados entre os óbitos ocorridos em um único hospital aponta para erro na emissão do documento. Supondo-se que este 
seja um erro sistemático do SIM em Ilhéus, talvez possa estar na gênese da grande variação observada ao longo dos anos no número de óbitos e da taxa de mortalidade neonatal, descritas anteriormente.

Considerando-se os óbitos captados pelo SIM como neonatais, a proporção de captação pelo SIM foi de $50,0 \%$, portanto muito baixa. Agregando-se ao cálculo os óbitos captados como fetais a cobertura do SIM seria de $92,6 \%$, ainda assim, baixa.

\section{* O perfil dos óbitos neonatais ocorridos na coorte de nascidos vivos hospitalares segundo captação pelo SIM}

A distribuição dos óbitos neonatais segundo área de residência e captação pelo SIM mostra que a proporção de residentes na zona urbana é ligeiramente superior entre os não captados, entretanto, a diferença não é estatisticamente significante.

Os óbitos neonatais analisados segundo hospital de ocorrência do falecimento e captação pelo sistema, distribuem-se com grande concentração de não captados no hospital e maternidade Santa Helena, seguido, à distância, do hospital e maternidade Santa Isabel. Os demais hospitais não contribuíram com nenhum óbito não captados. As diferenças observadas mostraram-se estatisticamente significantes.

A análise da distribuição dos óbitos neonatais por captação e idade da mãe mostra que as proporções de captados e não captados são semelhantes nas diversas faixas etárias, não havendo diferença estatisticamente significante entre elas.

Os óbitos neonatais segundo duração da gestação e captação pelo SiM distribuem-se com maior proporção de não captados em gestações de pré-termo, entretanto, a diferença não se mostrou estatisticamente significante. A alta proporção de gestações de duração ignorada entre os óbitos captados pode explicar os resultados encontrados.

A distribuição dos óbitos neonatais segundo peso ao nascer e captação pelo SIM apresenta uma maior freqüência de óbitos de baixo peso 
entre os captados e maior proporção de não baixo peso no grupo de não captados. Não foi encontrada associação entre o baixo peso ao nascer e captação pelo SIM.

A variável idade ao morrer mostra-se distribuída desigualmente nos grupos captados e não captados pelo SIM, observando-se concentração de óbitos ocorridos em crianças com tempo de vida inferior a 24 horas entre os não captados. Demonstrou-se associação estatisticamente significante entre idade ao morrer e captação pelo SIM.

O perfil dos óbitos neonatais de acordo com registro civil e captação pelo SIM permite constatar a maior proporção de não registrados entre os não captados. Os resultados encontrados mostram que há associação estatisticamente significante entre o registro civil e a captação pelo SIM.

Assim, verificou-se que, dentre os óbitos neonatais não captados pelo SIM, há uma maior proporção de residentes na zona urbana, ocorrência do óbito no hospital e maternidade Santa Helena, com idade da mãe entre 20 e 34 anos, nascidos de pré-termo, baixo peso, idade ao morrer inferior a 24 horas e não registrados em cartório. Tais resultados apontam possivel origem do erro de classificação do evento morte fetal na emissão da DO, no hospital Santa Helena, em crianças falecidas com idade inferior a 24 horas.

Estado civil e escolaridade da mãe tem alta proporção de informações ignoradas. Concluindo-se que, para as variáveis estado civil e escolaridade da mãe, a possibilidade de resgate dos dados a partir de registros hospitalares é baixa, reafirmando a necessidade da coleta oportuna das informações.

\section{A probabilidade de morte neonatal na coorte de nascidos vivos hospitalares}

Conclui-se que a probabilidade de morte neonatal em llhéus utilizando-se os dados provenientes do SIM e SINASC encontra-se subestimada, o que se deve em grande parte ao erro de classificação dos óbitos fetais e menos à falha de captação do sistema. 
A probabilidade de morte neonatal na coorte foi aproximadamente duas vezes superior à obtida para o SIM/SINASC, considerando-se para o cálculo apenas os captados corretamente pelo SIM como óbito neonatal.

Os resultados encontrados, de forma contundente, apontam para a necessidade de implantação de ações imediatas voltadas a melhoria da qualidade dos sistemas, especialmente o SIM. 


\section{RECOMENDAÇÕES}

Diante dos achados e conclusões do presente trabalho, recomendase o desenvolvimento de algumas ações relacionadas à organização e gerenciamento do sistema de saúde do município de llhéus:

- Capacitação dos recursos humanos responsáveis pela operação dos processos inerentes ao SINASC e SIM, destacando os cuidados para evitar a duplicação de eventos nos Sistemas;

- Capacitação de recursos humanos para tratamento epidemiológico das informações do SINASC e SIM;

- Desenvolvimento de instrumentos de acompanhamento e controle da distribuição e fluxo dos impressos DN e DO;

- Capacitação de profissionais para a realização da crítica de DN e DO recebidas e estabelecimento de fluxo monitorado de devolução de documentos inconsistentes;

- Capacitação e sensibilização de recursos humanos de unidades hospitalares para o correto e completo preenchimento da DN e DO, com ênfase para o conceito de nascido vivo, óbito fetal e óbito neonatal;

- Capacitação e sensibilização de auditores municipais do SUS, visando incorporar aos procedimentos de auditoria o acompanhamento do cumprimento às normas e fluxos do SINASC e SIM;

- Desenvolvimento de boletim informativo do SINASC e SIM, periódico, para divulgação entre os profissionais de saúde e unidades participantes dos sistemas de informação;

- Desenvolvimento de ações intersetoriais que proporcionem o registro civil oportuno de nascidos vivos e óbitos neonatais, hospitalares e domiciliares;

- Desenvolvimento e implantação de estratégias e mecanismos de captura, pelo SINASC e SIM, de nascimentos e óbitos não hospitalares e não registrados em cartório;

- Desenvolvimento de mecanismos administrativos, gerenciais e assistenciais para ações e práticas de saúde e intersetoriais, voltadas 
para gestantes e neonatos em situação de risco para morte fetal ou neonatal. 


\section{REFERÊNCIAS BIBLIOGRÁFICAS}

ABRASCO. Associação Brasileira de Pós-graduação em Saúde Coletiva. Comissão de Epidemiologia. III Plano Diretor para o desenvolvimento da epidemiologia no Brasil 2000-2004. Rio de Janeiro; 2000. 59 p.

Almeida MMG. Sub-registro de nascimento em Salvador, Ba (Brasil). Rev Saúde Pública 1979; 13: 208-19.

Almeida MF. Mortalidade Neonatal em Santo André. São Paulo; 1994. [Tese de Doutorado - Faculdade de Saúde Pública da USP].

Almeida MF. O uso das informações em saúde na gestão dos serviços. Revista Saúde e Sociedade 1995;4(1/2): 39 - 42.

Almeida MF, Mello Jorge, MHP. Pequenos para idade gestacional: fator de risco para mortalidade neonatal. Rev Saúde Pública 1998; 32(3):217-24.

Almeida, MF e Alencar, GP. Informações em Saúde: necessidade de introdução de mecanismos de gerenciamento dos sistemas. IESUS 2000; vol. 9(4).

Antunes MBC. Municipalização e Qualidade da Informação em Saúde: o processo de descentralização do Sistema de Informação sobre Mortalidade em Pernambuco e o preenchimento da Declaração de Óbito. Recife; 2001. [Dissertação de Mestrado Programa Integrado de PósGraduação em Saúde Coletiva - Centro de Ciências da Saúde - UFPE] .

Bahia. Secretaria de Planejamento, Ciência e Tecnologia - SEI/CAR. Classificação dos Municípios Baianos. Salvador; 1999(Vol.1). 
Baldijão MFA, Soboll MLMS, Mello Jorge MHP e Ferreira CEC. Sistema de Informação sobre Nascimentos - SINASC: sua importância para o aprimoramento das estatísticas vitais. In: Anais do $1^{\circ}$ Congresso Brasileiro de Epidemiologia; 1990 Campinas.

Barros FC, Victora CG, Tomasi E, Horta B, Menezes AM, César JA et al. Saúde materno-infantil em Pelotas, Rio Grande do Sul, Brasil: principais conclusões da comparação dos estudos das coortes de 1982 e 1993. Cad Sáude Pública 1996;12(Supl.1):87-92.

Bohland AK e Mello Jorge MHP. Mortalidade infantil de menores de um ano de idade na região do Sudoeste de Estado de São Paulo. Rev Saúde Pública 1999; 33 (4):366-73.

Branco MAF. Sistemas de Informação em Saúde no nível local. Cad Saúde Pública 1996; 12 (2): 267-270.

Brasil. Ministério da Saúde: Fundação Nacional de Saúde. Manual de Procedimentos do Sistema de Informação sobre Mortalidade. Brasília; agosto de 2001a.

Brasil. Ministério da Saúde: Fundação Nacional de Saúde. Manual de Instruções para o Preenchimento da Declaração de Óbito. Brasília; agosto de 2001b.

Brasil. Ministério da Saúde. Fundação Nacional de Saúde. Manual de Procedimentos do Sistema de Informação sobre Nascidos Vivos. Brasilia; agosto de $2001 \mathrm{c}$.

Brasil. Ministério da Saúde. Fundação Nacional de Saúde. Manual de Preenchimento da declaração de Nascido Vivo. Brasília; agosto de 2001d. 
Campos TP, Carvalho MS e Barcellos CC. Mortalidade infantil no Rio de Janeiro, Brasil: áreas de risco e trajetória dos pacientes até os serviços de saúde. Rev Panam Salud Publica/Pan Am J Public Health 2000; 8(3) :164-171.

Carvalho BG de e Costa MCN. Mortalidade Infantil e seus componentes em Salvador-BA, 1980-1991. IESUS 1998; Out/Dez, ,VII(4):36-1.

Carvalho DM. Grandes Sistemas Nacionais de Informação em Saúde: reunião e discussão da situação atual. IESUS 1997; V (4), 7-46.

César CLG. Fatores de risco associados a mortalidade infantil em duas áreas da região metropolitana de São Paulo(Brasil), 1984-1985. Proposta de instrumentos preditivos. Rev Saúde Pública 1990;24(4): 300-10.

Conrado ES. Evolução da mortalidade infantil evitável em dois municípios situados na região Sul da Bahia entre 1980 e 1999. Salvador, Bahia; 2002.[Dissertação de Mestrado - Instituto de Saúde Coletiva Universidade Federal da Bahia].

Costa CE e Gotlieb SLD. Estudo epidemiológico do peso ao nascer a partir da Declaração de Nascido Vivo: na epidemiological approach. Rev Saúde Pública 1998; 32(4):328-334.

Cunha J, Aerts D, Flores R, Leite JCL e Castilla EE. Defeitos congênitos em Porto Alegre: uma investigação da qualidade dos dados registrados na Declaração de Nascido Vivo. Rev Bras Epidemiol 2002; Supl. Esp., p.51, CC 13.1. 
Datasus. Informações de Saúde. Brasil; 2000.Disponível em < URL http:///www.datasus.gov.br/cgi/tabcgi.exe?sinasc/dxba.def.14/11/2000 Acesso em 14 de novembro de 2000 a.

Datasus. Informações de Saúde. Brasil; 2000.Disponível em < URL http:///www.datasus.gov.br/cgi/tabcgi.exe?ibage.def.05/12/2000 Acesso em 5 de dezembro de $2000 \mathrm{~b}$.

Datasus. Informações de Saúde. Brasil; 2000. Disponivel em < URL www.datasus.gov.br . Acesso em 04 de setembro de 2002.

Ferreira CEC. A definição dos fatos vitais e sua aplicação prática: a questão dos nascidos mortos. Informe Demográfico 1982; 8:20-32.

Ferreira CEC. A Declaração de Nascido Vivo, uma fonte promissora. Informe Demográfico 1995; 29: 1-4.

Frias PG, Lira PIC, Arruda S e Vanderlei LC. Subenumeração de óbitos em municípios do Nordeste brasileiro: um estudo de caso. Rev Bras Epidemiol 2002; Supl. Esp., p 55, CC 17.1.

FUNASA. Fundação Nacional de Saúde. Sistema de Informação de Nascido Vivo. Disponivel em <URL http://www.funasa.gov.br. Acesso em 12 de setembro de 2002 a.

FUNASA. Fundação Nacional de Saúde. Banco de dados dos Sistemas de Informação sobre Mortalidade (SIM) e Nascidos Vivos (SINASC) - 1996 a 2000 [CD ROM], 2002 b.

Instituto Brasileiro de Geografia e Estatística (IBGE). Censo Populacional 2000. Disponivel em http://www.ibge.gov.br . Acesso em 12 de setembro de 2002. 
Instituto Brasileiro de Geografia e Estatística (IBGE). Estatística do Registro Civil de 1998; Malha municipal digital do Brasil: situação em 1997. Rio de Janeiro: IBGE, 1999. Disponivel em <URL http://www.ibge.gov.br, cidades@, acesso em 15 de fevereiro de 2003.

Fundação Nacional de Saúde. FUNASA. Sistemas de Informação em Saúde. Disponível em < URL http://www.funasa.gov.br. Acesso em 30 de agosto de 2002.

Gadelha RJS. Avaliação da qualidade das informações do registro de nascimentos no Brasil. In: Anais do $2^{\circ}$ Encontro Nacional de Estudos Populacionais; 1982 Vitória, Brasil. São Paulo, Associação Brasileira de Estudos Populacionais, 1982. p. 603-4.

Giraldelli BW e Wong LR. O comportamento do registro Atrasado de Nascimento (RAN) no estado de São Paulo: uma tentativa de correção do sub-registro. In: Anais do $4^{\circ}$ Encontro Nacional de Estudos Populacionais;1984; Águas de Lindóia, São Paulo, Brasil. São Paulo: Associação Brasileira de Estudos Populacionais; 1984, v. 2, p. 825-59.

Goldani MZ, Barbieri MA, Berttiol H, Barbieri MR e Tomkins A. Mortalidade infantil e nível socioeconômico em uma cidade brasileira. Rev Saúde Pública 2001; 35(3):256-61.

Gomes JO e Santo AH. Mortalidade infantil em município da Região CentroOeste Paulista, Brasil, 1990 a 1992. Rev Saúde Pública 1997;31(4):330-41.

Ilhéus. Secretaria Municipal de Saúde. Relatório de Gestão. Ilhéus-Bahia; 1999. 
Ilhéus. Nossa Cidade. Disponivel em < URL http://ilheus.com.br. Acesso em 4 de dezembro de 2000 .

Iwakura MLH, Andrade SM, Soares DA e Matsuo T. Fatores associados ao não registro civil de nascidos vivos em Londrina (PR), 2000 [resumo]. Rev Bras Epidemiol 2002; Supl.Esp, p. 51, CC 13.2. [Apresentado no V Congresso Brasileiro de Epidemiologia; 2002 março 23-27; Curitiba]

Lansky S, Franca E e Leal MC. Mortes perinatais evitáveis em Belo Horizonte, Minas Gerais, Brasil, 1999. Cad Saúde Pública 2002; 18(5):1389-1400.

Laurenti R, Sayão FA e Silveira MH. Sub-registro de nascimento de crianças falecidas com menos de um ano de idade. Rev Saúde Pública 1971; 5:23742.

Leal MC e Szwarcwald CL. Evolução da mortalidade neonatal no Estado do Rio de Janeiro de 1979 a 1993: análise por grupo etário segundo região de residência. Rev Saúde Pública 1996;30:403-12

Leal MC e Szwarcwald CL. Características da mortalidade neonatal no Estado do Rio de Janeiro na década de 80: uma visão espaço-temporal. Rev Saúde Pública 1997;31(5):457-65.

Levy MS, Siqueira AA, Silveira MH e Taschner SP. O registro de nascimento e sua importância em planejamento materno-infantil. Rev Saúde Pública $1971 ; 5: 41-6$.

Machado CB, Penteado SMP, Evangelista CMN, Coriolano LS e Meireles MLM. Diagnóstico sobre Sistemas de Informação em Saúde e a melhora da cobertura de óbitos na microrregião de Baturité, Ceará [resumo]. Rev Bras 
Epidemiol 2002; Supl. Esp., p. 55, CC 17.4. [Apresentado no V Congresso Brasileiro de Epidemiologia; 2002 março 23-27; Curitiba]

Machado NS, Ichihara MX e Aquino EM. Avaliação da qualidade das informações DO Sistema de Nascidos Vivos, Salvador, 1998 [resumo]. Rev Bras Epidemiol 2002; Supl. Esp., p.51, CC 13.3. [Apresentado no V Congresso Brasileiro de Epidemiologia; 2002 março 23-27; Curitiba]

Mello Jorge MHP. Sub-registro de nascimento e óbito: sua importância em estatísticas de saúde. São Paulo, Faculdade de Saúde Pública da USP,1982. [apresentado ao Grupo de Trabalho de Geografia de Saúde, Brasília, 1982. Mimeografado].

Mello Jorge MHP. Registro dos eventos vitais: sua importância em Saúde Pública. Centro Brasileiro de Classificação de Doenças, 1990 (Série Divulgação no.5)

Mello Jorge MHP, Baldijão MFA e Gottlieb SLD. Análise e avaliação das informações de saúde disponíveis para o estado do Piaui. Relatório. São Paulo. Faculdade de Saúde Pública da USP, 1990. 211 p. mimeo.

Mello Jorge MHP, Gottieb SLD, Soboll MLM S, Almeida MF e Latorre MRDO. Sistema de Informação sobre Nascidos Vivos - SINASC. Informe Epidemiológico do SUS 1992; I (4): 5-16.

Mello Jorge MHP, Gottieb SLD, Soboll MLMS, Almeida MF e Latorre MRDO. Avaliação do Sistema de Informação sobre Nascidos Vivos e o uso de seus dados em epidemiologia e estatísticas de saúde. Rev Saúde Pública 1993; 27 (Supl.): $1-45$. 
Mello Jorge MHP, Gotlieb SLD, Soboll MLMS, Almeida MF e Latorre MRDO. Avaliação do Sistema de Informação sobre Nascido Vivo. Informe Demográfico 1995; 29: 5-13.

Mello Jorge MHP, Gotlieb SLD e Oliveira H. O Sistema de Informação sobre Nascidos Vivos: uma primeira avaliação dos dados brasileiros. IESUS $1996 ; \vee(2): 15-48$.

Mello Jorge MHP, Gottieb SLD e Andrade SM. Análise dos registros de nascimentos vivos em localidade urbana no Sul do Brasil. Rev Saúde Pública 1997; 31(1):78-89.

Menezes AMB, Victora CG, Barros FC, Albernaz E, Menezes FS, Jannke HA et al. Mortalidade infantil em duas coortes de base populacional no Sul do Brasil: tendências e diferenciais. Cad Saúde Pública 1996; 12(Supl.1):7986.

Milanesi ML e Silva EPC. Sub-registro de nascimentos no distrito de São Paulo. Rev Saúde Pública 1968; 2:23-78.

Miranda AJ, Silva GS, Oliveira HM, Scatena JHG e Silva VLS. Avaliação do SINASC em Cuiabá, 1995-2000 [resumo]. Rev Bras Epidemiol 2002; Supl.Esp., p. 174, Poster 140. [Apresentado no V Congresso Brasileiro de Epidemiologia; 2002 março 23-27; Curitiba]

Mishima FC, Scochi CGS, Ferro MAR, Lima RAG e Costa IAR. Declaração de nascido vivo: uma análise do seu preenchimento no município de Ribeirão Preto, São Paulo, Brasil. Cad Saúde Pública 1999; 15(2):387-395.

Monteiro CA, lunes RF e Torres AM. A evolução do País e suas doenças. IESUS 1996;2:7-14. 
Moraes IHS. Informações em saúde: da prática fragmentada ao exercício da cidadania. São Paulo- Rio de Janeiro: HUCITEC, ABRASCO; 1994. p. 172.

Moraes IHS. Política, tecnologia e informação em saúde. Salvador, Bahia: Casa da Qualidade; 2002. p. 171.

Morais Neto OLR e Barros MBA. Fatores de risco para mortalidade neonatal e pós-neonatal na Região Centro-Oeste do Brasil: linkage entre bancos de dados de nascidos vivos e óbitos infantis. Cad Saúde Pública 2000;16(2):477-85.

Noronha CP, Silva RI e Theme Filha MM. Concordância de dados das declarações de óbitos e de nascidos vivos para a mortalidade neonatal no município do Rio de Janeiro. IESUS 1997; V (4).

Oliveira $\mathrm{H}$ e Pereira IPA. Estatísticas de mortalidade e nascidos vivos, considerações sobre principais problemas. IESUS 1997; VI (3): 15-19.

Portela MHRB. Sub-registro de nascimentos vivos em localidade do estado do Piauí, Brasil. Rev Saúde Pública 1989; 23 (6): 493-501.

Ribeiro VS e Silva AAM. Tendências da mortalidade neonatal em São Luís, Maranhão, Brasil, de 1979 a 1996. Cad Saúde Pública 2000;16(2):429-38.

RIPSA. Rede Integrada de informações para a Saúde. Disponivel em < URL http:// www.ripsa.gov.br. Acesso em 23 de setembro de 2002.

Rothman KJ e Greenland S. Modern Epidemiology. 2a. Ed. Filadélfia, Lippincott Willians e Wilkins; 1998. 
Scorzelli Júnior A. Coleta de dados vitais em pequenas localidades. Rev Serv de Saúde Pública 1947; 1: 397-432.

Saade MJ. Verificação estatística do grau de deficiência do registro de nascimentos. Rev Serv Saúde Pública 1947; 1: 449-67.

Sanches KRB, Camargo Júnior Kr, Coeli CM e Cascão AM. Sistemas de Informação em Saúde. In: Epidemiologia. Medronho, R. A. et al. São Paulo: Atheneu, 2002. p. 337-359.

Schramm JMA e Szwarcwald CL. Sistema hospitalar como fonte de informações para estimar a mortalidade neonatal e a nati-mortalidade. Rev. Saúde Pública 2000; 34(3): 272-279.

Siegel S. Estatística não-paramétrica: para as ciências do comportamento. São Paulo: McGraw Hill; 1975.

Silva AAM, Ribeiro VS e Borba Júnior AF et al. Avaliação da qualidade de dados do Sistema de Informações sobre Nascidos Vivos em 1997-1998. Rev Saúde Pública 2001; 35(6):508-514.

Silva EPC. Estimativas de coeficientes e índices vitais e de subregistros de nascimentos no distrito de São Paulo, baseados em amostra probabilística de domicílios. São Paulo, 1970. [Monografia de Mestrado - Faculdade de Saúde Pública - Universidade de São Paulo].

Silveira MH e Laurenti R. Os eventos vitais: aspectos de seus registros e inter-relação da legislação vigente com as estatísticas de saúde. Rev Saúde Pública 1973; 7: 37-50.

Silveira MH e Soboll ML. Sub-registro de Nascimento: aspectos educativos visando à sua diminuição. Rev Saúde Pública 1973; 7: 151-60. 
Simões CC. Estimativas da mortalidade infantil por microrregiões e municípios. Brasília: Ministério da Saúde, Secretaria Executiva, Secretaria de Políticas de Saúde, 1999.

Simões CC de S. Perfis de saúde e de mortalidade no Brasil: uma análise de seus condicionantes em grupos populacionais específicos. Brasilia: Organização Pan-Americana de Saúde, 2002.

Souza RKT. Mortalidade infantil e sub-registro de nascidos vivos no município de Maringá - PR em 1989. São Paulo, 1992. [Dissertação de Mestrado - Faculdade de Saúde Pública - Universidade de São Paulo].

Souza RCA. Diagnósticos Sócio-Sanitário-Participativo do Bairro Nossa Senhora da Vitória e proposta de intervenção com base em problemas priorizado. Ilhéus; 2000. [Monografia apresentada ao Curso de Especialização de Saúde Coletiva e Gerenciamento de Programas Comunitários de Saúde - Instituto de Saúde Coletiva -Universidade Federal da Bahia].

Suarez L. Sub-registro de nascimento. São Paulo, 1968. [Dissertação de Mestrado - Faculdade de Saúde Pública - Universidade de São Paulo].

SEI - Superintendência de Estudos Econômicos da Bahia. Secretaria do Planejamento, Ciência e Tecnologia do Estado da Bahia. Perfil dos Municípios da Bahia (1998). Indicadores de Desenvolvimento Econômico e Social. Disponível em www.sei.ba.gov.br. Acesso em 12 de setembro de 2002.

Szwarcwald CL e Leal MC. Característica da mortalidade neonatal no estado do Rio de Janeiro na década de 80: uma visão espaço-temporal. Rev Saúde Pública 1997; 31(5):457-465. 
Szwarcwald CL, Leal MC, Castilho EA e Andrade CLT. Mortalidade Infantil no Brasil: Belíndia ou Bulgária? Cad Saúde Pública 1997;13(3):503-16.

Szcwarcwald CL, Bastos FI e Andrade CLT. Health inequality indicators: a discussion of some methodological approaches as applied to neonatal mortality in the Municipality of Rio de Janeiro, 2000. Cad Saúde Pública 2002; 18(4):959-970.

Szwarcwald CL, Leal MC, Andrade CLT e Souza Júnior PRB. Estimação da Mortalidade Infantil no Brasil: o que dizem as informações sobre óbitos e nascimentos do Ministério da Saúde? Cad. Saúde Pública 2002;18(6):17251736.

Vanderlei LCM, Arruda S, Fekisberto EC, Frias PG, Nery BM, Lopes CFC e Siqueira BLM. Avaliação da qualidade de preenchimento das declarações de óbitos no Instituto Materno Infantil de Pernambuco - IMIP [resumo]. Rev Bras Epidemiol 2002; Supl. Esp., p. 177, poster 153. [Apresentado no V Congresso Brasileiro de Epidemiologia; 2002 março 23-27; Curitiba].

Vasconcelos AMN. Estimação de níveis e tendências da mortalidade no Brasil: métodos diretos ou indiretos? [resumo]. Rev Bras Epidemiol 2002 Supl.Esp., p.45, cc 7.2. [Apresentado no $V$ Congresso Brasileiro de Epidemiologia; 2002 março 23-27; Curitiba].

Victora CG, Barros FC e Vaughan JP. Epidemiologia da Desigualdade. $2^{a}$.ed São Paulo: Hucitec;1989. 
ANEXO 1 


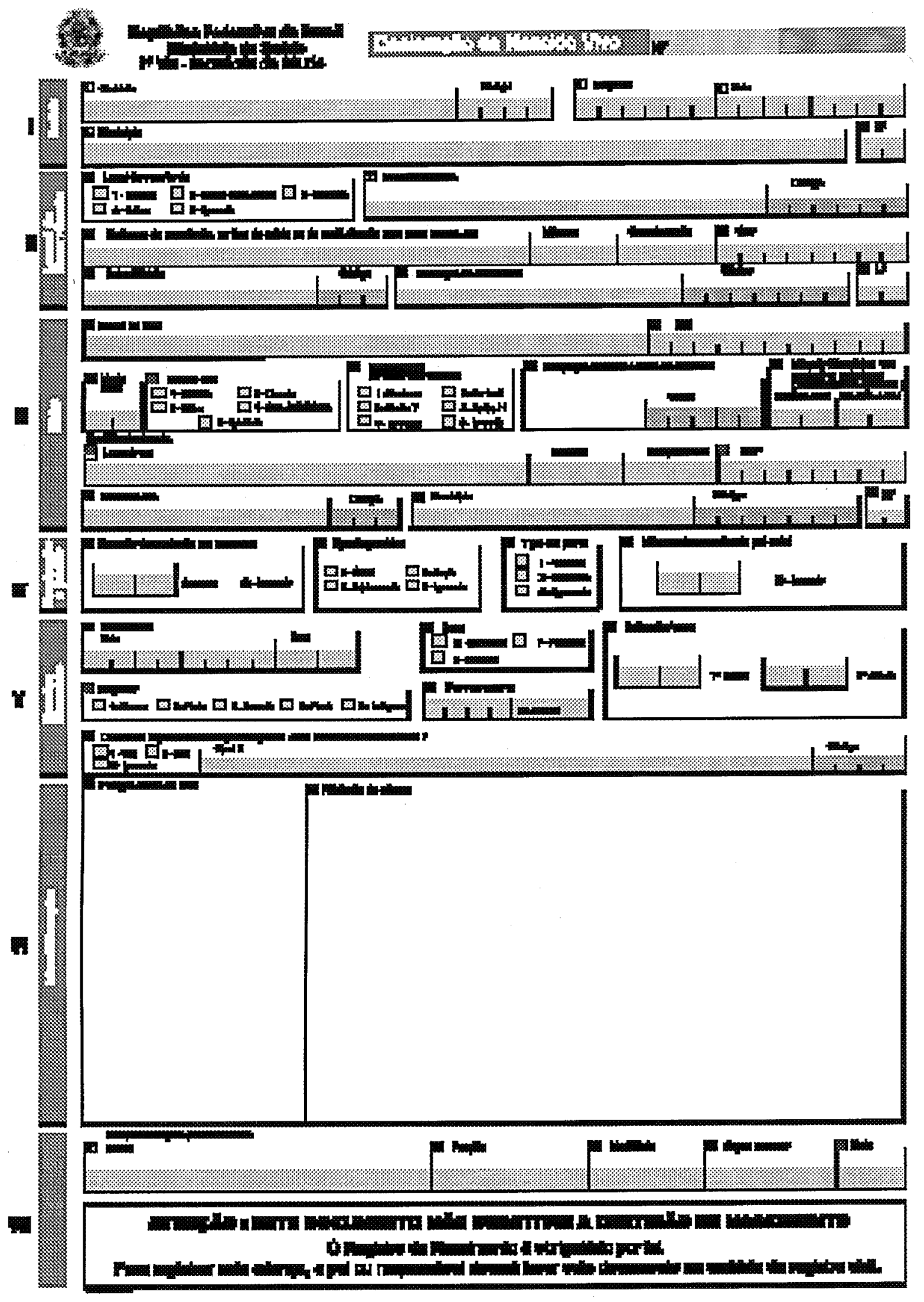


ANEXO 2 


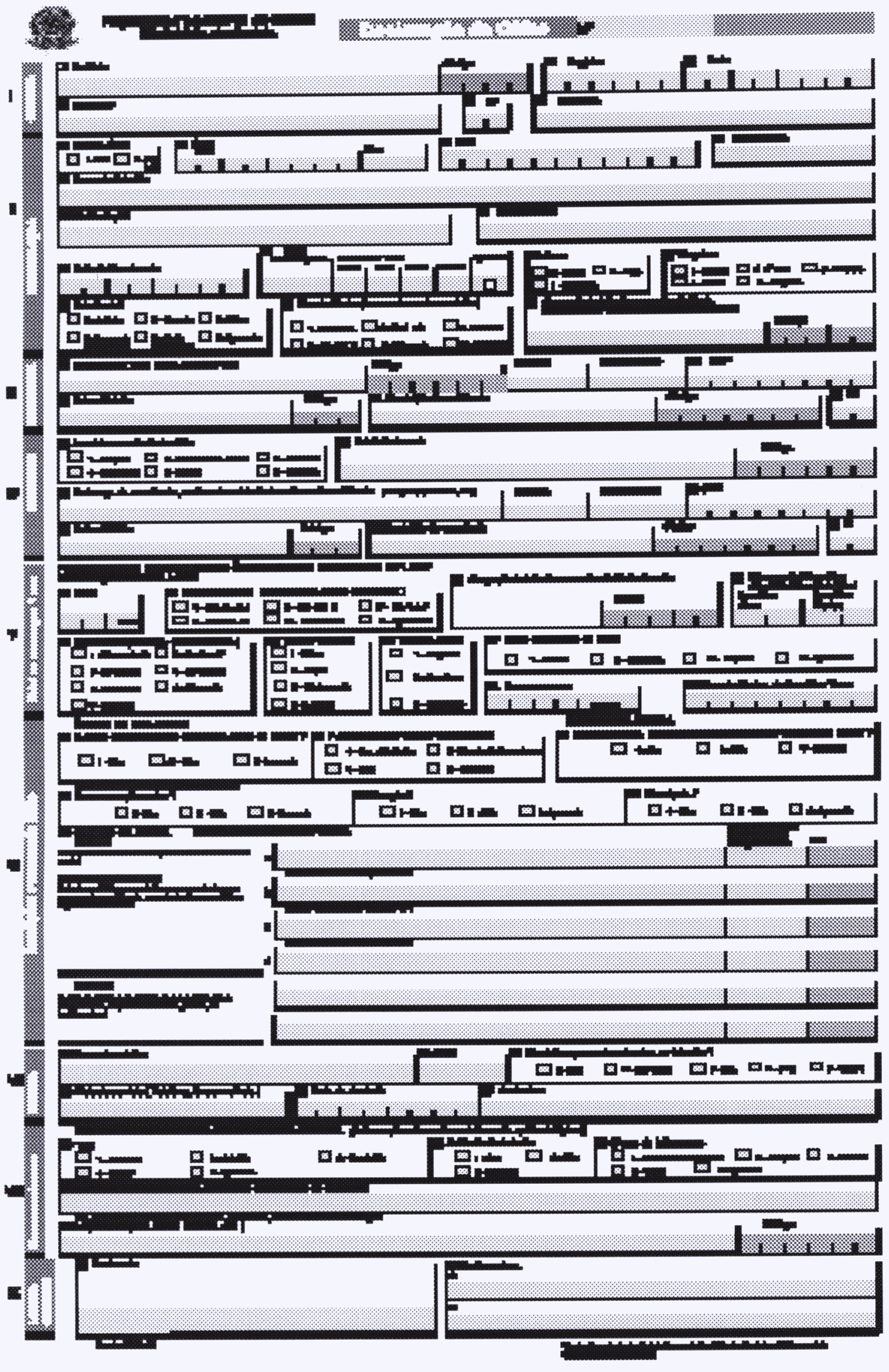




\section{ANEXO 3}




\section{TERMO DE CONSENTIMENTO LIVRE E ESCLARECIDO}

Como guardião dos arquivos do

(nome da unidade de saúde) autorizo o acesso aos livros de registro, prontuário médicos e Declaração de Nascidos Vivos-DN e Declaração de Óbito-DO das crianças nascidas vivas nesta unidade hospitalar, cujas mães residiam no município de llhéus, com o fim específico de pesquisa intitulada Os Sistemas de Informaçằo de Nascido Vivo e de Mortalidade em Ilhéus, Bahia e Mortalidade Neonatal no mesmo município, da pesquisadora Adélia Maria Carvalho de Melo Pinheiro, professora da Universidade Estadual de Santa Cruz-UESC e aluna do Doutorado da Faculdade de Saúde Pública da Universidade de São Paulo.

Fui informado que a pesquisa tem por objetivo analisar os sistemas de informação de nascidos vivos e de mortalidade e avaliar os determinantes da mortalidade neonatal (até 27 dias de vida) de crianças nascidas vivas de partos hospitalares e cujas mães eram residentes no município de llhéus - Bahia.

Sei que a pesquisa nos arquivos do hospital irá levantar informações sobre todos as crianças nascidas vivas e óbitos neonatais ocorridos neste hospital no período de janeiro de 2001 a dezembro de 2002, e que buscará informações sobre nome da mãe, sexo da criança, data de nascimento e endereço de residência, para que possa realizar entrevistas domiciliares com a mãe ou responsável pela criança.

Fui esclarecido (a) que os dados decorrentes da pesquisa serão sigilosos e não podem ser divulgados de forma a permitir individualização, bem como o seu uso restringir-se-á aos objetivos acima propostos.

Data:

1

(Assinatura do Diretor Clínico do Hospital)

(Assinatura da Pesquisadora)

Adélia Maria C. de Melo Pinheiro

Tels. para contato: 680-5014/680-5256/680-5114 (UESC) 
ANEXO 4 
Excelentíssimo Sr. Dr. Juiz de Direito da Vara de Registros Públicos da Comarca de Ilhéus do estado da Bahia

Adélia Maria Carvalho de Melo Pinheiro, médica, professora da Universidade Estadual de Santa Cruz, casada, doutoranda da faculdade de Saúde Pública da Universidade de São Paulo, portadora de identidade médica de número 9135, expedida pelo Conselho Regional de Medicina da Bahia, vem respeitosamente a presença de V.Excia., expor e requerer o que segue:

1-Como aluna do curso de Doutorado em Saúde Pública da Faculdade de Saúde Pública da USP, desenvolvo um trabalho de pesquisa intitulado "Mortalidade Neonatal no Municipio de llhéus - Bahia". A pesquisa tem por objetivo avaliar os determinantes da mortalidade neonatal ( até 27 dias de vida) de crianças nascidas vivas de partos hospitalares e cujas mães sejam residentes no município de llhéus Bahia. A pesquisa nos arquivos irá levantar informaçōes referentes ao período de 1999 a 2001 sobre o nome da mãe, sexo da criança, data de nascimento, data de óbito, e endereço de residência, para que possa realizar entrevistas domiciliares com a mãe ou responsável pela criança.. Os dados decorrentes da pesquisa serão sigilosos e não poderão ser divulgados de forma a permitir individualização, bem como o seu uso restringir-se-á aos objetivos acima propostos.

2 - Isto posto, considerando ser imprescindível a obtenção das informações contidas nos Livros dos cartórios de Registro Civil para os fins da pesquisa ora desenvolvida, requer se digne V.Excia., deferir vistas dos Livros nos quais constam os assentamentos de nascimentos e óbitos, bem como as correspondentes Declarações de Nascidos Vivos e Declarações de Óbitos, com autorização expressa para transcrição das informações pertinentes à pesquisa, expedindo-se para tanto os competentes ofícios.

Nestes termos, Pede deferimento.

Ilhéus, 06 de fevereiro de 2002. 
ANEXO 5 


\section{TERMO DE CONSENTIMENTO LIVRE E ESCLARECIDO}

Como guardião dos arquivos do

(nome do município) autorizo o acesso aos livros de registro, prontuário médicos e Declaração de Nascidos Vivos-DN e Declaração de Óbito-DO das crianças nascidas vivas em unidades hospitalares, cujas mães residiam no município de llhéus, com o fim específico de pesquisa intitulada Os Sistemas de Informação de Nascido Vivo e de Mortalidade em Ilhéus, Bahia e Mortalidade Neonatal no mesmo município, da pesquisadora Adélia Maria Carvalho de Melo Pinheiro, professora da Universidade Estadual de Santa Cruz-UESC e aluna do Doutorado da Faculdade de Saúde Pública da Universidade de São Paulo.

Fui informado que a pesquisa tem por objetivo analisar os sistemas de informação de nascidos vivos e de mortalidade e avaliar os determinantes da mortalidade neonatal (até 27 dias de vida) de crianças nascidas vivas de partos hospitalares e cujas mães eram residentes no município de llhéus - Bahia.

Sei que a pesquisa nos arquivos dos hospitais e Secretaria Municipal de Saúde irá levantar informações sobre todos as crianças nascidas vivas e óbitos neonatais ocorridos neste hospital no período de janeiro de 2001 a dezembro de 2002, e que buscará informações sobre nome da mãe, sexo da criança, data de nascimento e endereço de residência, para que, posteriormente, possa realizar entrevistas domiciliares com a mãe ou responsável pela criança.

Fui esclarecido (a) que os dados decorrentes da pesquisa serão sigilosos e não podem ser divulgados de forma a permitir individualização, bem como o seu uso restringir-se-á aos objetivos acima propostos.

Data:

(Assinatura do Diretor Clínico do Hospital)

(Assinatura da Pesquisadora)

Adélia Maria C. de Melo Pinheiro

Tels. para contato: 680-5014/680-5256/680-5114 (UESC) 
ANEXO 6 


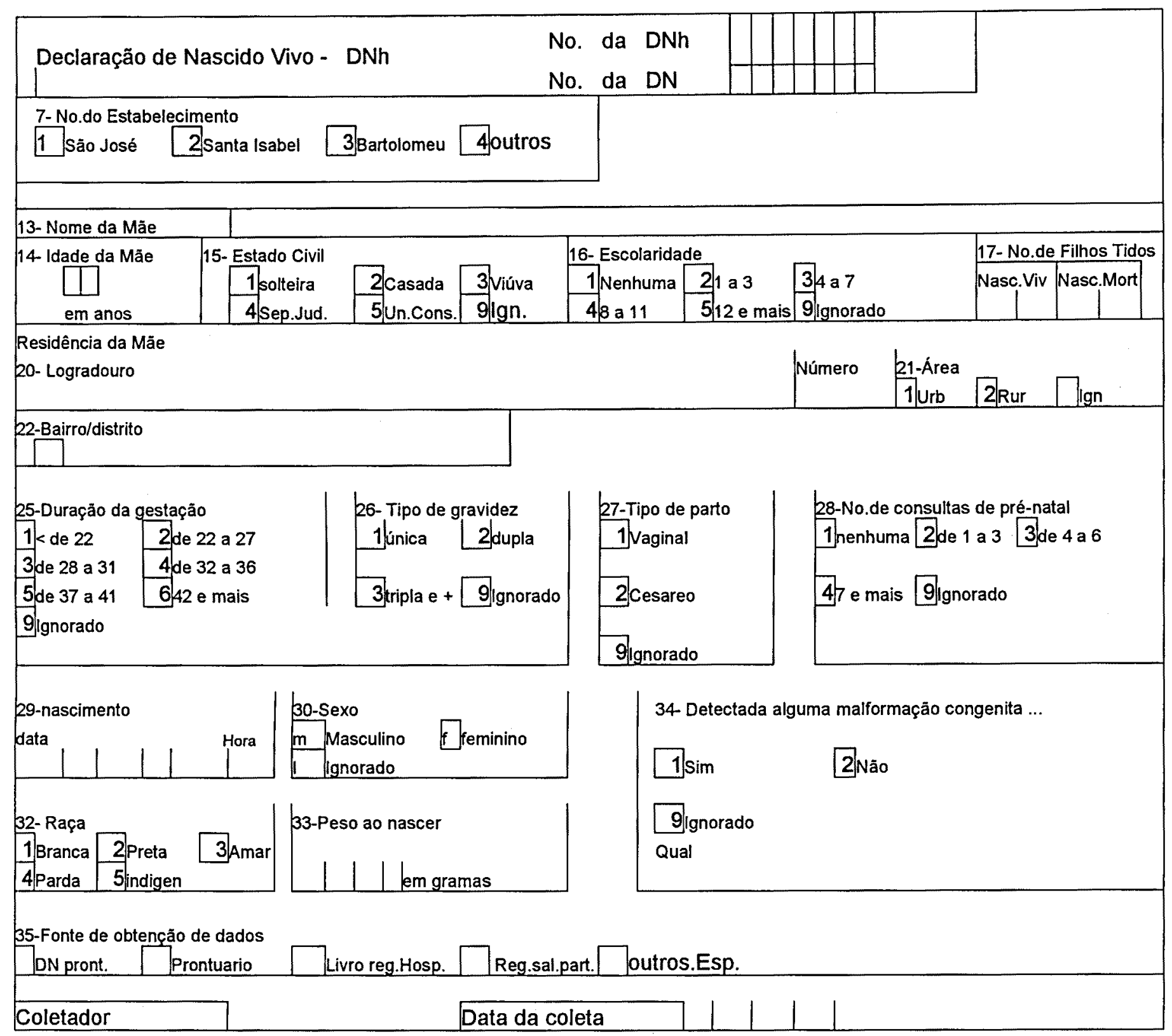


ANEXO 7 


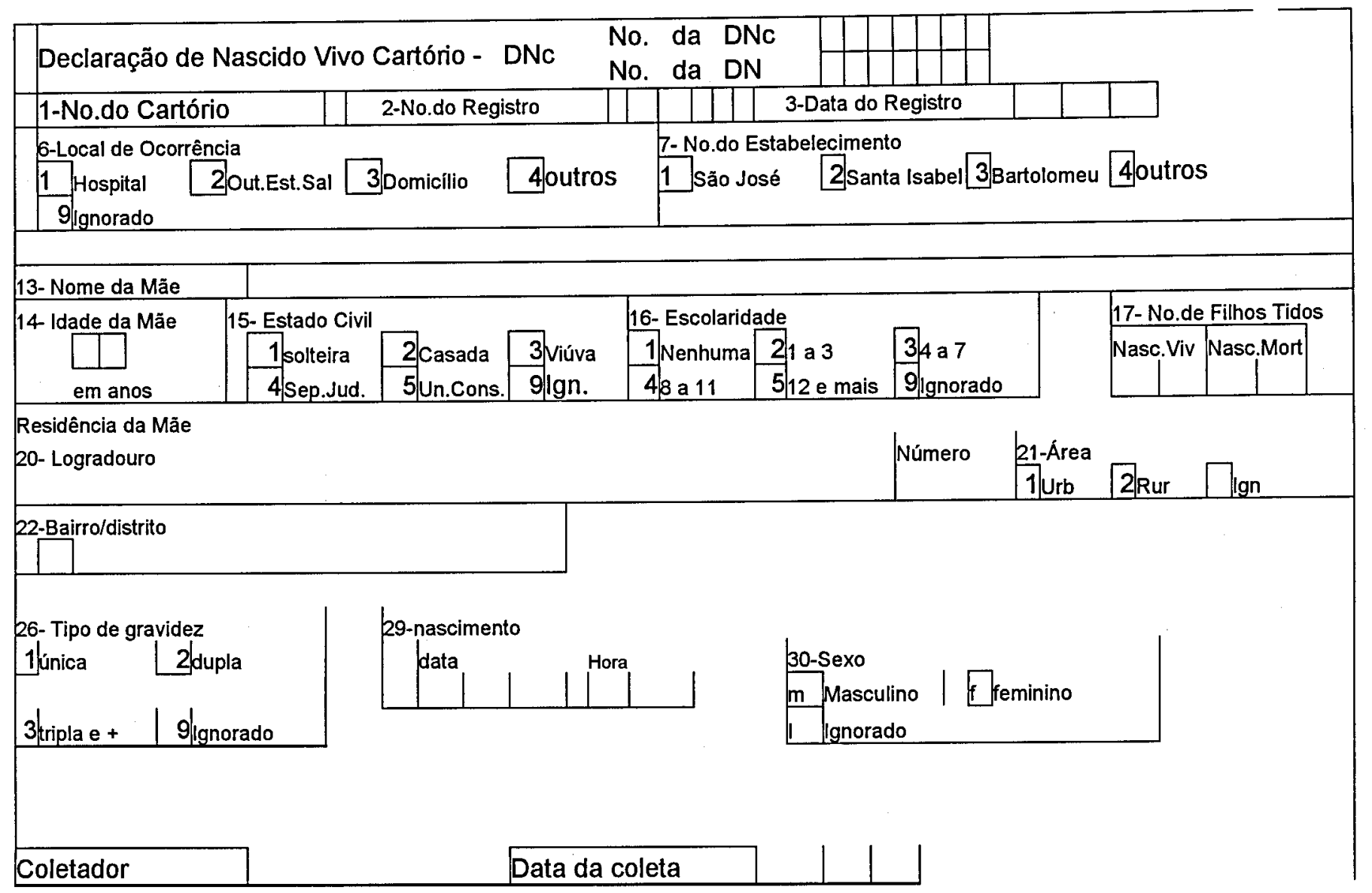


ANEXO 8 


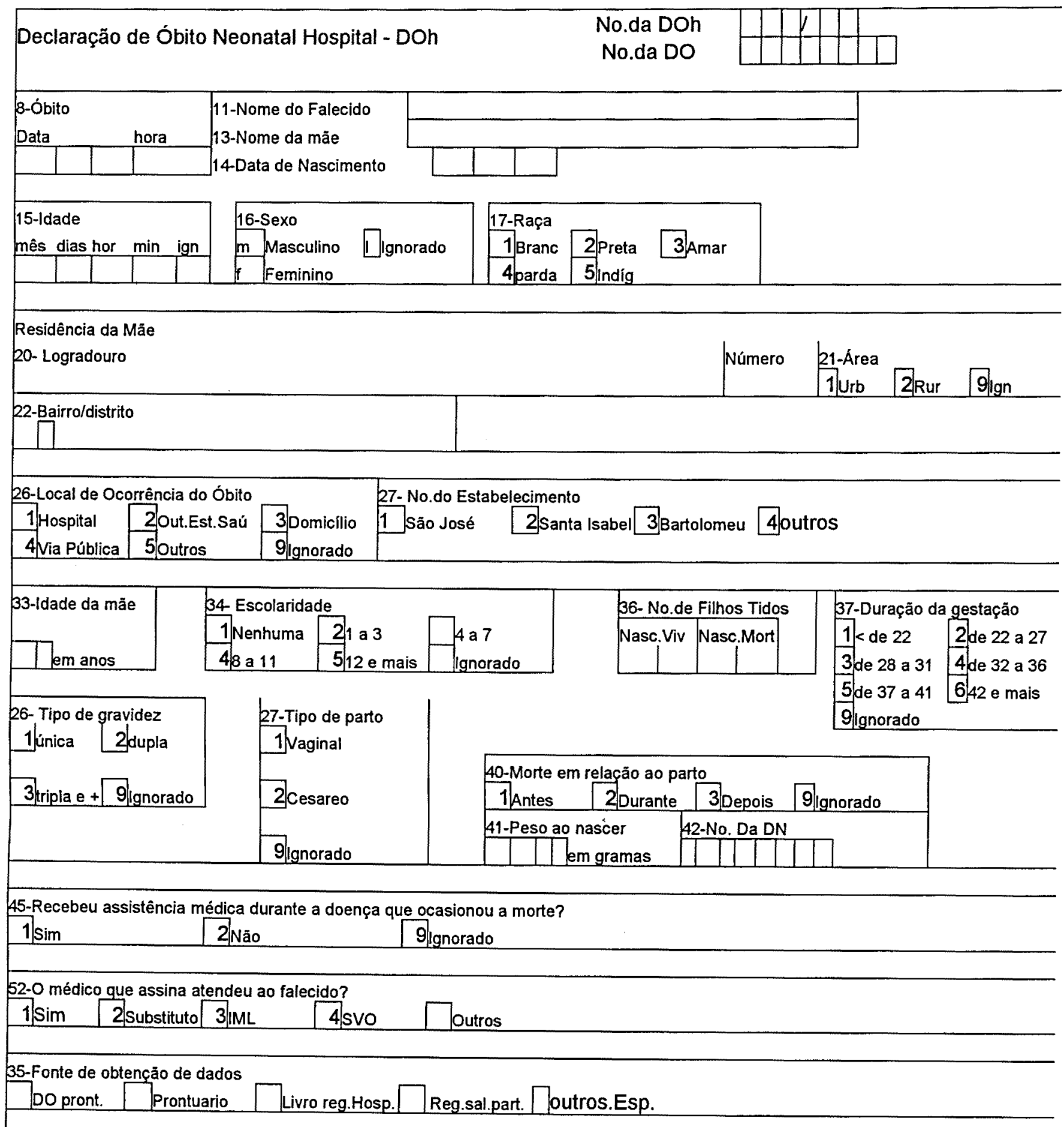

\section{Coletador}

Data da coleta 
ANEXO 9 


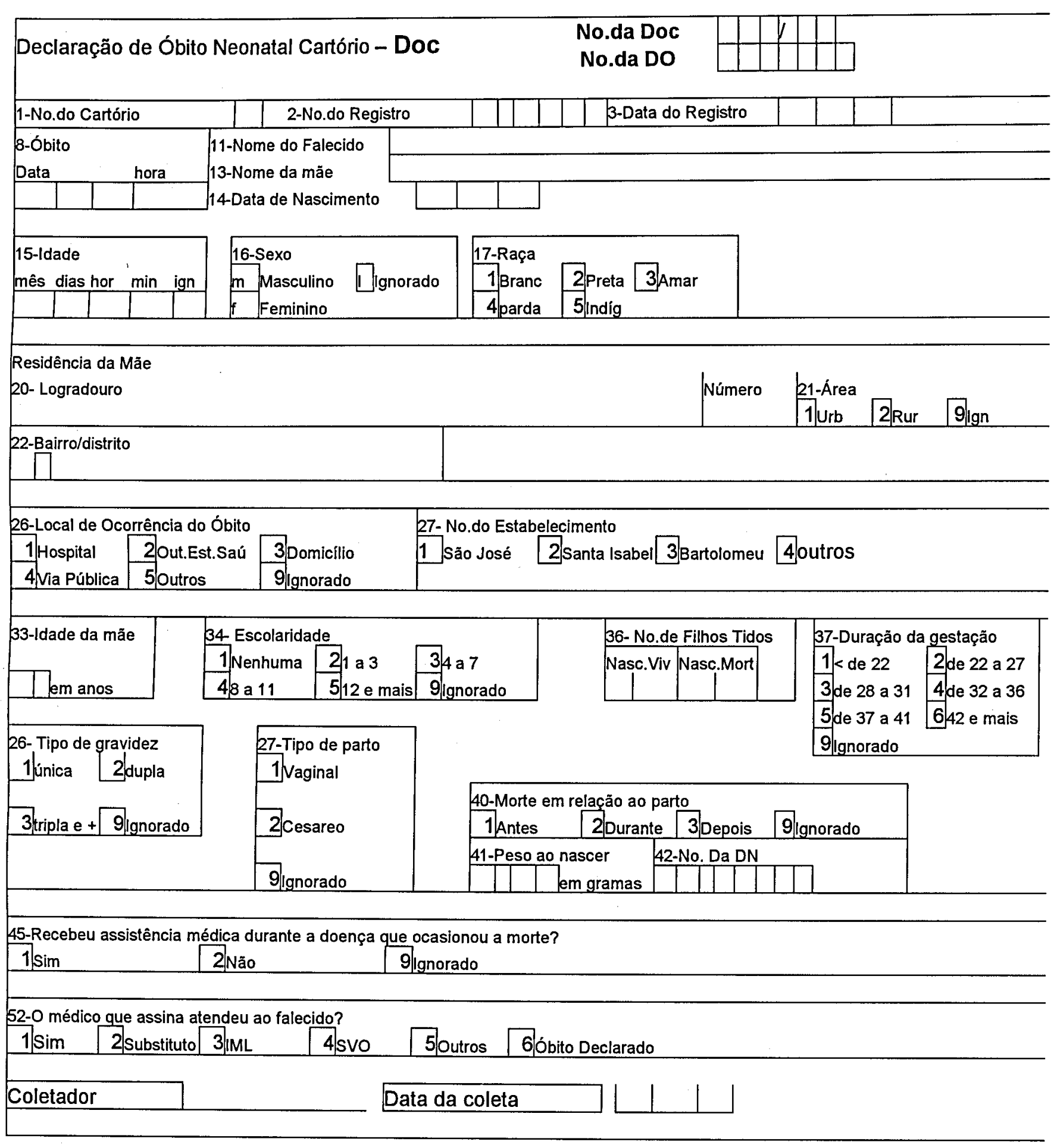

